Discussion Paper No. 02-55

\title{
What Determines Relative Sectoral Investment Patterns in EU Regions?
}

Claudia Stirböck

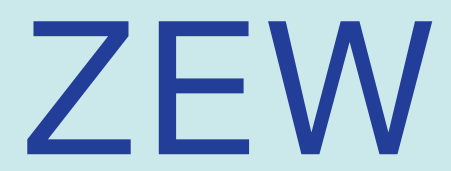

Zentrum für Europäische Wirtschaftsforschung GmbH

Centre for European Economic Research 
Discussion Paper No. 02-55

\title{
What Determines Relative Sectoral Investment Patterns in EU Regions?
}

\author{
Claudia Stirböck
}

Download this ZEW Discussion Paper from our ftp server:

ftp://ftp.zew.de/pub/zew-docs/dp/dp0255.pdf

Die Discussion Papers dienen einer möglichst schnellen Verbreitung von neueren Forschungsarbeiten des ZEW. Die Beiträge liegen in alleiniger Verantwortung der Autoren und stellen nicht notwendigerweise die Meinung des ZEW dar.

Discussion Papers are intended to make results of ZEW research promptly available to other economists in order to encourage discussion and suggestions for revisions. The authors are solely responsible for the contents which do not necessarily represent the opinion of the ZEW. 


\section{Non-technical summary}

The preparation of EMU was accompanied by a broad discussion of potential core-periphery tendencies and asymmetric regional developments due to a possible increase in sectoral concentration and regional specialisation. Up to date, we have no clear indication concerning the specialisation tendencies to be expected due to increased factor mobility and market integration. This paper thus aims at providing insights into the spatial patterns of relative sectoral investments of EU regions and the driving forces of sectoral investment specialisation. Regional investment patterns are compared to average EU patterns in order to identify the relative sectoral investment specialisation of EU regions.

An exploratory spatial data analysis of relative sectoral investments of 17 sectors displays spatial patterns such as sectoral clusters, i.e. regions with high relative sectoral investments surrounded by similar regions. We find a cluster of relative specialisation in agriculture across most Italian regions, textiles industries in North Italian regions and minerals \& mineral products in the middle parts of Italy as well as fuel \& power products across most Italian regions, and particular obvious in southern Italy. Relative investments in the services sectors are less clustered. We find a spatial concentration of trade \& lodging services along most Italian coastal regions, of transport \& communication services in northern Italy and the south of France as well as of other services in South Italian regions. But, we find no evidence for a significant positive spatial association for the latter two services sectors. Non-market services are consistently stronger, but still moderate, in French regions and are the highest in those regions far away from Paris. In addition, those regions with the highest levels of specialisation in the food sectors are mostly located in north-western France.

The econometric analyses aim at identifying the regional determinants of high relative sectoral investments, i.e. the regional investment specialisation in different sectors. The importance of a number of determinants from different theoretical approaches is tested controlling for heteroscedasticity and potential endogeneity. Regional factor cost or productivity differentials are supposed to matter according to traditional trade theory. We find no evidence for the relevance of labour cost differentials, however, sectoral productivity differentials between regions generally contribute to the explanation of relative investment shares in the manufacturing sectors analysed.

Since investments in most manufacturing sectors are attracted by those regions in central parts of each country and not by regions far away from the core, we might be confronted with backwash effects predicted by the polarisation theory for peripheral regions. In addition, the location close to large markets seems to matter for many manufacturing sectors. We find evidence of a further agglomeration potential in the manufacturing sectors due to the importance of the regional level of sector-specific economies of scale in the explanation of relative investment shares. Market integration, which according to the New Economic Geography (NEG) is supposed to enforce the agglomerative forces of economies of scale, however, does not play a particular role in any sector.

Stirboeck (2002a, 2002b) provide evidence for the stronger relative regional specialisation of core as well as of peripheral regions. The results of our econometric analysis now demonstrate that the determinants of the high relative specialisation of peripheral regions differ from those of economic centres. The driving forces of investment specialisation are favourable for core regions with respect to growth-oriented market services. Peripheral regions, however, are particularly specialised in those services sectors linked to economic activity in tourism. In addition, stronger relative investment shares of peripheral regions in non-market services as well as building \& construction point to their high dependence on non-market economic activities and poor sectoral diversification. Finally, the insignificant role of labour costs does not provide hope for the periphery to attract manufacturing production - a prediction of some NEG models once transaction costs are sufficiently low. 


\title{
What Determines Relative Sectoral Investment Patterns in EU Regions?
}

\author{
Claudia Stirboeck \\ Centre for European Economic Research (ZEW), Mannheim, Germany
}

August 2002

\begin{abstract}
This study analyses relative sectoral investment patterns in EU regions. In an exploratory spatial data analysis, spatial clusters of high relative investments can be identified for some sectors. In the econometric analysis, we control for heteroscedasticity and potential endogeneity and find that investments in manufacturing sectors are attracted by central regions, investments in services sectors, instead, by administrative centres as well as regions far away from their national administrative centre. A higher local level of sectoral economies of scale and of productivity strongly increases investments in manufacturing sectors. Labour cost differentials, however, are insignificant in explaining the location of relative sectoral investments.
\end{abstract}

Acknowledgements: Financial support by the Volkswagen-Stiftung within the project No. II/76547 is gratefully acknowledged. I would like to thank Laura Manthey, Paula Montoya, Jennifer Säwe, Elena Todorova, and especially Simone Giloth and Felix Morck for their enduring help in setting up the extensive regional data sets and Dennis Quinn for the kind deliverance of his liberalisation indicators. I am indebted to Herbert S. Buscher, Jürgen Kaehler and Michael Schröder for helpful comments. All remaining errors, however, are my own.

JEL classification: C30, F15, F2, R12

Keywords: Regional Specialisation, Sectoral Investments, Exploratory Spatial Data Analysis, Cross-Section Time-Series Regressions

Claudia Stirboeck

ZEW

PO Box 103443

D-68034 Mannheim

Tel.: +49-621-1235-218

Fax: +49-621-1235-223

E-Mail: stirboeck@zew.de 


\section{Motivation}

Prior to the inauguration of the EMU, fears of increasing specialisation and core-periphery tendencies had risen. Economic regions showing a rather heterogeneous industrial structure could find themselves confronted with the risk of economic shocks being intra-regionally unsmoothable. Potential contrasting specialisation tendencies between central and peripheral regions would thus lead to the need of improved and flexible shock absorbing mechanisms at the regional level. Up to date, we have no clear indication about the determinants of the level of regional specialisation in the EU and specifically not about the specialisation tendencies to be expected due to increased factor mobility and market integration.

Since Krugman (1991), the New Economic Geography (NEG) has gained a special focus of attention as according to these models, specialisation need not - like in the neo-classical world - develop according to the comparative advantage of regions, but can be the result of historical conditions, i.e. path dependency, and random macroeconomic events. Thus, even similar regions can develop differently and the resulting patterns of specialisation are ex ante unpredictable.

In the investigation of sectoral specialisation patterns, it is possible to either directly focus on output or trade data ${ }^{1}$ or to look at the allocation of the most important factors of production: labour and capital. In a descriptive analysis of the localisation patterns of employment in EU countries, Brülhart and Torstensson (1996) as well as Brülhart (1998) confirm that scaleintensive industries are marked by a strong concentration of employment across EU countries, while they are at the same time predominantly located in central EU countries. The process of concentration seems to be already more advanced in the high-technological and scaleintensive sectors than in labour-intensive and science-based sectors - the latter two now showing stronger tendencies of specialisation. The result that employment in small-scale industries is still relatively dispersed across EU countries is in contrast to the strong regional clustering in the US found by the seminal study in Krugman (1991). And already Krugman (1991) predicted increasing specialisation for a further economically integrated Europe.

Since the high mobility of employees across US states contrasts sharply with the low mobility of labour across the EU, we must not neglect the analysis of capital data - especially as inside the EU we face an increasing mobility of capital which is enforced by EMU and financial market integration. In addition, a profound analysis of regional, not only national, specialisation is still missing in recent research. This study therefore aims to identify the determinants of sectoral specialisation patterns of EU regions with respect to gross fixed capital formation, i.e. what causes a region to have especially strong investments in a particular sector.

\footnotetext{
${ }^{1}$ Trade data can be regarded to give insights into the specialisation of an economy insofar as the sectoral patterns of trade approximately reflect the structure of national production. Studies on trade patterns focus on the degree and development of inter- and intra-industrial trade of countries. Ireland, Denmark, Portugal, and Greece seem to be highly specialised, but there is no clear evidence of strongly increasing specialisation tendencies of EU countries according to e.g. European Commission (1997) and Greenaway and Hine (1991).
} 
Factor cost differentials between regions, due to e.g. productivity differentials, are essential in the explanation of specialisation patterns according to traditional trade theory. Market integration increases regional specialisation in line with trade expansion. Agglomeration tendencies such as a high density of population, capital or economic activity in only one regional area and a disequilibrium in economic developments are, however, not to be expected. Polarisation theory, instead, stresses possible circular and cumulative agglomeration tendencies in the centre accompanied by "backwash-effects" which are unfavourable for peripheral regions. The NEG also predicts that, due to the existence of economies of scale, the production of each differentiated good is locally concentrated. It locates close to large markets due to forward and backward linkages, i.e. advantages from being close to consumers and (intermediate-) input markets. The core thus specialises in scale-intensive economic activity, the periphery in sectors with constant or decreasing economies of scale. The centripetal forces of economies of scale are the lower, the higher centrifugal forces such as transaction costs are. Increased market integration might thus lead to enforced agglomeration tendencies. As soon as transaction costs are sufficiently low, low labour costs in the periphery may act as a dispersion factor. Recent NEG models thus predict an inverse U-shaped curve of sectoral concentration.

The few econometric studies testing the predictions of the NEG mostly focus on the geographic concentration of industries across countries or regions neglecting the explanation of regional specialisation. The level of sectoral concentration across EU countries is investigated by Amiti (1999) and Haaland et al. (1999), the one across Spanish regions by Paluzie, Pons and Tirado (2001). These studies have identified a higher level of demand concentration, human capital, stronger scale intensity and intermediate-input intensity of a sector to increase its level of concentration while a high labour intensity seems to decrease the sector's uneven allocation across space ${ }^{2}$. Amiti (1999) additionally finds significant positive time effects and concludes that reductions in trade barriers have possible increasing impacts on sectoral concentration. Middlefart-Knarvik et al. (2001) focus on the determinants of the location of sectors analysing gross value added. Sectors which are intensive in unskilled labour are located in peripheral, low wage countries while those industries highly dependent on intermediate inputs and subject to increasing returns to scale are significantly stronger attracted by central regions. In addition, all industries prefer to locate in big regions, i.e. close to large markets.

Investigating the manufacturing specialisation of regions, Kalemli-Ozcan, Sorensen and Yosha (1999) find higher population density, lower per capita gross regional product, lower number of population of a region as well as a higher degree of risk sharing (supposed to represent financial market integration or development) to have a significant increasing impact on regional specialisation. In an investigation of the level of relative regional investment specialisation of EU regions, Stirboeck (2002a, 2002b) detect that the location of a region in either the economic centre or in the periphery increases the uneven relative allocation of investments across sectors within the region. The level of regional investment specialisation is also augmented by a region's small size, weak market potential (gross regional product), high population density, high unemployment rate and increasing economic openness or capital

\footnotetext{
${ }^{2}$ The finding of Haaland et al. (1999) of a significant negative impact of economies of scale on sectoral concentration for 1992, one of the two years analysed, however, is a controversial outcome.
} 
market integration. The fact that economically central regions as well as peripheral regions are stronger specialised than other regions is of particular interest when analysing the regional specialisation patterns in specific sectors in the following.

Our analysis is twofold. In section II, we start with an exploratory spatial data analysis of regional specialisation patterns in order to identify the spatial structure of relative sectoral investment shares, i.e. where are clusters of regional specialisation in the different sectors. Section III contains the econometric analyses on the determinants of strong or weak relative sectoral investments, i.e. what sort of EU regions are specialised in specific sectors. This is intended to give insight into regional characteristics that influence the allocation of economic activity across sectors within a region and thus regional specialisation patterns.

\section{Exploratory Spatial Data Analyses of Relative Sectoral Specialisa- tion Patterns of EU Regions}

EU regional entities are defined by the Eurostat Nomenclature on territorial units (NUTS Nomenclature des unités territoriales statistiques). We analyse EU regions at the NUTS 2level for the period 1985 to 1994 . The maximum number of regions included is 56 . These regions belong to Belgium, Denmark, France, Luxembourg, Ireland as well as Italy ${ }^{3}$. For all other countries and years, the availability of regional data for different sectors is not sufficient for our kind of analysis. The disaggregation of EU countries into NUTS-regions is primarily based on political or administrative entities. Such "normative" regions are regarded for practical reasons of data availability in the REGIO database, but also in accordance with the implementation of regional policies ${ }^{4}$. These regions are not defined on the basis of economic criteria. This is often criticised by economists as this might not give us the actual degree of specialisation of economic entities. However, the definition of economic regions might differ for each variable or even sector regarded, i.e. a general specification of regional disaggregation is inappropriate. In addition, the analysis of normative regions, disaggregated according to NUTS, allows us to focus on the degree of specialisation of a territorial community which is authorised to implement regional policies or is in the focus of regional structural programmes. The debate concerning the specialisation level of EU's regions originates in questioning their regional shock absorbing potential and the need to improve regional policies, the analysis of administrative regional entities is one relevant empirical aspect.

Up to 17 differentiated sectors (see Table 1) - consistent to the industrial classification of NACE Rev. 1 - Nomenclature des activités économiques dans les Communautés Européennes - are available in the REGIO database. These refer to agriculture, manufactured products as well as market and non-market services.

In our analysis of the investment patterns in these 17 sectors, we focus on their investment shares in relation to an economy of reference. Thus, relative investment specialisation

\footnotetext{
${ }^{3}$ Details and further explanation are given in the appendix A.

${ }^{4}$ Since the 1961 Brussels Conference on Regional Economies, regional policies are generally applicated in NUTS 2-regions (Eurostat, 1999).
} 
(SPCFEU: SPecialisation of gross fixed Capital Formation in relation to $\mathbf{E} \mathbf{U}$ patterns) is measured. This is important as the absolute allocation of production across sectors does not give any information about a region's particularly high level of sectoral engagement, while this is what we focus on: relative allocation and hence, relative specialisation in the different sectors. It is the unequal size of regions or sectors that generally causes the difference between the absolute and the relative specialisation ${ }^{5}$.

Table 1: Sectors disaggregated according to NACE Rev. 1

\begin{tabular}{|l|l|}
\hline Sector & Abbr. \\
\hline Agricultural, forestry and fishery products & AGRO \\
\hline Manufactured products & FUEL \\
\hline Fuel and power products & META \\
\hline Ferrous and non-ferrous ores and metals, other than radioactive & MINE \\
\hline Non-metallic minerals and mineral products & CHEM \\
\hline Chemical products & METP \\
\hline Metal products, machinery, equipment, electrical goods & TREQ \\
\hline Transport equipment & FOOD \\
\hline Food, beverages, tobacco & TEXT \\
\hline Textiles and clothing, leather and footwear & PAPE \\
\hline Paper and printing products & VARI \\
\hline Products of various industries & BUIL \\
\hline Building and construction & \\
\hline Services & TRLO \\
\hline Recovery, repair, trade, lodging and catering services & TRCO \\
\hline Transport and communication services & CRED \\
\hline Services of credit and insurance institutions & OTHS \\
\hline Other market services & NMSE \\
\hline Non-market services &
\end{tabular}

Relative investment indices have therefore been constructed measuring the sectoral investment share of the respective region $s_{i j}$ in relation to the average sectoral share of the EU being the reference economy $\boldsymbol{r}_{i}{ }^{6}$ :

\footnotetext{
${ }^{5}$ While measures of absolute allocation are influenced by regional size and sectoral classification, measures of relative allocation are influenced by the sectoral patterns of either the economy of reference or the average pattern of the group of countries included. In case of a very special pattern of the reference economy, the relative specialisation pattern of the economic entities analysed can be biased. See e.g. Stirboeck (2001) or Krieger-Boden (1999).

${ }^{6}$ As sectoral GFCF data are not in all cases as complete as we wish it to be, we had to use adequate but different data representing the economic extent or importance of the different sectors to calculate sectoral specialisation indices with respect to GFCF. Therefore we refer to data of gross value added at factor costs as the denominator when calculating the specialisation indices in relation to EU average patterns. Eurostat (2000b) similarly uses the regional contributions of national gross value added as distributional weights when the national values of gross domestic product (GDP) need to be divided among the regions.
}

Sectoral investment shares of each region as well as the average EU sectoral shares of value added at factor costs (VAFC) are given in the appendix in Table A5. For most sectors, average EU sectoral shares of VAFC are comparable to the average sectoral share of total GFCF in Italy or France. Only for OTHS, the sectoral shares of VAFC are much lower than those of GFCF, thus potentially leading to an upward bias, i.e. an increase in the level of SPCFEU. In contrast to OTHS, the average sectoral shares of VAFC are higher than those of GFCF for the sectors BUIL, CRED (however, not for Luxembourg), and TRLO. As a consequence the level of SPCFEU might be biased downwards for these sectors. However, such effects do not disturb the analysis 


$$
\operatorname{SPCFEU}_{i j}=\frac{S_{i j}}{r_{i}}=\left(x_{i j} / \sum_{i} x_{i j}\right) /\left(\sum_{j} x_{i j} / \sum_{i} \sum_{j} x_{i j}\right)
$$

with i (j) as the sectoral (regional) index. As a result, this adapted „Balassa-index “7 ${ }^{\text {" }}$ reflects the relative sectoral investment "performance" of a region. If the region's investment in one sector is relatively strong (low) compared to the average sectoral share in EU, the index is higher (smaller) than $1^{8}$. Table A6 presents the average level of SPCFEU for each sector of the 56 NUTS 2-regions analysed.

The investigation of regional indices of sectoral specialisation does not give insights into the level of sectoral concentration across space. Relative sectoral investment shares simply tell in which regions investments in a sector are particularly strong or weak. A spatial agglomeration of the sector is only evident in case of high Balassa-indices in one or few nearby regions.

Paying attention to possible discrepancies or core-periphery tendencies, we find many regions far away from the centre to have an allocation of investments particularly different from the EU average, most regions near the centre to have a more or less even relative allocation and the economic centres (proxied by the administrative centres ${ }^{9}$ ) to have a strongly uneven relative allocation as well (Stirboeck, 2002a/2002b). Thus, the level of relative regional specialisation of the core as well as the peripheral regions is particularly high. Depending on the specific sectoral specialisation, the regional growth potential differs. A region might profit from relative specialisation, it might also suffer from relative specialisation in case of an unbalanced or unfavourable specialisation.

We use Moran scatterplots in order to display spatial patterns in sectoral investment structures such as clusters of similar sectoral investment shares or outlying regions. These are one tool of the exploratory spatial data analysis ${ }^{10}$. The Moran scatterplot was introduced by Anselin (1995) and is used to visualise the patterns of spatial association between neighbouring regions. It thus gives a description of the spatial distribution of the variable observed, i.e. the spatial allocation of sectoral investments and the spatial association between nearby regions. For such a spatial analysis, spatial weights matrices defining the spatial structure of interaction are needed. We use the squared inverse distances between the regional capitals which reflects a decreasing strength of influence of neighbouring locations with increasing distance.

of relative sectoral specialisation patterns as long as each sector is analysed in separate estimates since the bias is symmetric for each region.

${ }^{7}$ This kind of specialisation index has first been introduced by Balassa for the analysis of the relative export "performance" of a country by use of export data and is known as the "revealed comparative advantage" index in international trade theory [see e.g. Balassa (1989:19)].

${ }^{8}$ In some few (four) cases, negative investments were replaced by zero investments in order to avoid problems in the interpretation and calculation of further indicators. Such negative investments are mostly due to realignments and depreciation and are always close to zero investments.

${ }^{9}$ In some countries like Germany, the administrative centre would not adequately represent the economic centre. However, in the countries analysed, the administrative centre is a good proxy.

${ }^{10}$ The exploratory spatial data analysis tools rely on the methods of exploratory data analysis following e.g. Tukey (1977). 
The Moran scatterplot in Graph 1 displays the spatial association between the 56 regions (Anselin, 1996) with respect to their average specialisation index in transport and communication services and the spatially weighted average of the neighbouring values (W_SPCFEU). The sectoral specialisation indices are taken as deviations from the sectoral mean (Z_SPCFEU). The scatterplot is thus centred around $[0,0]$ and different scatterplots are comparable. In the upper right and the lower left quadrant, those regions are displayed which are surrounded by regions similarly specialised in the respective sector and are thus marked by positive spatial association. Regions with dissimilar neighbours are located in the upper left (regions with low specialisation in a sector surrounded by regions highly specialised in this sector) and the lower right quadrants (regions highly specialised in a sector surrounded by regions with a low specialisation in this sector). Those points which are more than two units away from the origin are regions that can be characterised as outliers ${ }^{11}$. Graph 1 displays the scatterplot for TRCO, Graph 2 the one for FOOD, and the other sectors' scatterplots are given in the appendix B (see Graph B1 to B15).

Graph 1: Moran Scatterplot: Transport \& Communication Services, NUTS 2

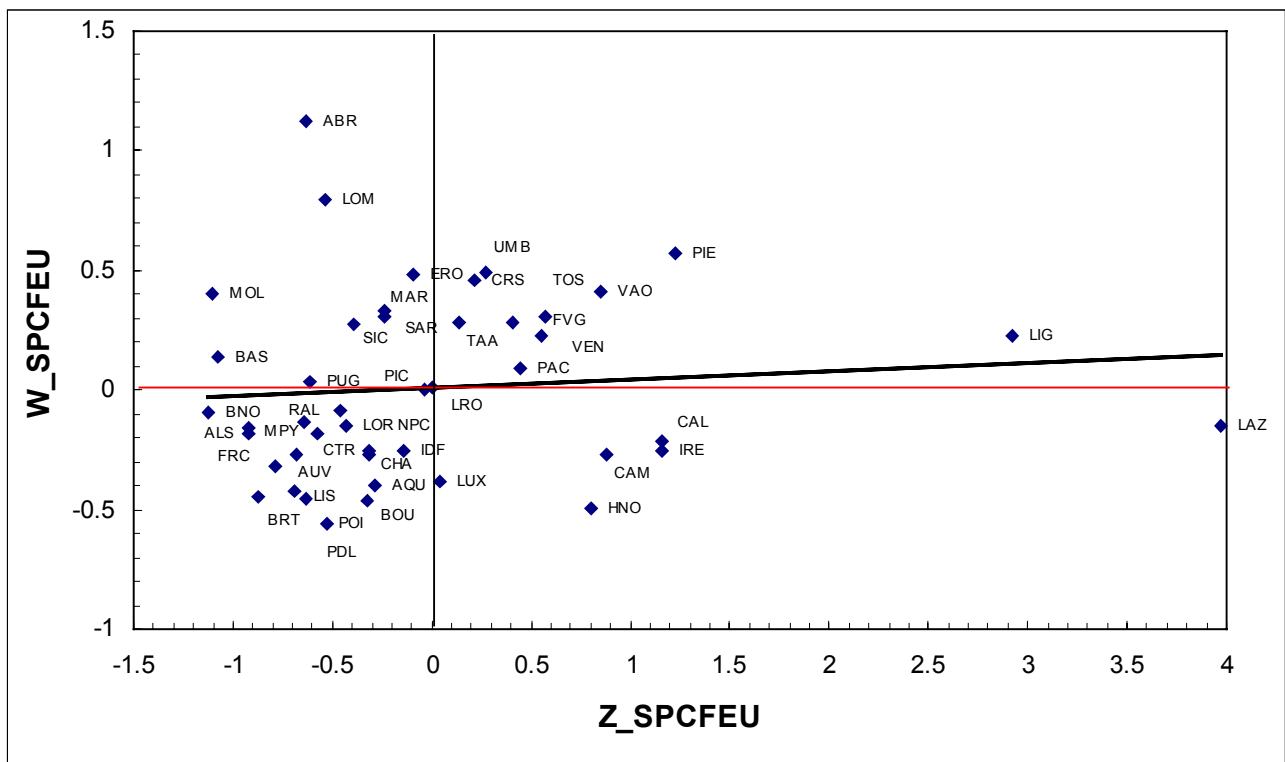

Note: Average pattern for 1985-94; Z_SPCFEU displays the deviation of the different SPCFEU from their mean while W_SPCFEU represents the spatially weighted average of the neighbouring values.

It is important to note that Moran scatterplots present spatial distributions, i.e. tell us which regions are surrounded by similar or dissimilar regions. Due to the standardisation of SPCFEU, i.e. its presentation in deviation from the mean, it becomes visible which regions have a higher or lower level of relative investment shares than the average level of the regions regarded. However, the actual (or non-standardised) level of relative specialisation in a sector - which is presented in Table A6 - is not given in the plot. We might thus see a cluster of very similar, though not strongly specialised regions in a sector. It is therefore important to

\footnotetext{
${ }^{11}$ Since the values are standardised in the Moran scatterplot, i.e. expressed in deviation from their mean, those values further than two units away from the origin are generally treated as outliers according to the twosigma rule (Anselin, 1995: 45).
} 
pay attention to the non-standardised level of relative specialisation (SPCFEU) in a sector as well.

The scatterplot for relative specialisation in transport and communication services gives evidence of a very high relative specialisation in the regions Liguria and Lazio compared to the other regions. There is no region with an outlying low value of relative specialisation in TRCO. The North and North-Western Italian regions Liguria, Piemonte, Valle d'Aosta, Toscana, Venetio, Umbria, Trentino-Alto-Aldige, and Friuli-Venezia Giulia, as well as the French regions Provence-Alpes-Côte d'Azur and Corse, show an above average relative specialisation and are surrounded by similar regions, i.e. regions highly specialised in TRCO as well. The level of specialisation of Corse, however, is above average, but rather moderate. In addition, Provence-Alpes-Côte d'Azur is somewhat stronger specialised than Corse, but not as high as one would have expected from the existence of e.g. the technological centre Sophia-Antipolis near Nice. The reason for this only moderate relative specialisation is the stronger diversification of this Mediterranean region, compared to the Italian regions. Highly specialised in TRCO, though surrounded by regions with a low specialisation in TRCO, are Ireland, the Haute-Normandie, Campania as well as Calabria. Of the named regions, only Corse and Trentino-Alto-Aldige show a level of relative specialisation slightly below 1.5, all these regions are thus highly specialised in TRCO compared to average EU patterns.

Graph 2: Moran Scatterplot: Food, Beverages \& Tobacco, NUTS 2

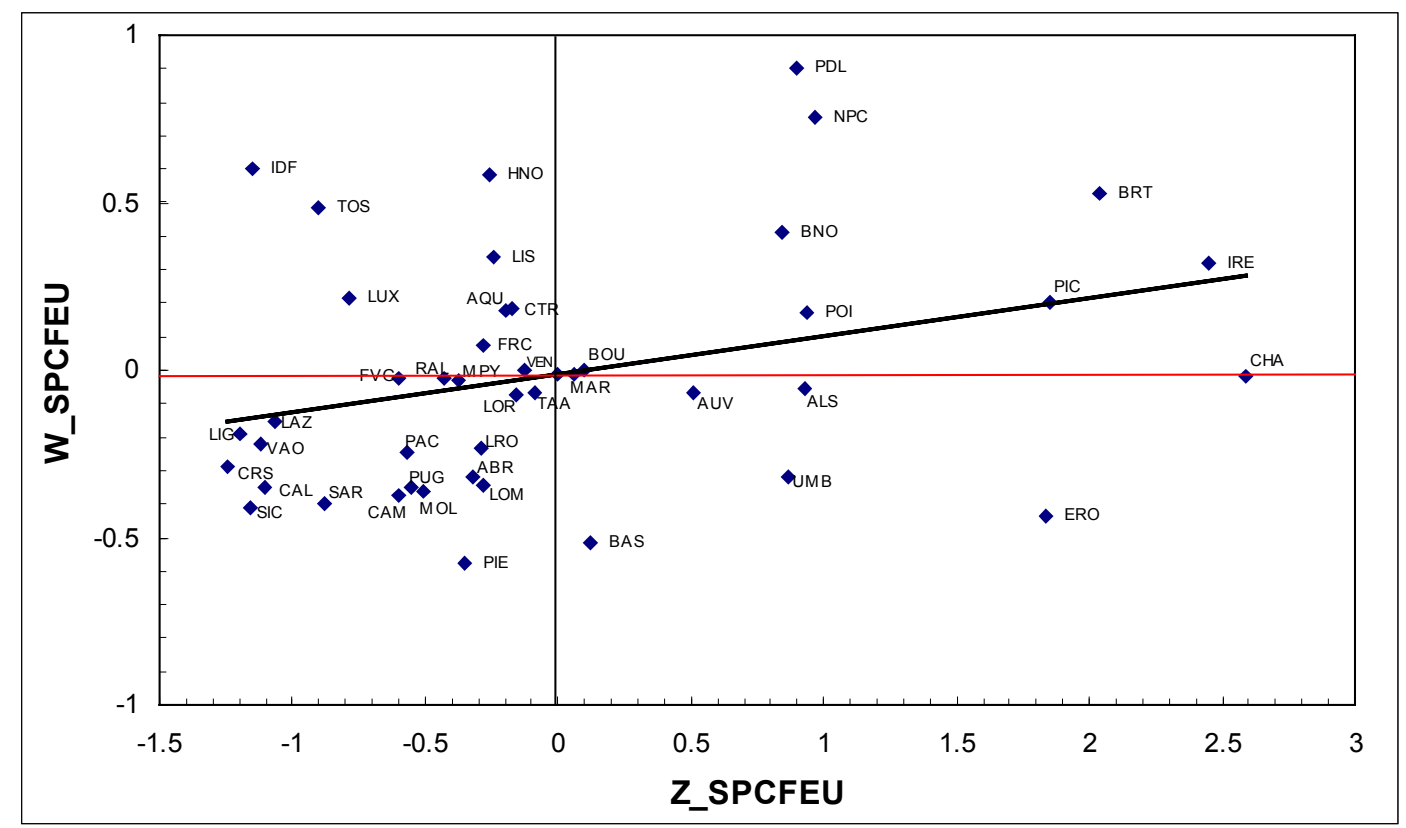

Note: See Graph 1.

In the FOOD sector, we have three regions with outlying strong relative investments (i.e. Z_SPCFEU > 2): Bretagne, Ireland, and Champagne-Ardenne. The upper right quadrant gives those regions which are highly specialised in FOOD and are surrounded by similarly specialised regions. Most of these are located in France. Regions with a high relative importance of investments in the FOOD sector, thus, appear to be locally concentrated in the North-West of France (Picardie, Nord-Pas de Calais, Pays de la Loire, Bretagne, Basse-Normandie as well as Poitou-Charentes). In Italy, we see three central Italian regions with high relative investment shares in FOOD: Basilicata, Umbria, and Emilia-Romagna. These are, however, never sur- 
rounded by similar regions, but by regions with a below average specialisation in the sector "food, beverage \& tobacco". Compared to TRCO, relative investment shares in FOOD have a lower level. Only five regions, three of them in France, show regional investment shares which are 50\% higher than average EU investment shares in the sector FOOD.

A particularly high specialisation in agricultural, forestry \& fishery products (AGRO) is obvious for the two Italian regions Basilicata and Molise in contrast to the Île de France which has the lowest relative investment share. While a cluster of regions with a high relative specialisation in FOOD was visible for the North-Western French regions, we now have evidence of a spatial cluster in AGRO across Italy as most, i.e. 14 of the 20 Italian regions are highly specialised in AGRO while being surrounded by similar regions. In addition, 17 of the 20 Italian regions and 13 of the 22 French regions have Balassa-indices for AGRO of more than 1.5 which demonstrates the high relative importance of this sector in France and Italy. Italian regions with a relative specialisation below the mean (i.e. Z_SPCFEU $<0$ ) in agriculture are e.g. Lazio, Liguria, and Campania, i.e. a number of those regions, we identified to show a high importance of investments in TRCO. Ireland, instead, provides evidence of strong relative investments in AGRO in addition to TRCO. Champagne-Ardenne shows the highest relative investment share of the French regions - this is not surprising since AGRO also includes investments in wine-growing.

Like for AGRO, though not as widespread, we have a clustering of the textiles industries (TEXT) in Italy. Eight Italian regions are highly specialised in the sector TEXT while surrounded by highly specialised regions. In constrast to AGRO, this cluster is concentrated mainly in the central and Northern parts of Italy. Four regions have above average relative investment shares when analysing the standardised values of relative investment specialisation: Marche, Toscana, Lombardia, and Veneto. But only these four as well as Piemonte also show a high non-standardised value of relative specialisation of more than 1.5.

Another cluster located in Italy can be found for relative investments in non-metallic minerals and mineral products (MINE) which is especially strong in Toscana, Umbria, and EmiliaRomagna, and more moderate in Molise, Sardegna, Sicilia, Veneto, Puglia, and Abruzzo. Relative investments in fuel \& power products (FUEL) are also clustered in Southern Italian regions with especially strong specialisation indices in Sardegna followed by Sicilia, Puglia, Calabria as well as Molise, Basilicata, Abruzzo, Umbria, and finally Lazio. High relative investments, though not surrounded by regions with similar patterns, are also to be found in the French regions Provence-Alpes-Côte d'Azur, Haute-Normandie, and Centre (F). Finally, building \& construction (BUIL) is clustered in Italy as well. We find regions with above average investments in BUIL surrounded by similar regions mostly in Southern Italy: Sicilia, Puglia, Campania, Molise, and outstanding Calabria and Basilicata ${ }^{12}$. While in the before mentioned Italian regions the non-standardised value of the relative specialisation indicator is near or above 1.5 for both, MINE and FUEL, this is not the case for BUIL. We can thus iden-

\footnotetext{
${ }^{12}$ Relative investments in BUIL are only slightly above average in Puglia, though it is obviously surrounded by a number of regions with high relative investments in this sectors and is thus clearly part of the identified cluster. In addition, a number of French regions is specialised in BUIL, but not surrounded by similar regions.
} 
tify a geographical proximity of South Italian regions with the highest relative investment specialisation indices in BUIL. However, the absolute level of relative specialisation in this sector is rather low ${ }^{13}$.

There is no clear pattern of clustering neither for CHEM, META, METP, PAPE, TREQ, nor for VARI. We find that Sardegna and Haute-Normandie have outstanding relative investments in the chemicals industries, and the Basse-Normandie in "ferrous \& non-ferrous ores \& metals" (META). Auvergne is relatively strong in investments in various industries, Molise, Franche-Comté, and Piemonte in transport equipment, Lombardia and Emilia-Romagna in "metal products, machinery, equipment \& electrical goods", Haute-Normandie and Limousin in paper \& printing products.

With respect to credit and insurance services (CRED), we have an outstanding high relative investment share in Luxembourg, dominating the whole spatial patterns of association, followed at a large distance by Ireland and the Île de France. The high credit specialisation of Luxembourg even causes the outlier-position of Lorraine (more than two units away from the origin with respect to the spatially weighted average of neighbouring values), its neighbour, which, itself, turns out to show a specialisation moderately below average. Relative investments in other services (OTHS) are especially strong in the Île de France and particularly low in Luxembourg. A number of those regions with a high relative specialisation in OTHS, we find to be regionally clustered in Southern Italy (Puglia, Sicilia, Campania, Calabria, and Molise) ${ }^{14}$. Relatively high trade, repair \& lodging services (TRLO) investments are clustered in the traditional tourist (and mostly also coastal) Italian regions Veneto, Lombardia, Liguria, Toscana, Emilia-Romagna, and Friuli-Venezia Giulia as well as the isle of Corse. Outstandingly high are relative investments in TRLO in Trentino-Alto Adige - a region in the Alpes where some of the most important Italian ski stations are located. However, besides TrentinoAlto Adige, none of these regions shows a particularly high level of relative investment shares ${ }^{15}$.

The scatterplot for non-market services (NMSE) provides evidence of outstanding high investment shares of the state sector in two regions being the isle of Corse as well as the small North-Western Italian Valle-d'Aosta sharing borders with Switzerland and France. Both regions, and only these two, indeed show a non-standardised relative specialisation level of more than 1.5. These two as well as Basilicata are surrounded by dissimilar regions, thus being three local points - and not clusters - of relatively high non-market services investments. In addition, we have another 19 of the 56 regions marked by high relative investments in nonmarket services which are also surrounded by similar regions. Besides Luxembourg, these regions are mostly located in France, those regions with the highest relative investment shares

\footnotetext{
${ }^{13}$ To some extent, this is due to the described downward bias in the indicator. However, the indicators ${ }^{`}$ levels are - like for TRLO - consistently rather low.

${ }^{14}$ Since the relative investment shares of OTHS are supposedly biased upwards as explained above, we need not interpret their absolute levels here.

${ }^{15}$ To some extent, this is due to the described downward bias in the indicator. However, the indicators ${ }^{`}$ levels are consistently comparably low.
} 
are located far away from the French capital, e.g. in the South of France. Most of the regions with a relatively low specialisation in NMSE are to be found in Italy or Ireland.

The degree of linear association between the vectors Z_SPCFEU and W_SPCFEU is displayed by the linear regression line superimposed in the graphs (see Anselin, 1996: 115ff; Anselin, 1992: 132f). The regression lines in the Moran scatterplots point to significant positive spatial autocorrelation of the relative specialisation of most sectors, i.e. regions are more spatially clustered than in the case of random patterns with respect to their sectoral investment specialisation. In other words, regions with a high (low) relative specialisation in a specific sector are more likely to be surrounded by regions which are also highly (low) specialised in this sector ${ }^{16}$. The only exception is the spatial pattern of the relative specialisation in the credit and insurance services, transport equipment as well as metal production. Regions highly specialised in these sectors are likely to be surrounded by regions with a low specialisation.

Table 2: Moran's I-tests

\begin{tabular}{|l|r|r|l|}
\hline Sector & Moran I & z-value & \\
\hline AGRO & 0.256 & 4.412 & ${ }^{* *}$ \\
\hline FUEL & 0.191 & 3.386 & $* *$ \\
\hline META & -0.054 & -0.454 & \\
\hline MINE & 0.315 & 5.234 & $* *$ \\
\hline CHEM & 0.016 & 0.611 & \\
\hline METP & 0.114 & 2.126 & $* *$ \\
\hline TREQ & -0.026 & -0.036 & \\
\hline FOOD & 0.117 & 2.164 & $* *$ \\
\hline TEXT & 0.129 & 2.360 & $*$ \\
\hline PAPE & 0.085 & 1.675 & $*$ \\
\hline VARI & 0.103 & 1.955 & $*$ \\
\hline BUIL & 0.238 & 4.125 & $* *$ \\
\hline TRLO & 0.225 & 3.757 & $* *$ \\
\hline TRCO & 0.038 & 0.940 & \\
\hline CRED & -0.022 & 0.024 & \\
\hline OTHS & 0.032 & 0.846 & \\
\hline NMSE & 0.237 & 4.115 & *** \\
\hline
\end{tabular}

In addition to the visualisation of the linear association by use of the bivariate regression line in a Moran scatterplot, its degree, i.e. the slope of the bivariate regression line, is also formally indicated by the Moran I statistic. Moran's I test is defined as $I=\sum_{j} \sum_{k} w_{j k}\left(Y_{j}-\mu\right)\left(Y_{k}-\mu\right) / \sum_{j}\left(Y_{j}-\mu\right)^{2}$ with $\mathrm{W}$ as the row-standardised weights matrix and $\mathrm{Y}$ as the variable whose spatial distribution is analysed (Anselin, 1992: 138) ${ }^{17}$. Moran's I coefficient is centred around its theoretical expected mean which is $[-1 /(\mathrm{N}-1)]$. Values larger than its expected mean, which in case of a high number of observations is approximately zero, display positive spatial autocorrelation.

\footnotetext{
${ }^{16}$ However, from this kind of analysis, we only get information about spatial associations or spatial clustering. Evidence on spatial dependencies or even causal interactions have to be derived from spatial regression analyses which is not the focus of this analysis.

${ }^{17}$ For further details on the Moran I coefficient see Anselin (1996: 115ff) and Anselin (1992: 132f).
} 
Table 2 displays the Moran I values for all sectors which reflect the slope in the regression line. None of the three negative Moran I values is significant. Eleven sectors show a significant positive Moran I value. These sectors are AGRO, FUEL, MINE, BUIL, TRLO and NMSE at the $1 \%$-level of significance, METP, FOOD, and TEXT at the 5\%-level as well as PAPE and VARI at the $10 \%$-level of significance. We thus find a positive spatial association which is significant for many sectors while the negative spatial association is not. In addition, most of the services sectors, besides TRLO which is naturally concentrated in coastal or mountainous areas, are not spatially associated, but randomly distributed. Though TRCO seemed to be spatially clustered in Northern Italy and OTHS in Southern Italy, according to the Moran scatterplot presented above, we do not find a significant positive spatial association between nearby regions for these sectors.

\section{Explaining sectoral investment patterns}

In order to explain relative investment specialisation in the different sectors, a number of important theoretical determinants can be identified as explained above within the traditional trade theory as well as regional economics such as polarisation theories and the NEG. The location of the region, economies of scale, market integration, comparative advantages such as factor cost or productivity differentials, and the regional market size are, according to the different theoretical approaches, to be taken into consideration when explaining the regional patterns of sectoral specialisation.

Value added in relation to employment captures the level of regional productivity in the different sectors. Since productivity differentials are important for the explanation of comparative advantages in traditional trade theory, we use the (annual) deviation of the regional productivity in a sector from the mean of all regions (DPROD) in the estimates. The regional level of sectoral wages and salaries per employee reflects average regional labour costs in the sector. Again, we measure particularly high or low regional levels of labour costs by the (annual) deviation from the mean (DLABCOST). A positive deviation of regional labour costs from the mean should lead to decreasing investments according to the theory if labour costs are important. A negative sign of DLABCOST thus explains investments which are in line with comparative advantages. In addition, a significant negative sign of DLABCOST provides evidence for the importance of labour costs as a factor of dispersion in a particular sector and a potentially inverse U-shaped curve of sectoral concentration.

We use an indicator variable reflecting the location of a region in the economic centre (CENTR) - proxied by the administrative centre of each country ${ }^{18}$ - and the regional population density (PODEN) in addition to the distance to the economic centre (DIST) of the respective country as an indicator of the peripherality of the region. A positive sign of CENTR and PODEN as well as a negative sign of DIST in the estimates for the important growthoriented sectors would support the hypothesis of the polarisation theory of cumulative agglomeration tendencies in the centre and backwash effects for peripheral regions.

\footnotetext{
${ }^{18}$ See footnote 9 .
} 
The size of the regional market (MAR) is approximated by gross regional product (GRP). The importance of the market size in the explanation of the location of sector provides evidence in favour of the New Economic Geography which predicts that scale-intensive sectors concentrate production close to large markets. The regional level of economies of scale (ES) in a sector is measured by dividing sectoral value added at factor costs by the number of firms in the given sector ${ }^{19}$. The significance of the regional level of ES indicates the further agglomeration potential of the respective sector.

In order to measure the impact of market integration (INT), we use an indicator of economic openness by Quinn $(1997,2000)^{20}$. We expect an increasing impact on the level of regional specialisation according to both the traditional trade theory and the NEG. However, adding this variable in the analysis of sectoral specialisation indices might tell us which sectors do profit particularly from increasing economic openness.

In addition, we add further regional characteristics and economic performance variables which can be assumed to be important in the explanation of investment decisions. These regional control variables included in the estimations are the regional size (AREA), the unemployment rate (UEWP) as well as the number of regional patent applications in relation to GRP proxying the regional research intensity (RDINT). Since we do not dispose of any variable reflecting sectoral research and development activity in EU regions, we have to refer to the regional research intensity. We also include indicator variables for the different countries (DUM_FRA, DUM_LUX etc.) as further control variables capturing country-specific impacts.

We thus test the following specification for each sector in a pooled regression for the time period 1985 to 1994 :

$$
\begin{aligned}
\text { SPCFEU }_{i j}= & \beta_{0}+\beta_{1} \text { MAR }_{j}+\beta_{2} \text { AREA }_{j}+\beta_{3} \text { PODEN }_{j}+\beta_{4} U E W P_{j}+\beta_{5} D I S T_{j} \\
& +\beta_{6} I N T_{j}+\beta_{7} \text { CENTR }_{j}+\beta_{8} R D I N T_{j}+\beta_{9} E S_{i j}+\beta_{10} D P R O D_{i j} \\
& +\beta_{11} D L A B C O S T_{i j}+\text { country dummies }+\varepsilon_{i j}
\end{aligned}
$$

with $\mathrm{i}(\mathrm{j})$ as the sectoral (regional) index.

In the estimates, we cannot exclude potential interactions or reverse causation between the relative sectoral investments of a region, i.e. its sectoral specialisation, and the regional unemployment rate, GRP, research intensity as well as the sectoral level of economies of scale, labour costs, and productivity in the specific region. In order to control for these potential endogeneity problems, instrumental variable regressions have to be conducted additionally.

Neither the number of firms in the different sectors, the number of patent applications, nor the sectoral level of wages and salaries are available for all regions and years. Thus, our dataset is

\footnotetext{
${ }^{19}$ Data availability limits us to this simple measure of economies of scale. A more complex proxy of ES is the average value of shipments per firm, considering the $50 \%$ largest firms, assuming that the larger firms are likely the efficient size to exploit economies of scale (Saunders, 1982; Caves, 1974). The average value added per firm, we use, is a common proxy in empirical studies as well and according to Lall/Siddharthan (1982)'s correlation analysis a sufficient proxy.

${ }^{20}$ The construction of this indicator is explained in the appendix A.
} 
restricted when including these variables in the analysis. We include the regional research intensity independent of the sector focussed on. However, when referring to region-specific sectoral economies of scale, DLABCOST as well as DPROD, the analysis is unfortunately restricted to only nine manufacturing sectors with available sector-specific data. Separate estimates have therefore been displayed for each of these additional sector-specific explanatory variables. Thus, theoretically very important variables can only be included in additional estimates with less observations.

Table 2 displays the qualitative results for the pooled estimates which include those regionspecific characteristics available for all the years for which we have calculated specialisation indices. Results are displayed in case of significance only - which has to be at least $10 \%$, though significance is achieved at the $1 \%$-level in most cases. Detailed results are given in the appendix in Table $\mathrm{C} 1$. We used generalised least squares ${ }^{21}$ instead of ordinary least squares estimates to control for potential heteroscedasticity in the pooled data of 56 regions and 10 years. The number of observations is given in the last line. In the case of Denmark, data availability is very poor since we only have specialisation indices for four sectors. In addition, information on Irish investments in TRLO and OTHS is not available. Controlling for potential endogeneity between the level of specialisation and regional GRP as well as UEWP, we conducted instrumental-variables estimates. Following a common approach in econometric analysis, lagged values of the unemployment rate as well as of GRP are included as instruments. Results are given in Table C2 which are very similar.

Investments in many manufacturing sectors are attracted by large markets (MAR - proxied by GRP). Relative investment shares in credit and insurance services, other services, transport and communication as well as trade and lodging services are lower in larger markets. Investments in market services seem to be strengthened in smaller markets, in contrast to investments in manufacturing industries. Relative investments in e.g. agriculture as well as the food industry, paper \& printing products, the textiles industries, and the metal industries are significantly lower in the economic centre (CENTR) of the respective country. We thus can assume that labour-intensive producing sectors prefer to locate outside the economic centres. In addition, investments in chemical products, various industries, transport equipment as well as mineral products are significantly lower inside the administrative centres. Market services, instead, have higher relative investment shares in the centre as well as in densely-populated regions (PODEN) - in addition to their relative strength in small markets.

Significantly lower relative investments are to be found in larger regions (AREA) in agriculture, metal production (META), non-market services as well as transport equipment, while the inverse is evident for fuel \& power products, metal products \& electrical goods (METP) as well as the services sectors CRED, TRCO, and TRLO. The location far away from the centre (DIST), i.e. in the periphery, leads to significantly lower relative investments in agriculture and most manufacturing sectors, but to stronger relative specialisation in the market

\footnotetext{
${ }^{21}$ We thus estimate variance-corrected standard errors to prevent that potential heteroscedasticity influences the coefficients' significance.
} 
services sectors (besides CRED), non-market services as well as building \& construction. Results for the level of the regional unemployment rate (UEWP) as well as for regions being located in countries with a higher economic openness (INT) do not provide clear patterns with respect to the nature of sectoral investment strength. We thus have no evidence that increasing European integration might influence investments in particular sectors.

Summarising, we find market services sectors to have a significantly stronger relative gross fixed capital formation in small markets, central regions, regions with high population density as well as peripheral regions. Manufacturing sectors are mainly located outside the national administrative centres, however, not too far away from this economic centre. Investments in manufacturing sectors are, thus, stronger in the central parts of each country, but not in the centre itself. Non-market services investment shares are higher in the peripheral and small regions as well as regions with high unemployment and a low population density. Relative investments in agriculture, finally, are located neither in the centre nor the periphery, and are stronger in smaller, not densely populated regions, but also in large markets.

Table 3: Influence of regional characteristics on sectoral investment patterns

\begin{tabular}{|l|c|c|c|c|c|c|c|c|c|c|c|c|c|c|c|c|c|c|}
\hline & AGRO & FUEL & META & MINE & CHEM & METP & TREQ & FOOD & TEXT & PAPE & VARI & BUIL & TRLO & TRCO & CRED & OTHS & NMSE \\
\hline \hline MAR & + & & + & + & + & + & & + & + & & & + & - & - & - & - & \\
\hline CENTR & - & + & - & - & - & - & - & - & - & - & - & + & + & + & + & + & \\
\hline UEWP & + & + & & & + & - & & - & - & - & - & + & - & - & - & + & + \\
\hline PODEN & - & - & - & - & & & & - & - & & & - & + & + & + & + & - \\
\hline AREA & - & + & - & & & + & - & & & & + & & + & + & + & & - \\
\hline INT & & + & & & & & + & + & & & & - & & + & - & - & \\
\hline DIST & - & & & - & - & - & - & - & - & - & - & + & + & + & & + & + \\
\hline DUM_FRA & - & - & + & - & & & & + & - & + & & - & - & - & + & + & + \\
\hline DUM_IRE & + & - & + & & + & + & & + & + & & & - & n.a. & - & + & n.a. & \\
\hline DUM_LUX & - & - & + & & & + & & & + & & + & - & & - & + & - & + \\
\hline DUM_DEN & - & - & n.a. & n.a. & n.a. & n.a. & n.a. & n.a. & n.a. & n.a. & n.a. & & n.a. & n.a. & n.a. & n.a. & + \\
\hline \hline no. of obs. & 377 & 377 & 353 & 361 & 360 & 361 & 353 & 361 & 360 & 361 & 361 & 377 & 358 & 363 & 363 & 358 & 377 \\
\hline
\end{tabular}

Note: Results are displayed in case of statistical significance only. Detailed results are given in the appendix in Table $\mathrm{C} 1$.

The additional inclusion of the regional research intensity (RDINT) in separate estimates due to the availability of the number of patents for the restricted time period 1989 to 1994 provides evidence of the importance of the regional research intensity in 7 of the 17 sectors ${ }^{22}$. Table 4 shows that a high research intensity leads to a regional investment share which is lower than the average sectoral investment share in agriculture, credit services as well as nonmarket services. Relative investments, instead, are high in mineral products, chemical, various and metal industries in case of high research intensity. The higher importance of investments in agriculture and non-market services in regions with low research intensity is not surprising. However, we expect investments in the manufacturing sectors to be higher in those regions with a higher research activity due to knowledge spillovers etc. - especially for those sectors marked by high research \& development activity like e.g. transport equipment and the chemicals industries. We found significant effects for four of the eleven manufacturing sectors including the chemical industries, but not transport equipment. The regional research intensity

\footnotetext{
${ }^{22}$ Due to the strongly decreased number of observations, we refrained from instrumental-variable estimates.
} 
thus seems to be of minor importance in many manufacturing sectors. Though, it is to be expected that these estimation results can be improved with a better, more complete database as well as sector-specific information on regional research activity. The other explanatory variables' coefficients - given in Table C3 - remain extremely robust compared to the sharply decreased number of observations. Only in a few cases ${ }^{23}$, they loose or gain significance, but never change their sign when remaining significant.

Table 4: Additional influence of the regional research intensity

\begin{tabular}{|l|c|c|c|c|c|c|c|}
\hline & AGRO & MINE & CHEM & METP & VARI & CRED & NMSE \\
\hline \hline RDINT & - & + & + & + & + & - & - \\
\hline
\end{tabular}

Note: Results are displayed in case of significance only. Detailed results are given in the appendix in Table C3.

Similar to the research intensity variable, we also added the above described variables on the regional deviation from the average level of productivity (DPROD) in the different sectors, on sectoral economies scale (ES), and on the regional deviation from average labour costs per employee (DLABCOST) in the sector in three separate estimates ${ }^{24}$ to the regional characteristics displayed in Table 3. The results for these three sectoral variables are given in Table 5. Detailed results, including instrumental-variable estimates (by use of lagged values of GRP, UEWP, DPROD, ES as well as DLABCOST), are displayed in the appendix in Tables C4 to C6. As explained above, we only have the necessary data for nine manufacturing sectors, and not of all the 17 sectors. In addition, the data availability and thus the number of observations differs in each case. Again, the influence of the explanatory variables, we have already discussed above, is mostly robust in spite of the decreased number of observations ${ }^{25}$.

Table 5: Additional influence of sector-specific regional characteristics

\begin{tabular}{|l|c|c|c|c|c|c|c|c|c|}
\hline & FUEL & MINE & CHEM & METP & TREQ & FOOD & TEXT & PAPE & BUIL \\
\hline \hline DPROD & + & + & + & & + & + & & + & - \\
\hline DLABCOST & & & & - & & & & - & + \\
\hline ES & + & + & + & + & + & + & + & + & \\
\hline
\end{tabular}

Note: Results are displayed in case of significance only. Detailed results are given in the appendix in Table C4 to Table C6.

${ }^{23}$ With respect to the estimates for FUEL, three variables become insignificant, in the estimates for TREQ, BUIL, CRED, and NMSE, two variables loose significance - though in any case, RDINT is only significant in the estimates for CRED and NMSE. However, no systematic pattern is obvious in these changes. CENTR is the variable which looses significance most often (in four cases), though RDINT is only significant in one of these cases. This means that the inclusion of RDINT influences the other variables' significance in very few cases, does never change a significant variable's sign while some variables loose significance in the estimates due to the decreased number of observations.

${ }^{24}$ We tried to add all three variables jointly in one regression for each sector. The results do not change much. The number of observations, however, is still further decreased.

${ }^{25}$ Again, we have no change in sign of any significant variable. With respect to the estimates for TREQ, we have an additional significance of three variables in the estimates including DPROD, in the estimates including DLABCOST, however, two explanatory variables loose significance. A number of changes, though, occur for the regressions including ES: regarding FUEL, four variables become insignificant, regarding FOOD, three, and regarding TEXT, two. Most often, i.e. in three cases, the variable PODEN changes its level of significance. 
The results do provide evidence of a consistent significant impact of the sector-specific regional level of productivity and the level of economies of scale. Unsurprisingly, those regions with higher economies of scale ${ }^{26}$ as well as a higher productivity in the different sectors attract a higher relative share of gross fixed capital formation. These impacts, however, cannot be found for building \& construction. In addition, the regional level of sectoral productivity seems to be of no importance in textiles as well as metal \& electrical products.

The impact of the region-specific level of sectoral labour costs is not a general one, instead, and is rather mixed. According to traditional trade theory, one would expect all sectors to increase production (and thus investments) in regions with a lower level of labour costs. This impact should be especially strong or obvious in labour-intensive sectors like the textiles industries. In the estimates, however, we only find significant impacts of DLABCOST for investments of three sectors. For the paper and printing as well as the metal \& electrical products industry, a lower regional level of sectoral labour costs seems to attract investments while the opposite is the case for the building $\&$ construction sector.

When conducting additional instrumental-variable estimates, most results can be confirmed ${ }^{27}$ - except for the three cases with significant DLABCOST. Thus, the importance, traditional trade theory accords to labour cost differentials cannot be confirmed for regional specialisation patterns. Only productivity differentials play an according role. However, in contrast to the other manufacturing sectors, building \& construction even seems to counteract theoretical assumptions of the traditional trade theory.

\section{Conclusion}

In this paper, we investigate the spatial patterns and driving forces of relative sectoral investment shares and thus the relative specialisation of EU regions in specific sectors. Analysing regional specialisation in relation to the average sectoral structure of EU, we often find a clustering of high relative sectoral investments in a number of regions within countries reflecting the geographical proximity of similarly specialised regions. This result is especially obvious for agriculture across most Italian regions, textiles industries in North Italian regions and minerals \& mineral products in the middle parts of Italy as well as fuel \& power products across most Italian regions, but particularly strong in southern Italy. Relative investments in the services sectors are less clustered, but we find a spatial concentration of trade \& lodging services along most Italian coastal regions, of other services in South Italian regions as well as of transport \& communication services in northern Italy and the south of France. But, in contrast to all other described clusters, we find no evidence for a significant positive spatial association for the latter two services sectors.

\footnotetext{
${ }^{26}$ This result is consistent with Amiti (1999) who found significant positive effects of economies of scale on sectoral concentration in addition to the intermediate goods intensity.

${ }^{27}$ In some few case, the respective region-specific sectoral variable or one of the other explanatory variables loses significance. However, to some extent this can be explained by the lower number of variables included.
} 
With respect to the French regions, we cannot identify a regional clustering of high relative investments in a sector. But, across French regions, non-market services are consistently stronger, though still moderate, than in the other regions analysed and are the highest in those regions far away from Paris, e.g. in the South of France. In addition, those regions with the highest levels of specialisation in the food sectors are mostly located in north-western France.

The econometric analyses aim at identifying the regional determinants of high relative sectoral investments. We test a number of determinants from different theoretical approaches and control for heteroscedasticity and potential endogeneity. Regional factor cost or productivity differentials are supposed to matter according to the traditional trade theory. We find no evidence for the relevance of labour cost differentials, but sectoral productivity differentials between regions generally contribute to the explanation of relative investment shares in those nine manufacturing sectors analysed.

Since investments in most manufacturing sectors are attracted by regions close to (and not far away from) the administrative centre (though not by the administrative centres themselves), we might be confronted with backwash effects predicted by the polarisation theory for peripheral regions. In addition, core regions and densely-populated regions provide evidence for stronger relative investment shares in the important and growth-orientied services sectors. But we cannot directly conclude on cumulative agglomeration of services in the core since peripheral regions show higher relative investment share in some services sectors as well.

Gross regional product proxying the market potential is significant and positive for many manufacturing sectors. For those sectors, the location close to large markets - predicted by the New Economic Geography - thus seems to matter. In addition, the consistently significant and positive sign of the regional level of sector-specific economies of scale for the manufacturing sectors points to a further agglomeration potential in these sectors. In addition, market integration, which according to the New Economic Geography is supposed to enforce the agglomerative forces of economies of scale does not play a particular role in any sector.

Finally, country-specific dummies are mostly significant as well. This means that countryspecific characteristics which are not captured by the regional determinants in our estimates do influence the regional investment level in most sectors. However, these country-specific effects differ with respect to each sector.

The studies of Stirboeck (2002a, 2002b) provide evidence for the stronger relative regional specialisation of core as well as of peripheral regions. Core regions - in contrast to peripheral regions - are marked by a higher potential of economic performance. The results of our econometric analysis now demonstrate that peripheral regions compared to core regions, indeed, play a different role in the location of sectoral investments. The driving forces of investment specialisation are favourable for core regions with respect to growth-oriented market services like transport \& communication services and credit $\&$ insurance services. The services sectors with the highest regional specialisation of peripheral regions, however, are repair, trade \& lodging services as well as other services - both linked to economic activity in tourism. 
In addition to some of the services sectors, relative investments in non-market services as well as building \& construction are stronger in peripheral regions as well. As long as investments in NMSE and BUIL support education or infrastructure measures, a high relative regional specialisation can be beneficial. However, in general, high relative investments in NMSE as well as BUIL do not necessarily represent a specific advantage, but rather a high dependence on non-market economic activities and a poor sectoral diversification. When regarding "absolute" regional investment shares (presented in Table A5), i.e. regional investment shares not given in relation to EU, these only amount to about $2.5 \%(3 \%)$ of total investments in France (Italy) in BUIL and to about 15\% (8.5\%) in France (Italy) in NMSE. Thus, the respective importance of those sectors, peripheral regions are more strongly specialised in than regions in the central parts of a country, is not too high. However, to be precise, sectoral investment shares vary between $5.3 \%$ for Lazio and $27.5 \%$ for Valle d'Aosta in NMSE. This shows that differences between central and some of the peripheral regions are rather large. In addition, those regions with the highest relative investments shares are clustered in Southern Italy with respect to the sector BUIL, and located in the French regions far away from the French capital, e.g. in Southern France, with respect to NMSE.

Regarding the lower relative specialisation in manufacturing sectors of those regions far away from the economic centre, the insignificant role of labour costs does not provide hope for the periphery to attract manufacturing production - a prediction of some NEG models once transaction costs are sufficiently low. Though, we do not find a strong regional clustering of manufacturing sectors in central or core regions pointing to a disadvantageous situation of peripheral regions. However, it is a waste of ressources to promot or even subsidise the location of manufacturing sectors in peripheral regions if these sectors are already established in other regions while profiting from increasing returns to scale at sector level.

A good sign is the stronger relative importance of some of the services sectors - in addition to NMSE and BUIL - in the regions far away from the centre. Though, there are large differences with respect to the sector's importance across space. These are the most obvious for transport \& communication services. Its share is only about 6 to $9 \%$ in Southern Italian regions while it amounts to $24 \%$ in Lazio. However, for repair, trade \& lodging services as well as other services - mostly linked with tourism or a coastal location - the variation of regional investment shares is much less pronounced. 


\section{References}

Aмiтi, M. (1999): Specialization Patterns in Europe, Weltwirtschaftliches Archiv 135 (4), 573-593.

ANSELIN, L. (1992): SpaceStat Tutorial, A Workbook for Using SpaceStat in the Analysis Spatial Data, available: http://www.spacestat.com/docs/spacestat tutorial.pdf.

ANSELIN, L. (1995): SpaceStat Version 1.80 User's Guide, available: http://www.spacestat.com/docs/V180man.pdf.

ANSELIN, L. (1996): The Moran scatterplot as an ESDA tool to assess local instability in spatial association, in: Fisher, M. and D. Unwin (eds.): Spatial analytical perspectives on GIS, Taylor and Francis, London.

BAlassa, B. (1989): Comparative advantage, trade policy and economic development, Hasvester Wheatsheaf, Hestfordshire, 18-79.

BRÜLHART, M. (1998): Trading Places: Industrial Specialisation in the European Union, Journal of Common Market Studies 36 (3), 319-346.

BRÜLharT, M. AND TORSTENSSON, J. (1996): Regional Integration, Scale Economies and Industry Location in the European Union, CEPR Discussion Paper No. 1435.

EuROPEAN COMMISSION (1997): Trade Patterns inside the Single Market, The Single Market Review Impact on Trade and Investment, Subseries IV (2):.

CAVES, R.E. (1974): Causes of Direct Investment: Foreign Firms' Shares in Canadian and United Kingdom Manufacturing Industries, The Review of Economics and Statistics LVI, 279-293.

EuROSTAT (1999): Statistik kurzgefaßt, Allgemeine Statistik 1-3/1999, Luxembourg.

Greene, W.H. (1997): Econometric Analysis, $3^{\text {rd }}$ edition, Prentice Hall, New Jersey.

GREENAWAY, D., AND R.C. HINE (1991): Intra-industry Specialization, Trade Expansion and Adjustment in the European Economic Space, Journal of Common Market Studies 29(6), 389-403.

HAALAND, J.I. , KInD, H.J., MidelfarT-KNARVIK, K.H. AND J. TORSTENSSON (1999): What determines the economic geography of Europe?, Centre for Economic Policy Research, Discussion Paper No. 2027, London.

Kalemli-OzCan S., B.E. Sorensen AND O. Yosha (1999): Risk Sharing and Industrial Specialization: Regional and International Evidence, mimeo.

KRIEGER-BODEN, C. (1999): Nationale und regionale Spezialisierungsmuster im europäischen Integrationsprozeß, Die Weltwirtschaft (2), 234-254.

KrugMan, P. (1991): Geography and Trade, Cambridge/Massachusetts.

LALL, S. AND N.S. SidDHARTHAN (1982): The Monopolistic Advantages of Multinationals: Lessons from Foreign Investment in the U.S., The Economic Journal, 92, 668-683.

MIDELFART-KNARVIK, K.H., OVERMAN, H.G., REDDING, S.J. AND A.J. VENABLES (2000): The Location of European Industry, Economic Papers No. 142, Report prepared for the DG for Economic and Financial Affairs, European Commission, Brussels.

PaluZie, E., Pons, J. AND A. TIRADO (2001): Regional Integration and Specialization Patterns in Spain, Regional Studies (35), 285-296.

QuINN, D. (1997): The Correlates of Change in International Financial Regulation, American Political Science Review, 91(3), 531-551.

QUINN, D. (2000): Democracy and International Financial Liberalization, mimeo.

SAUNDERS, R.S. (1982): The determinants of interindustry variation of foreign ownership in Canadian manufacturing, Canadian Journal of Economics, XV (1), 77-84.

STIRBoecK, C. (2001): Agglomeration Tendencies in EU Regions: Where Does Capital Go?, ZEW Discussion Paper No.01-28.

STIRBOECK, C. (2002A): Relative Specialisation of EU Regions: An Econometric Analysis of Sectoral Gross Fixed Capital Formation, ZEW Discussion Paper No.02-36.

StiRBoeCK, C. (2002B): Explaining the Level of Relative Investment Specialisation: A Spatial Econometric Analysis of EU Regions, ZEW Discussion Paper No.02-49. 


\section{Appendix}

\section{A Data description}

The regional disaggregation of the data is given according to the Nomenclature of Territorial Units for Statistics (NUTS - Nomenclature des unités territoriales statistiques). The REGIO database disaggregates data for the three aggregation levels NUTS 1, 2 and 3. However, data for GFCF is not available further disaggregated than the NUTS 2-level. In addition, it is not complete (with regard to the regional and/or the sectoral disaggregation - the latter needed for the calculation of the specialisation indices).

Table A1: Regional data for GFCF from the REGIO database

\begin{tabular}{|l|l|l|l|}
\hline Country & $\begin{array}{l}\text { NUTS } \\
\text { level }\end{array}$ & $\begin{array}{l}\text { Respective national dis- } \\
\text { aggregation level }\end{array}$ & $\begin{array}{l}\text { Number of } \\
\text { regions } \\
\text { NUTS 2 }\end{array}$ \\
\hline Belgium & 2 & Provinces & 11 \\
\hline France & 2 & Régions & 22 \\
\hline Italy & 2 & Regioni & 20 \\
\hline Denmark & $1 \& 2$ & - & 1 \\
\hline Ireland & $1 \& 2$ & - & 1 \\
\hline Luxembourg & $1 \& 2$ & - & 1 \\
\hline \multicolumn{2}{|l|}{ Total number of regions } & 56 \\
\hline
\end{tabular}

Note: Version of NUTS 1995. French oversea departments (DOM - départements outre-mer) are not counted in total sums for France as well as for the EU.

Table A2: Overview on NUTS 2-regions included

\begin{tabular}{|c|c|c|c|c|c|}
\hline France & & Italy & & Belgium & \\
\hline NUTS 2 & & NUTS 2 & & NUTS 2 & \\
\hline Alsace & ALS & Abruzzo & ABR & Antwerpen & ANT \\
\hline Aquitaine & AQU & Basilicata & BAS & Brabant Wallon & BWA \\
\hline Auvergne & AUV & Calabria & CAL & Bruxelles-capitale & BRU \\
\hline Basse-Normandie & BNO & Campania & CAM & Hainaut & HAl \\
\hline Bourgogne & $\mathrm{BOU}$ & Emilia-Romagna & ERO & Liège & LIE \\
\hline Bretagne & BRT & Friuli-Venezia Giulia & FVG & Limburg (B) & LIM \\
\hline Centre $(F)$ & CTR & Lazio & LAZ & Luxembourg (B) & LUB \\
\hline Champagne-Ardenne & $\mathrm{CHA}$ & Liguria & LIG & Namur & NAM \\
\hline Corse & CRS & Lombardia & LOM & Oost-Vlaanderen & OVL \\
\hline Franche-Comté & FRC & Marche & MAR & Vlaams Brabant & VBR \\
\hline Haute-Normandie & $\mathrm{HNO}$ & Molise & $\mathrm{MOL}$ & West-Vlaanderen & WVL \\
\hline Île de France & IDF & Piemonte & PIE & & \\
\hline Languedoc-Rousillon & LRO & Puglia & PUG & & \\
\hline Limousin & LIS & Sardegna & SAR & & \\
\hline Lorraine & LOR & Sicilia & SIC & & \\
\hline Midi-Pyrénées & MPY & Toscana & TOS & & \\
\hline Nord - Pas-de-Calais & NPC & Trentino-Alto Adige & TAA & Monoregional Co & tries \\
\hline Pays de la Loire & PDL & Umbria & UMB & Denmark & DEN \\
\hline Picardie & PIC & Valle d'Aosta & VAO & Ireland & IRE \\
\hline Poitou-Charentes & POI & Veneto & VEN & Luxembourg & LUX \\
\hline Provence-Alpes-Côte d'Azur & PAC & & & & \\
\hline Rhône-Alpes & RAL & & & & \\
\hline
\end{tabular}


Data availability at NUTS 2-level is sufficient for the six countries presented in Table A1 and A2. Luxembourg, Denmark as well as Ireland are only regarded as one single region at the NUTS 1- as well as at the NUTS 2-level (=monoregional countries). The maximum number of regions available at the NUTS 2-level is 56 .

All data included in the analysis are based on the European System of Accounting established for data since 1979 (ESA79). Data are taken from the Eurostat REGIO Database (yearbooks up to 2000) which - for gross fixed capital formation - comprises data for the years 1985 to 1994. Sectoral wages and salaries as well as local units of entreprises are available in the Structural Business Statistic (SBS) of Eurostat.

Table A3: List of explanatory variables, REGIO and SBS Database

\begin{tabular}{|l|l|l|}
\hline abbreviation & variable & unit \\
\hline GFCF & Gross Fixed Capital Formation & Currency: Billions of ECU \\
\hline TOTEM & Total Employment & in 1000 persons \\
\hline COE & Compensation of employees & Currency: Billions of ECU \\
\hline VAFC & Gross value added at factor costs & Currency: Billions of ECU \\
\hline GDP & Gross domestic product & Currency: Billions of ECU \\
\hline PAT & European R\&D patent applications & total number \\
\hline UEWP & Total Unemployment rates & in \% OF WORKING POPULATION \\
\hline POP & Total annual average population & in Mio. PERSONS \\
\hline PODEN & Population density & in 1000 INHABITANTS/KM2 \\
\hline WAGSAL & Wages and Salaries & Currency: Billions of ECU \\
\hline UNITENT & Local units of entreprises & total number \\
\hline
\end{tabular}

In addition to the available national account data, a number of further variables has been used in the econometric analysis. The distance to the centre (DIST) captures peripheral effects. It is measured by the optimal route distance between the regional capital and the centre of the respective country. Centres are Paris, Rome, London and Brussels. The distance is defined to be 1 for Denmark, Luxembourg as well as Ireland, and it is equally 1 for the regions containing the capital of the respective country. These economically most important regions (CENTR) in the analysis are Île de France (France), Brussels (Belgium), and Lazio (Italy).

Table A4: List of further explanatory variables

\begin{tabular}{|l|l|l|}
\hline abbreviation & variable & unit \\
\hline DIST & Distance to centre, index of peripherality & $1000 \mathrm{~km}$ \\
\hline CENTR & Regional dummy set for central region & 0 or 1 \\
\hline QUINN_OPENN & Indicator of openness per country & $0-14$ (variation by 0.5$)$ \\
\hline RDINT & Reasearch intensity & PAT/GDP \\
\hline LABCOST & Regional labour cost per unit in sector i & WAGSAL $_{\mathrm{i}} / \mathrm{TOTEM}_{\mathrm{i}}$ \\
\hline PROD & Regional productivity in sector i & VAFC $_{\mathrm{i}} / \mathrm{TOTEM}_{\mathrm{i}}$ \\
\hline ES & Regional level of economies of scale in sector $\mathrm{i}$ & $\mathrm{VAFC}_{\mathrm{i}} / \mathrm{UNITENT}_{\mathrm{i}}$ \\
\hline
\end{tabular}

Available indicators of liberalisation arising from official sources are mostly indicator variables being either 0 or 1 . However, such indicator variables do not allow to differentiate the varying levels of control or to capture a decreasing level of control over time. Measuring a level of integration for each year is therefore a better solution from an econometric point of view. Quinn $(1997,2000)$ has constructed such a yearly index of openness on the basis of 
those restrictions published by the IMF since the 1950s. This index is scaled from 0 (highest degree of restrictions) up to 14 (highest degree of liberalisation) and aggregates the different indicators of liberalisation progress in seven specified fields (capital in - and outflows, imand exports of goods and of services as well as international conventions of liberalisation) with a respective degree of liberalisation between 0.5 and 2 .

Quinn weighs quantitative restrictions of imports for example the highest (i.e. he attributes the lowest partial liberalisation index of 0 in case of full and 0.5 in case of partly quantitative restrictions), existence of laws requiring the approval of international transactions are scored 1 , taxes 1.5 and finally free trade 2. With regard to capital account liberalisation, Quinn attributes 0 in case of required approval for capital transactions which are rarely granted, 0.5 (1) in case of occasional (frequent) approval and finally 1.5 in case of taxing measurements (without the need of an official approval). A subindex of the overall liberalisation index is a financial liberalisation indicator ranging on a score between 0 and 4 which is aggregated from restrictions of capital inward and outward flows in the way explained above. All named potential indicators, however, are only available at country, not regional, level, which has to be taken into account in econometric analysis. Detailed restrictions for Luxembourg are not available as Luxembourg and Belgium are part of a common monetary union since the 1950s. In our analysis the „Quinn-indicator“ for Luxembourg is therefore naturally set equal to the one of Belgium.

The construction of the variables RDINT, ES, LABCOST as well as PROD is explained throughout the text. 
Table A5: Sectoral shares of GFCF in total regional GFCF compared to sectoral share of EU-VAFC in total EU VAFC: averages for 1985-94

\begin{tabular}{|c|c|c|c|c|c|c|c|c|c|c|c|c|c|c|c|c|c|c|c|c|c|}
\hline SFCF & AGRO & \begin{tabular}{|l|} 
MANU \\
\end{tabular} & SERV & \begin{tabular}{|l|} 
FUEL \\
\end{tabular} & \begin{tabular}{|l|} 
META \\
\end{tabular} & \begin{tabular}{|l|} 
MINE \\
\end{tabular} & CHEM & METP & TREQ & FOOD & TEXT & PAPE & VARI & BUIL & TRLO & TRCO & CRED & OTHS & NMSE & TOTA & $\%$ of nat. \\
\hline FRA & (0.029 & 0.231 & 0.740 & \begin{tabular}{|l|}
0.050 \\
\end{tabular} & 0.012 & \begin{tabular}{|l|l|}
0.008 \\
\end{tabular} & 0.016 & |0.040 & (0.022 & |0.024 & 0.007 & |0.014| & .014 & 0.024 & 0.085 & | 0.086 & $\mid$ & | 0.401 & \begin{tabular}{ll|l}
0.147 \\
\end{tabular} & 173815.26 & 1.000 \\
\hline LS & .017 & 0.262 & \begin{tabular}{|l|}
0.721 \\
\end{tabular} & \begin{tabular}{|l|}
0.023 \\
\end{tabular} & 0.007 & \begin{tabular}{|l|}
0.013 \\
\end{tabular} & 0.023 & 0.053 & 0.026 & 0.039 & \begin{tabular}{|l|}
0.013 \\
\end{tabular} & 0.025 & \begin{tabular}{|l|}
0.016 \\
\end{tabular} & \begin{tabular}{|l|l|}
0.023 \\
\end{tabular} & 0.077 & $\begin{array}{l}0.066 \\
\end{array}$ & $\begin{array}{l}0.018 \\
\end{array}$ & 0.438 & 0.122 & 6058.46 & 0.035 \\
\hline $\mathrm{AQU}$ & 660 & 0.210 & 07 & .056 & 0.001 & 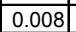 & & 0.026 & 0.016 & & & & & & & & & & & 7139.73 & \\
\hline \begin{tabular}{|l|} 
AUV \\
\end{tabular} & 059 & .240 & \begin{tabular}{|l|l|}
0.701 \\
\end{tabular} & \begin{tabular}{|l|l|}
0.030 \\
\end{tabular} & 007 & 0.009 & 012 & 0.037 & 0.009 & & 0.00 & 0.01 & .058 & 02 & 0.078 & 0.071 & 0.021 & 0.335 & 0.196 & 3293.50 & 0.019 \\
\hline BNO & 0.049 & 0.397 & \begin{tabular}{|l|}
0.554 \\
\end{tabular} & \begin{tabular}{|l|}
0.023 \\
\end{tabular} & 0.198 & \begin{tabular}{|l|}
0.005 \\
\end{tabular} & 0.005 & 0.042 & 0.036 & & 0.003 & 0.012 & 012 & 0.02 & 0.080 & $0.05 \mathrm{c}$ & \begin{tabular}{|c|}
0.014 \\
\end{tabular} & 0.262 & 0.140 & 4247.96 & 0.024 \\
\hline$\overline{B O U}$ & 0.067 & 0.236 & \begin{tabular}{|l|}
0.697 \\
\end{tabular} & \begin{tabular}{|l|}
0.030 \\
\end{tabular} & \begin{tabular}{|l|}
0.013 \\
\end{tabular} & \begin{tabular}{|l|}
0.013 \\
\end{tabular} & 0.015 & 0.054 & 0.014 & 0.027 & 0.006 & 0.010 & 0.025 & 0.02 & 0.091 & \begin{tabular}{|c|}
0.087 \\
\end{tabular} & & 0.343 & 0.156 & 4309.67 & 0.025 \\
\hline BRT & 0.07 & 0.195 & \begin{tabular}{|l|l|}
0.734 \\
\end{tabular} & 0.025 & 0.001 & 0.007 & 0.004 & 0.024 & 0.029 & 0.056 & $\overline{0.00}$ & 0.0 & 201 & 0.02 & 0.089 & 0.068 & 0.020 & & & 299.36 & 0.042 \\
\hline CTR & 0.05 & 0.268 & 0.68 & \begin{tabular}{|l|}
0.078 \\
\end{tabular} & 0.00 & 0.008 & ( & 0.055 & 0.019 & 0.023 & 0.004 & 80 & & & 0.080 & 0.075 & 0.021 & & & 831.59 & \\
\hline CHA & 0.093 & 0.274 & \begin{tabular}{|c|}
0.633 \\
\end{tabular} & \begin{tabular}{|l|}
0.058 \\
\end{tabular} & 0.005 & \begin{tabular}{|l|}
0.012 \\
\end{tabular} & 0.006 & 0.061 & $\begin{array}{l}0.010 \\
\end{array}$ & $\begin{array}{l}0.058 \\
\end{array}$ & 0.013 & 0.010 & 0.026 & 0.021 & 0.072 & $\begin{array}{l}0.079 \\
\end{array}$ & \begin{tabular}{|c|}
0.017 \\
\end{tabular} & 0.326 & & 3957.71 & 0.023 \\
\hline CRS & 0.043 & 0.101 & \begin{tabular}{|l|}
0.856 \\
\end{tabular} & \begin{tabular}{|l|}
0.041 \\
\end{tabular} & & \begin{tabular}{|l|}
0.007 \\
\end{tabular} & 0.000 & 0.005 & \begin{tabular}{l|l|}
0.002 \\
\end{tabular} & 0.007 & 0.000 & 0.002 & 0.003 & 0.033 & 0.110 & 0.104 & 0.018 & 0.380 & 0.243 & 583.04 & 0.00 \\
\hline RC & 0.03 & 0.303 & 0.665 & \begin{tabular}{|l|}
0.019 \\
\end{tabular} & 0.003 & \begin{tabular}{|l|}
0.009 \\
\end{tabular} & 0.019 & 0.073 & 0.090 & 0.021 & $\begin{array}{l}0.004 \\
\end{array}$ & 0.00 & 80 & 2027 & 0.072 & $\begin{array}{l}0.067 \\
\end{array}$ & 0.015 & 0.352 & & 3030.36 & 0.017 \\
\hline HNO & 0.026 & 0.346 & & \begin{tabular}{|l|}
0.080 \\
\end{tabular} & 0002 & 0.007 & 062 & 0.050 & 0.038 & & & 0.040 & & & 0.065 & 126 & & & & 258.40 & \\
\hline IDF & 0.002 & 0.169 & 0.82 & \begin{tabular}{|l|}
0.043 \\
\end{tabular} & 005 & \begin{tabular}{|l|}
0.003 \\
\end{tabular} & 013 & 0.032 & 0.024 & 0.008 & 0.003 & 0.012 & 0.005 & 0.020 & 0.093 & 0.092 & 0.029 & 0.511 & & 52066.87 & 0.300 \\
\hline LRO & 0.015 & 0.163 & 0.82 & \begin{tabular}{|l|}
0.039 \\
\end{tabular} & 0.016 & \begin{tabular}{|l|}
0.013 \\
\end{tabular} & 0.008 & 0.023 & 0.001 & 0.021 & 0.004 & 0.006 & 0.006 & 0.026 & 0.090 & \begin{tabular}{|c|}
0.097 \\
\end{tabular} & 0.021 & 0.392 & & 5146.97 & 0.030 \\
\hline Is & 0.059 & 0.231 & 0.710 & \begin{tabular}{|l|}
0.033 \\
\end{tabular} & 0.013 & \begin{tabular}{|l|}
0.009 \\
\end{tabular} & 0.003 & \begin{tabular}{|c|}
0.048 \\
\end{tabular} & 0.007 & 0.022 & 0.005 & 0.044 & 0.026 & 0.027 & \begin{tabular}{|l|}
0.073 \\
\end{tabular} & 0.074 & 0.023 & 0.320 & & 708.46 & 0.01 \\
\hline LOR & 0.032 & 0.289 & 0.67 & \begin{tabular}{|l|}
0.055 \\
\end{tabular} & 0.028 & \begin{tabular}{|l|}
0.010 \\
\end{tabular} & 0.018 & 0.042 & 0.036 & \begin{tabular}{|l|}
0.023 \\
\end{tabular} & 0.0 & 0.024 & $0.01 \varepsilon$ & 024 & 0.065 & 0.083 & 0.014 & 0.369 & & 4.31 & 0.03 \\
\hline MPY & 0.049 & 0.225 & \begin{tabular}{|l|}
0.726 \\
\end{tabular} & \begin{tabular}{|l|}
0.064 \\
\end{tabular} & 003 & \begin{tabular}{|l|}
0.011 \\
\end{tabular} & 0.009 & 0.024 & \begin{tabular}{|c|}
0.037 \\
\end{tabular} & 0.020 & 0.010 & 0.012 & 0.005 & 0.026 & $\begin{array}{l}0.085 \\
\end{array}$ & 0.078 & 0.020 & 0.353 & & 6559.99 & 0.03 \\
\hline PC & 0.017 & 0.262 & \begin{tabular}{|l|}
0.721 \\
\end{tabular} & \begin{tabular}{|l|}
0.040 \\
\end{tabular} & 0.020 & \begin{tabular}{|l|}
0.012 \\
\end{tabular} & 0.018 & 0.034 & 0.024 & 0.040 & 0.023 & 0.021 & 0.010 & 0.021 & 0.080 & 0.087 & 0.018 & 0.375 & 0 & 9877.04 & 0.057 \\
\hline$\overline{D L}$ & 0.048 & 0.221 & \begin{tabular}{|l|l}
0.731 \\
\end{tabular} & \begin{tabular}{|l|}
0.039 \\
\end{tabular} & 0.004 & \begin{tabular}{|l|}
0.006 \\
\end{tabular} & 0.004 & 0.043 & \begin{tabular}{|l|}
0.019 \\
\end{tabular} & 0.039 & 0.008 & 0.011 & 0.020 & 0.028 & 0.080 & 0.080 & 0.021 & 0.379 & & 8158.94 & 0.047 \\
\hline PIC & 0.059 & 0.286 & \begin{tabular}{|c|}
0.655 \\
\end{tabular} & \begin{tabular}{|l|}
0.022 \\
\end{tabular} & 014 & \begin{tabular}{|l|}
0.016 \\
\end{tabular} & 27 & 056 & 0.012 & $\begin{array}{l}0.053 \\
\end{array}$ & (012) & 0.01 & & & 0.0 & & & & & & \\
\hline OOI & 0.070 & 0.192 & \begin{tabular}{|l|}
0.739 \\
\end{tabular} & \begin{tabular}{|l|}
0.031 \\
\end{tabular} & 000 & \begin{tabular}{|l|}
0.012 \\
\end{tabular} & 0.007 & 0.029 & \begin{tabular}{|l|}
0.013 \\
\end{tabular} & 0.040 & 0.004 & 0.013 & 0.016 & 0.026 & 0.088 & 0.076 & $\begin{array}{l}0.027 \\
\end{array}$ & 0.359 & & 4162.61 & 0.02 \\
\hline PAC & 0.015 & 0.218 & 0.768 & \begin{tabular}{|l|}
0.095 \\
\end{tabular} & 0.005 & \begin{tabular}{|l|}
0.008 \\
\end{tabular} & 0.026 & 0.019 & $\begin{array}{ll}0.009 \\
\end{array}$ & 0.017 & 0.001 & 0.006 & \begin{tabular}{|l|l|}
0.005 \\
\end{tabular} & 0.027 & 0.093 & \begin{tabular}{|c|}
0.113 \\
\end{tabular} & \begin{tabular}{l|}
0.021 \\
\end{tabular} & $\begin{array}{ll}0.372 \\
\end{array}$ & & 11988.69 & 0.065 \\
\hline RAL & 0.017 & \begin{tabular}{l|l}
0.257 \\
\end{tabular} & 0.725 & \begin{tabular}{|l|}
0.049 \\
\end{tabular} & 0.007 & \begin{tabular}{|l|}
0.010 \\
\end{tabular} & 0.020 & 0.066 & \begin{tabular}{l|}
0.009 \\
\end{tabular} & 0.019 & 0.0 & 0.013 & \begin{tabular}{|l|}
0.022 \\
\end{tabular} & 0.029 & 0.084 & 0.076 & 0.017 & $\begin{array}{l}0.383 \\
\end{array}$ & & 17371.57 & 0.100 \\
\hline A & 0.065 & 0.282 & & \begin{tabular}{|l|}
0.062 \\
\end{tabular} & $\overline{112}$ & \begin{tabular}{l|l}
16 \\
\end{tabular} & 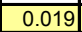 & 0.048 & \begin{tabular}{l|l|}
0.019 \\
\end{tabular} & 0.020 & & 0.01 & & & 0.0 & & D17 & & & & \\
\hline$\overline{A B R}$ & 0.089 & 0.317 & \begin{tabular}{|l|}
0.594 \\
\end{tabular} & \begin{tabular}{|l|}
0.080 \\
\end{tabular} & 005 & \begin{tabular}{|l|}
0.022 \\
\end{tabular} & 0.009 & 0.054 & 0.045 & 0.020 & 0.01 & 0.026 & \begin{tabular}{|l|}
0.017 \\
\end{tabular} & 0.021 & 0.062 & 0.075 & 0.011 & 362 & & 3236.98 & 0.022 \\
\hline BAS & 0.140 & 0.248 & 0.612 & \begin{tabular}{|l|}
0.084 \\
\end{tabular} & 0.002 & \begin{tabular}{|l|}
0.010 \\
\end{tabular} & 0.015 & 0.019 & $\begin{array}{l}0.030 \\
\end{array}$ & 0.027 & 0.00 & 0.003 & \begin{tabular}{|l|l|}
0.007 \\
\end{tabular} & 0.046 & 0.036 & \begin{tabular}{l|l|}
0.061 \\
\end{tabular} & 0.009 & 25 & & 1462.09 & 0.01 \\
\hline CAL & 0.084 & 0.205 & \begin{tabular}{|l|}
0.711 \\
\end{tabular} & \begin{tabular}{|l|}
0.097 \\
\end{tabular} & 0.001 & \begin{tabular}{|l|}
0.012 \\
\end{tabular} & 0.005 & 0.004 & \begin{tabular}{|l|}
0.003 \\
\end{tabular} & 0.009 & 0.0 & 0.003 & \begin{tabular}{|l|}
0.014 \\
\end{tabular} & 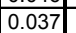 & 0.068 & 0.139 & $\begin{array}{l}0.008 \\
\end{array}$ & 396 & & 4221.65 & $0.02 \varepsilon$ \\
\hline AM & 0.050 & 0.208 & \begin{tabular}{|l|l} 
& \\
\end{tabular} & 0.046 & 0.006 & \begin{tabular}{|l|}
0.012 \\
\end{tabular} & 0. & 0.024 & 0.0 & 0.016 & 0.0 & 0.00 & 0.6 & & 0.0 & & 014 & & & & 0.072 \\
\hline ERO & 0.094 & 0.337 & 0.570 & 0.050 & 005 & \begin{tabular}{|l|}
0.036 \\
\end{tabular} & 0.019 & 0.083 & \begin{tabular}{|l|}
0.014 \\
\end{tabular} & 0.053 & 0.0 & 0.013 & 0.02 & 0.02 & 0.112 & 0.095 & 0.019 & 268 & & 11149.81 & 0.07 \\
\hline FVG & 0.064 & 0.276 & 0.65 & \begin{tabular}{|l|}
0.060 \\
\end{tabular} & 8 & \begin{tabular}{|l|}
0.013 \\
\end{tabular} & 0.012 & 0.058 & 0.008 & \begin{tabular}{|c|}
0.017 \\
\end{tabular} & 0.0 & 0.028 & 0.0 & 0. & 0.119 & 0.111 & $\begin{array}{l}0.017 \\
\end{array}$ & & & & 0.0 \\
\hline LAZ & 0.03 & 0.193 & & \begin{tabular}{|l|}
0.069 \\
\end{tabular} & 2 & \begin{tabular}{|l|}
0.008 \\
\end{tabular} & 0.015 & 0.021 & \begin{tabular}{|l|}
0.014 \\
\end{tabular} & & 0.0 & 0.014 & & & 0.091 & & & & & & 0.111 \\
\hline IG & 0.02 & \begin{tabular}{|l|l|}
0.218 \\
\end{tabular} & \begin{tabular}{|l|}
0.76 \\
\end{tabular} & \begin{tabular}{|l|}
0.069 \\
\end{tabular} & D13 & \begin{tabular}{|l|}
0.013 \\
\end{tabular} & 0.028 & 0.034 & 0.012 & 0.007 & 0.0 & 0.005 & 0.0 & 0.0 & 0.120 & & 0.019 & & & & \\
\hline OM & 0.04 & 0.347 & \begin{tabular}{|l|l|}
0.610 \\
\end{tabular} & 0.043 & 21 & 10 & 0.033 & 0.085 & 0.014 & 0.021 & 0.042 & 0.020 & 0.0 & 0.02 & 0.100 & 0.080 & 0.020 & 0.345 & & 27848.89 & 0.18 \\
\hline$\overline{A R}$ & 0.09 & 0.254 & \begin{tabular}{|l|}
0.654 \\
\end{tabular} & 0.033 & 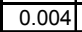 & 0. & 0.0 & 0.055 & $\begin{array}{l}0.008 \\
\end{array}$ & 0.027 & 0.0 & 0.01 & 0. & 0.024 & 0.093 & 0.090 & $\begin{array}{l}0.017 \\
\end{array}$ & 0.364 & & 3551.63 & 0.024 \\
\hline $\mathrm{L}$ & & & & & & & & & & & & & & & & & & & & & \\
\hline गIE & 0.062 & 0.368 & 0.570 & \begin{tabular}{|l|}
0.050 \\
\end{tabular} & 0.027 & \begin{tabular}{|l|}
0.015 \\
\end{tabular} & 0.019 & 0.076 & 0.070 & 0.020 & 0.03 & 0.015 & 0.0 & 0.021 & 0.067 & & 017 & 0.284 & & 12864.73 & 0.086 \\
\hline UG & 0.091 & 0.271 & 0637 & 104 & |2018 & 16 & 011 & 26 & 010 & 0.017 & .014 & 0.004 & 0.0 & & 0.063 & 0.078 & 0.014 & & & & 0.04 \\
\hline SAR & 0.09 & 0.304 & & 0. & 3 & & & 0.008 & 0.0 & & 0. & 0.00 & & 0.023 & 0.091 & 0.6 & 0.010 & 0.306 & & & \\
\hline SIC & 0.081 & 0.213 & 0.70 & \begin{tabular}{|l|}
0.106 \\
\end{tabular} & 0.003 & \begin{tabular}{|l|}
0.017 \\
\end{tabular} & 0.013 & 0.010 & 0.008 & 0.008 & 0.006 & 0.003 & 0. & \begin{tabular}{|l|l|}
0.034 \\
\end{tabular} & 0.058 & 0.084 & 0.012 & 0.437 & & .05 & 0.064 \\
\hline TOS & 0.07 & 0293 & 0.636 & $\mid$ & 0.016 & 0.032 & 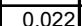 & 0.030 & 001 & 0.012 & 0.04 & 0.022 & & & 0.118 & & 0.02 & & & & 0.05 \\
\hline$\overline{\mathbf{A A}}$ & 0.0 & 0.193 & \begin{tabular}{|l|l|}
0.7 \\
\end{tabular} & \begin{tabular}{|l|}
0.036 \\
\end{tabular} & 111 & 12 & 0.005 & 00 & 000 & 0.024 & 000 & 0.011 & 0.02 & 0.0 & 0.20 & 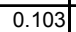 & 0.013 & & & & \\
\hline UMB & 0. & 0.312 & 0. & \begin{tabular}{|l|}
0.078 \\
\end{tabular} & 45 & & & 0.025 & 0.004 & & 0.0 & 0.01 & & & 0.073 & & 0.014 & 0.332 & & 2125.34 & 0.014 \\
\hline VAO & 0.060 & 0.137 & \begin{tabular}{|l|}
0.803 \\
\end{tabular} & \begin{tabular}{|l|}
0.047 \\
\end{tabular} & 0.020 & \begin{tabular}{|l|}
0.013 \\
\end{tabular} & 0.003 & 0.010 & 0.001 & 0.009 & 0.001 & 0.001 & 0.004 & 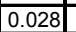 & 0.055 & 0.131 & 0.008 & 0.334 & & 674.56 & 0.00 \\
\hline VEN & 0.076 & 0.303 & \begin{tabular}{|l|}
0.622 \\
\end{tabular} & \begin{tabular}{|l|}
0.037 \\
\end{tabular} & 0.011 & \begin{tabular}{|l|}
0.019 \\
\end{tabular} & 0.020 & 0.064 & 0.007 & 0.024 & 0.042 & 0.020 & \begin{tabular}{|l|}
0.032 \\
\end{tabular} & 0.027 & 0.097 & 0.117 & 0.016 & 0.322 & 0.070 & 13051.87 & 0.08 \\
\hline DNA & 005 & 0.258 & & \begin{tabular}{|l|l|}
0.073 \\
\end{tabular} & & \begin{tabular}{|l|}
0.012 \\
\end{tabular} & & & & 0.027 & 200 & 0.019 & & 2 & & 0.1 & 0.019 & & & & \\
\hline IRE & 0. & 0.248 & 0. & \begin{tabular}{|l|}
0.047 \\
\end{tabular} & 0.003 & & 0.026 & 0.041 & 0.003 & 0.053 & & 0.01 & \begin{tabular}{|l|l|}
0.011 \\
\end{tabular} & [0.021] & & & 0.047 & & & 79 & \\
\hline LUX & \begin{tabular}{|l|}
0.024 \\
\end{tabular} & 0.180 & 0.592 & \begin{tabular}{|l|}
0.026 \\
\end{tabular} & 0.046 & 0.011 & 0.004 & 0.022 & 0.001 & 0.011 & \begin{tabular}{l|}
0.021 \\
\end{tabular} & 0.005 & 0.026 & \begin{tabular}{|l|}
0.0199 \\
\end{tabular} & 0.082 & 0.080 & 0.119 & 0.166 & $\begin{array}{ll}0.187 \\
\end{array}$ & 1834.36 & 1.000 \\
\hline$j-v$ & 0.030 & 0.323 & 0.600 & \begin{tabular}{|l|}
0.036 \\
\end{tabular} & 013 & 0.013 & 031 & 0.074 & 0.026 & 0.030 & $\overline{0.018}$ & & 0.015 & 0.060 & 0.152 & 0.070 & 0.052 & 0.181 & 0.154 & 4069823.55 & \\
\hline
\end{tabular}


Table A6: Relative sectoral investment shares for GFCF: averages for 1985-94 (in case of complete data)

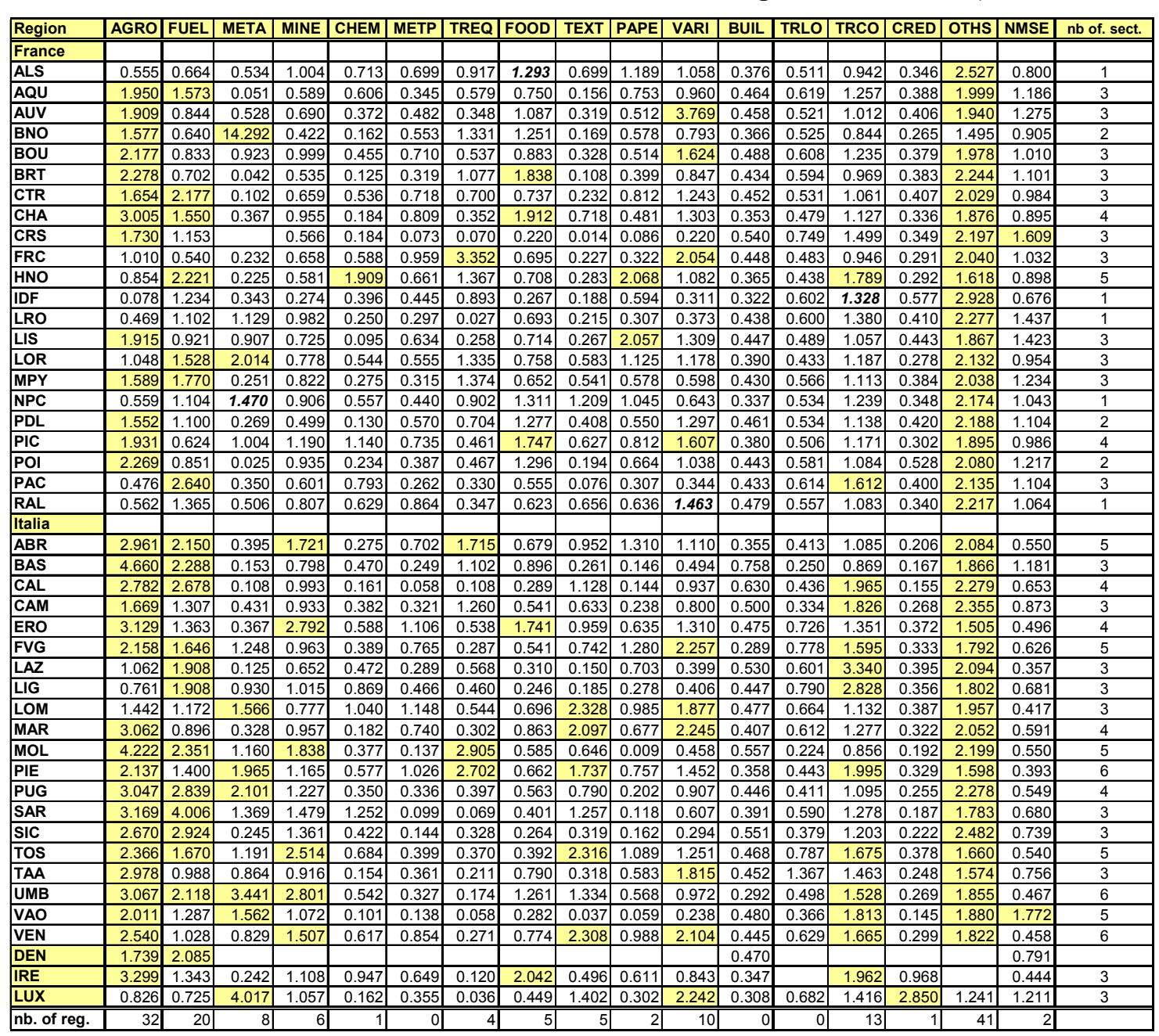

Note: Box is shaded when the index reaches at least 1.5; box is cursive and bold when the sector turns out to be one of the two most important in the respective region though the index does not reach 1.5 . 


\section{B Moran Scatterplots}

Graph B1: Moran Scatterplot: Agricultural, forestry \& fishery products, NUTS 2

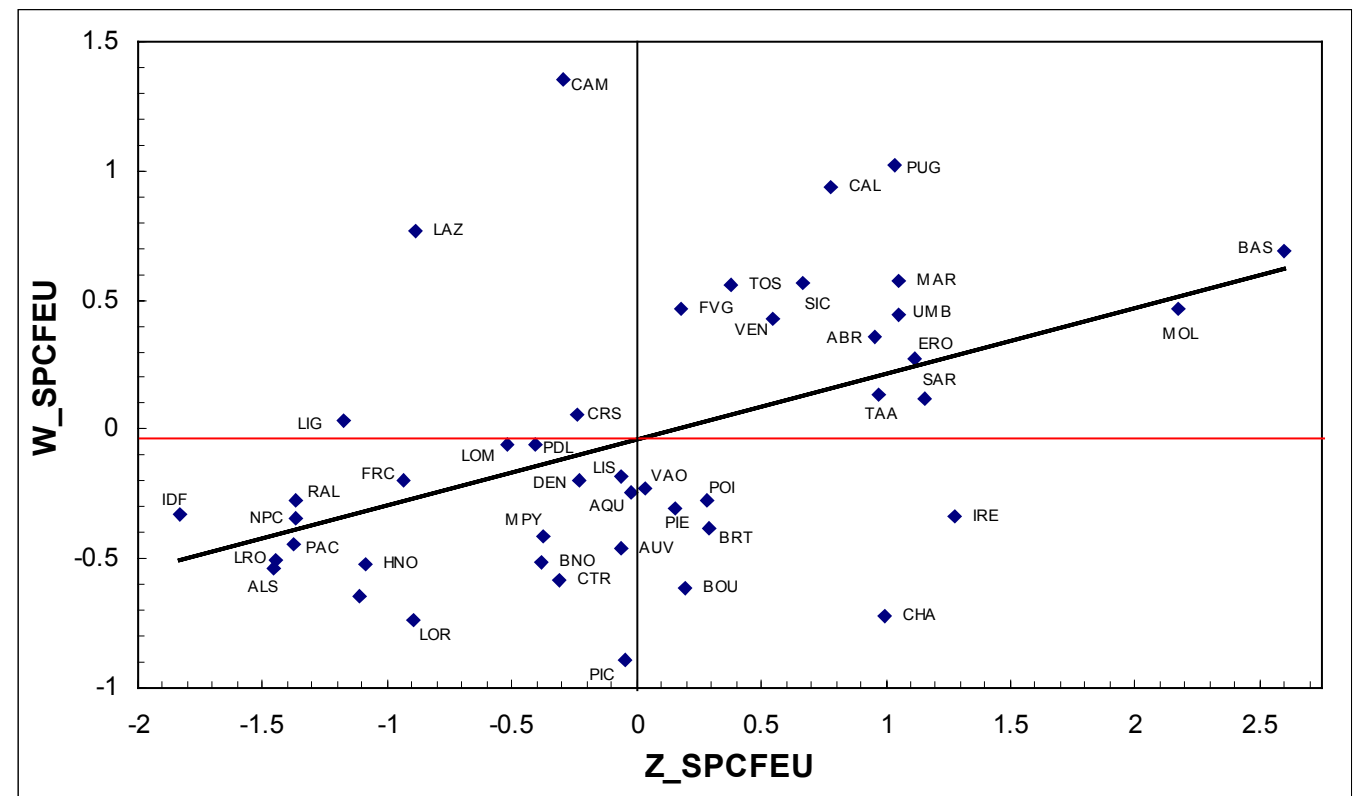

Note: See Graph 1.

Graph B2: Moran Scatterplot: Fuel \& power products, NUTS 2

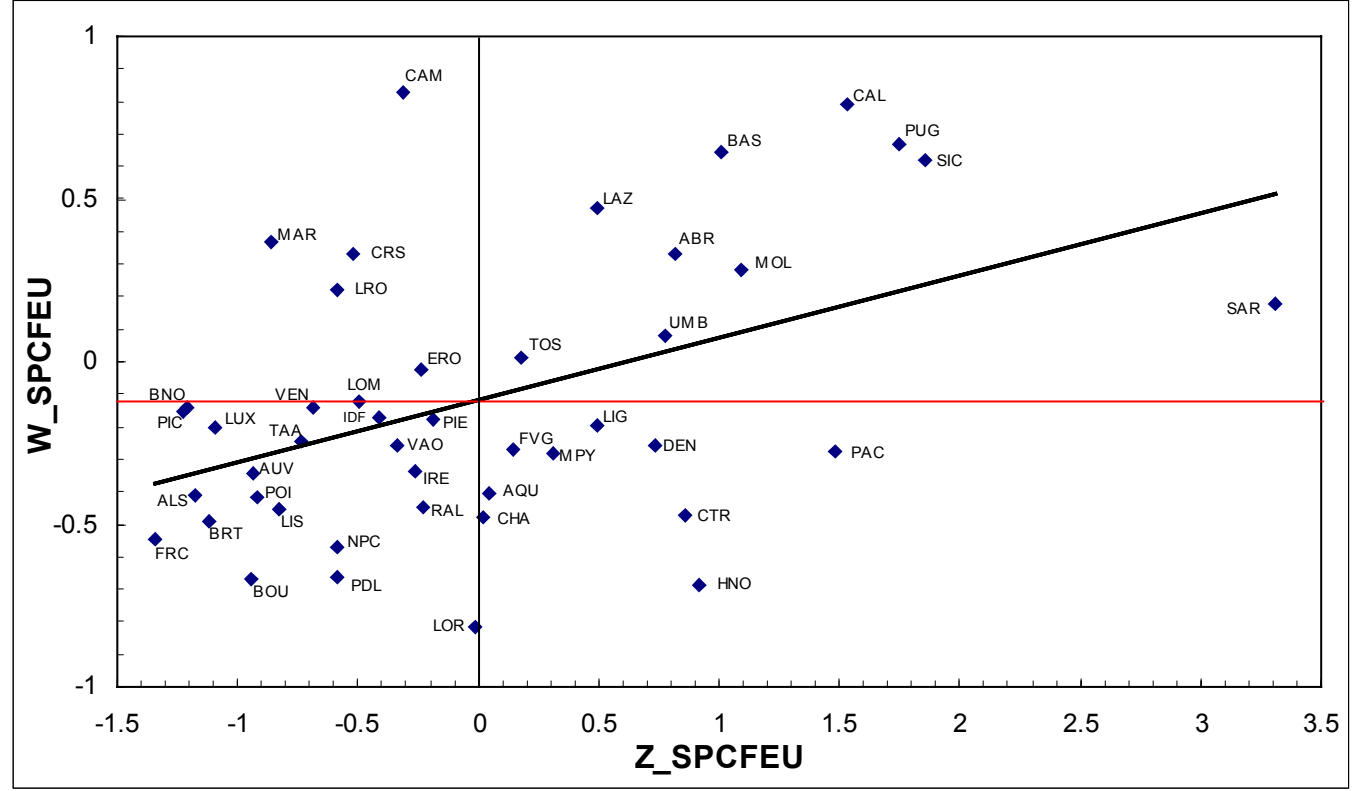

Note: See Graph 1. 
Graph B3: Moran Scatterplot: Ferrous \& non-ferrous ores \& metals, NUTS 2

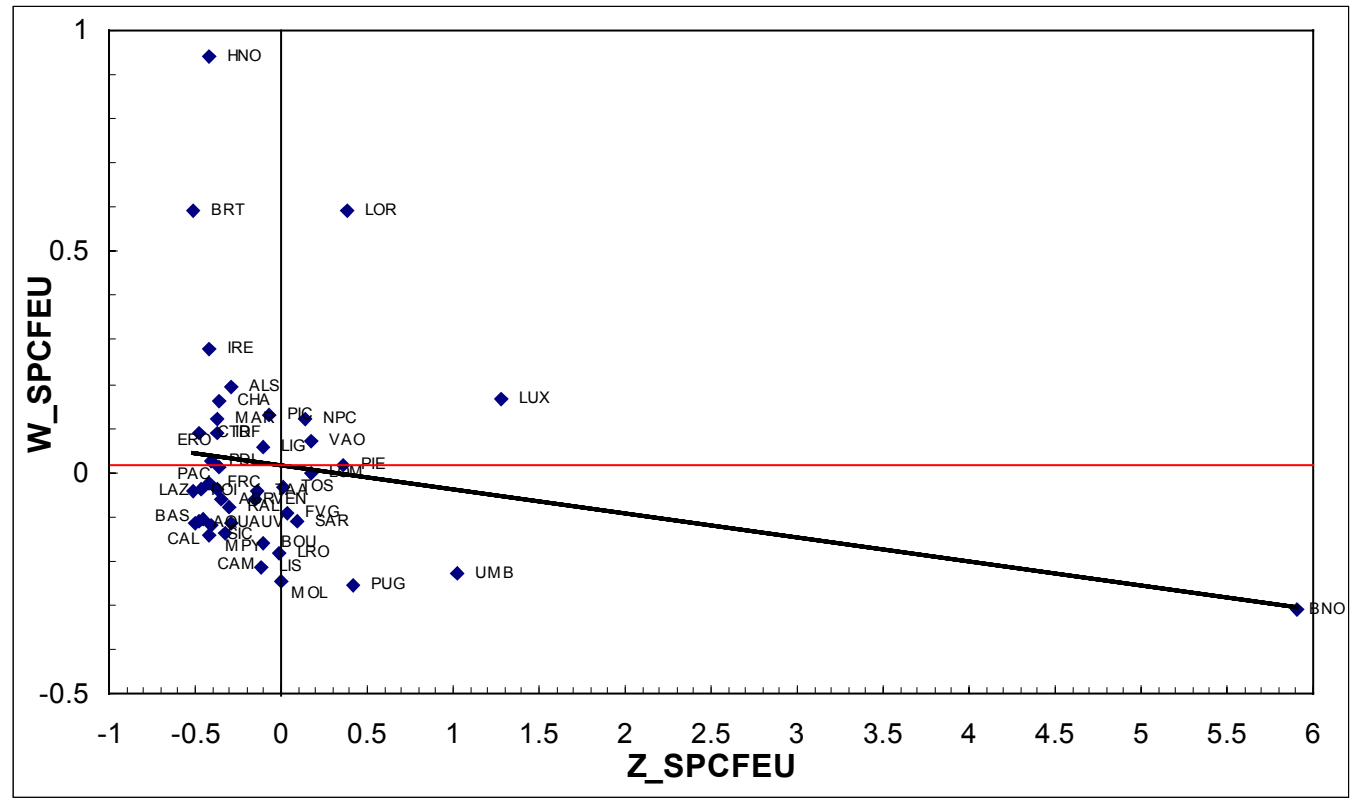

Note: See Graph 1.

Graph B4: Moran Scatterplot: Non-metallic minerals \& mineral products, NUTS 2

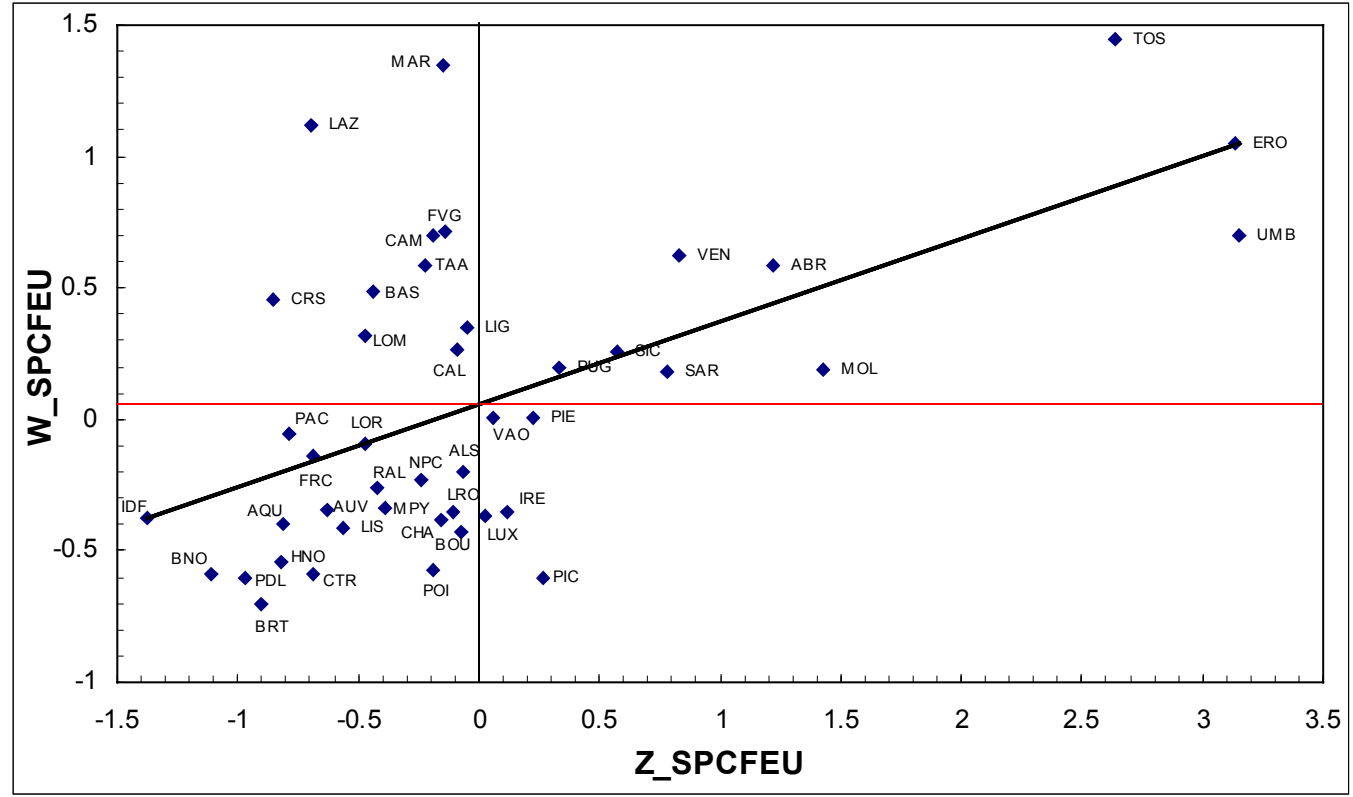

Note: See Graph 1. 
Graph B5: Moran Scatterplot: Chemical products, NUTS 2

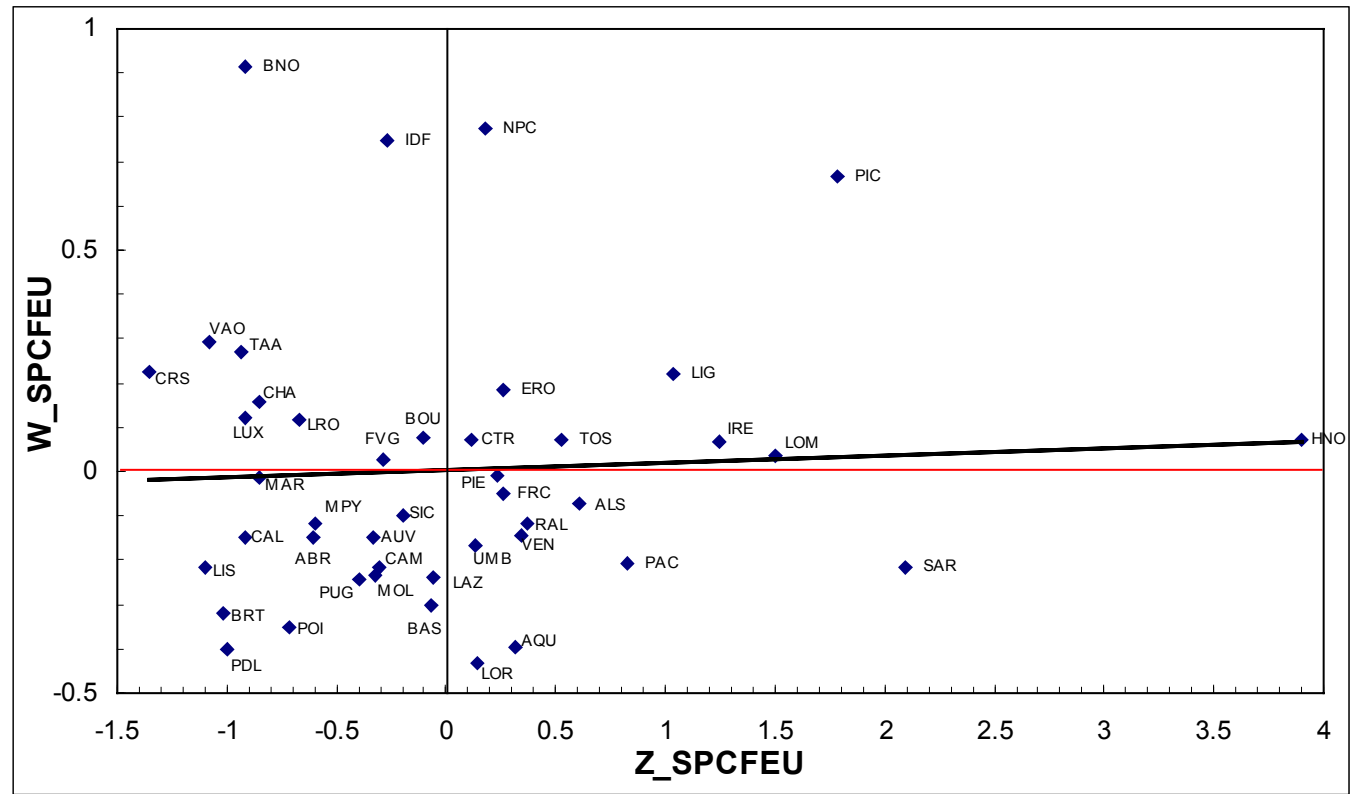

Note: See Graph 1.

Graph B6: Moran Scatterplot: Metal products, machinery, equipment, electrical goods, NUTS 2

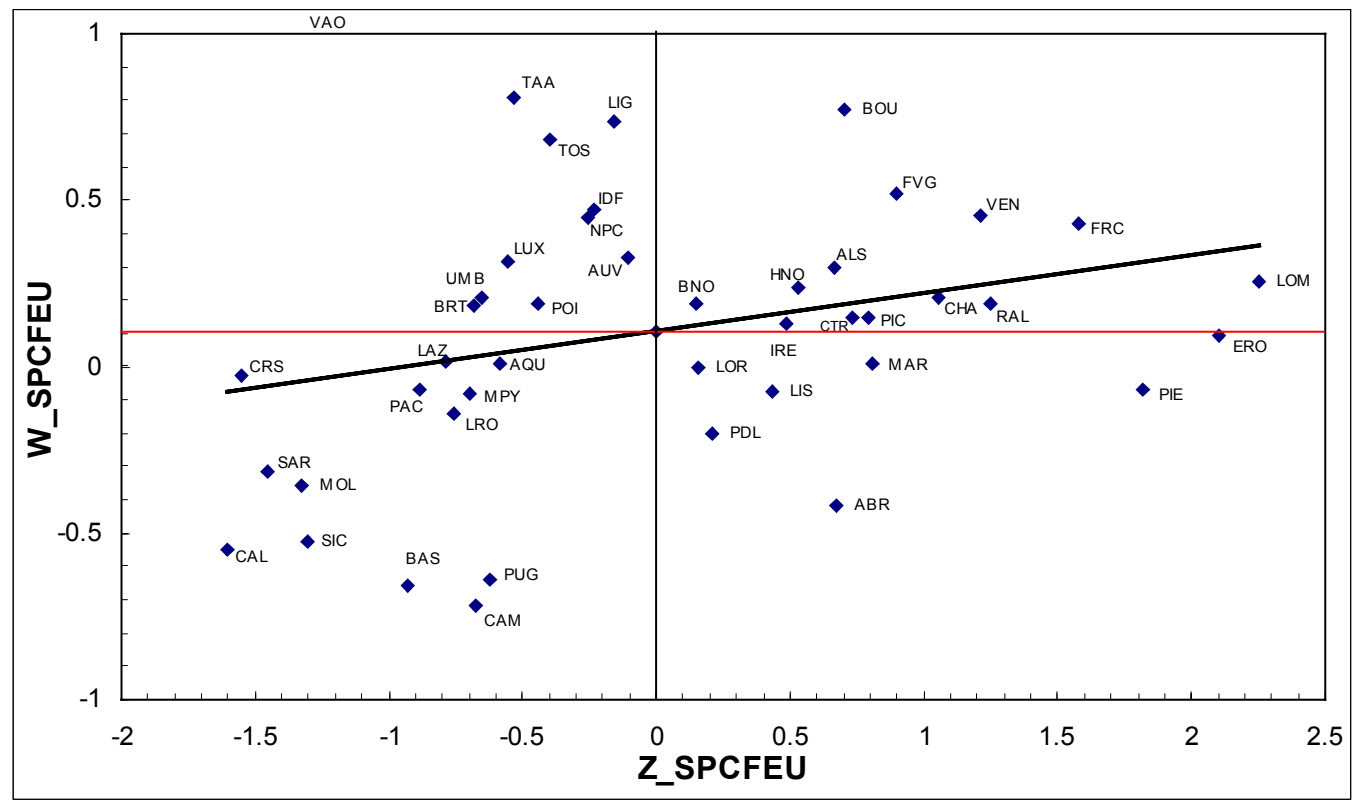

Note: See Graph 1. 
Graph B7: Moran Scatterplot: Transport equipment, NUTS 2

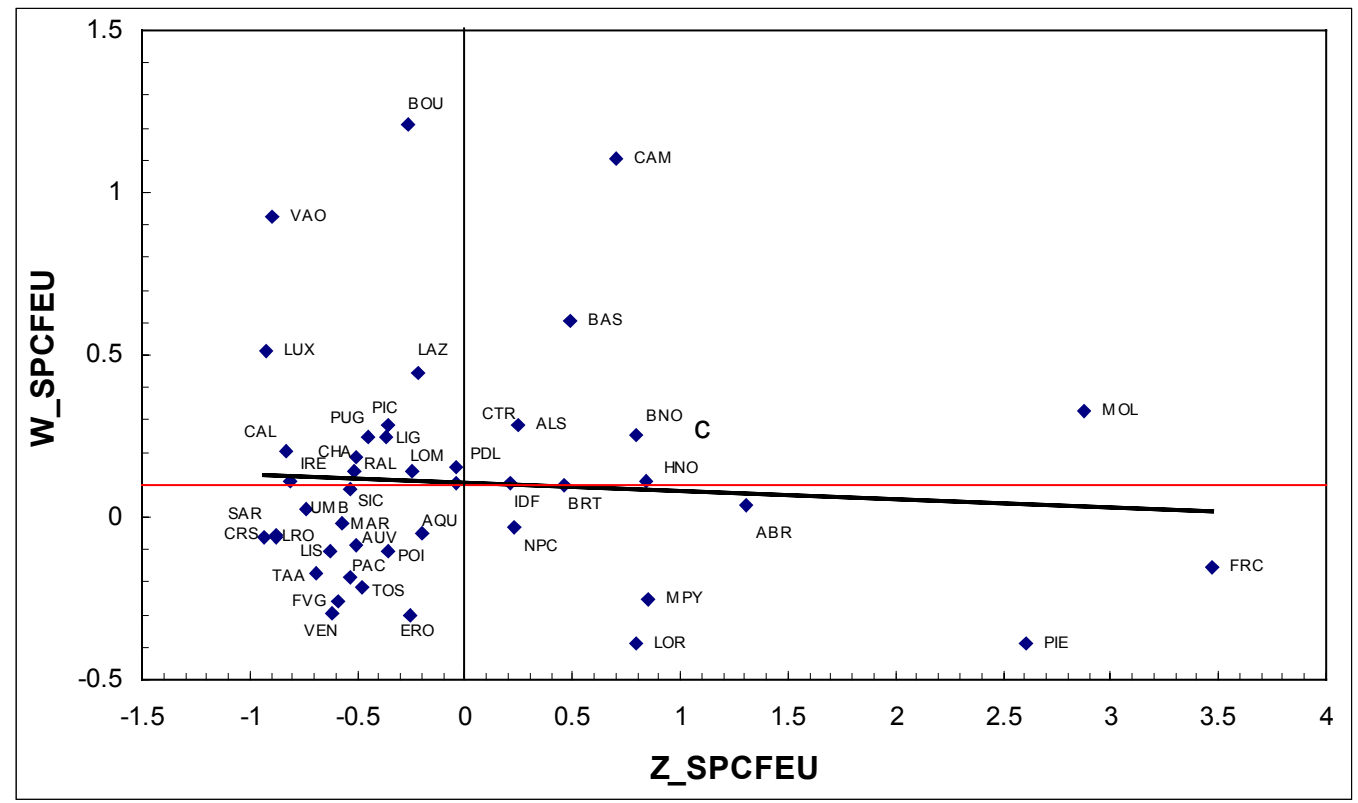

Note: See Graph 1.

Graph B8: Moran Scatterplot: Textiles industries, NUTS 2

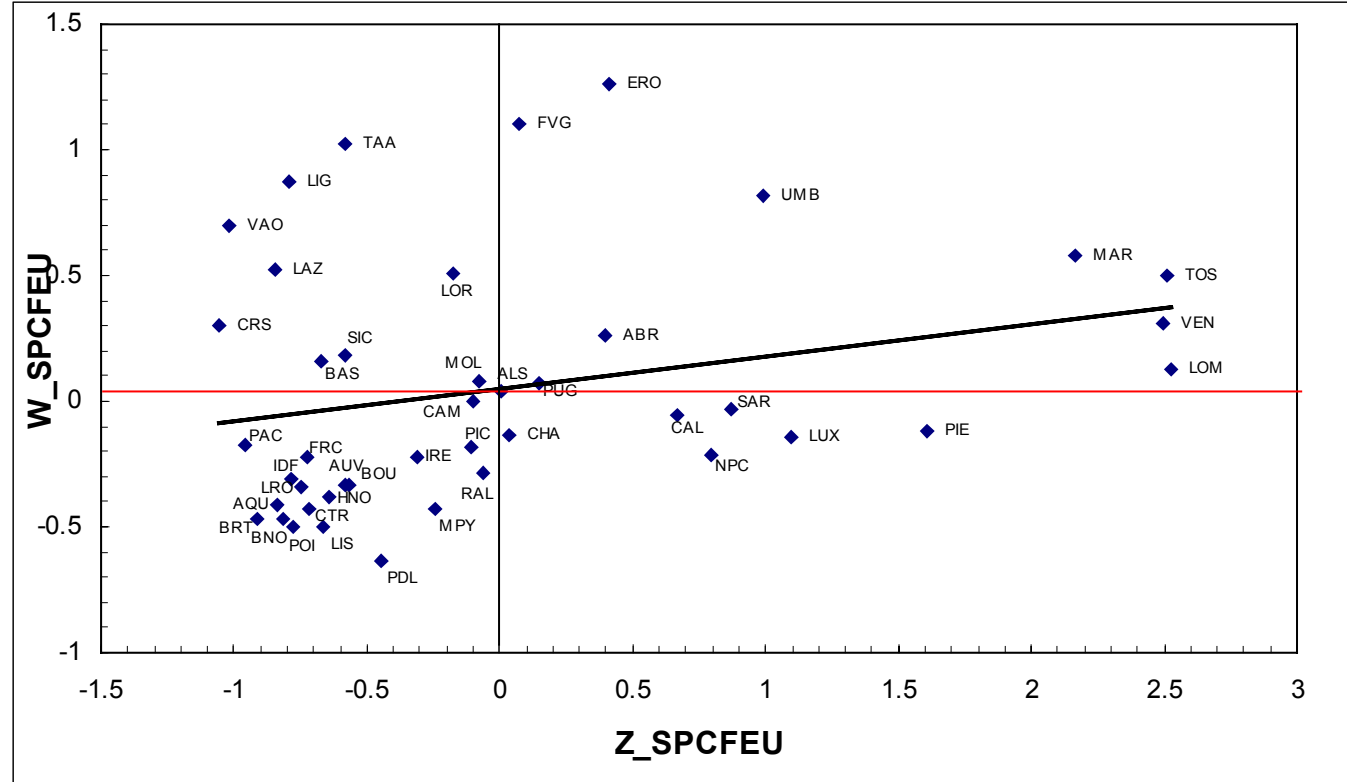

Note: See Graph 1. 
Graph B9: Moran Scatterplot: Paper \& printing products, NUTS 2

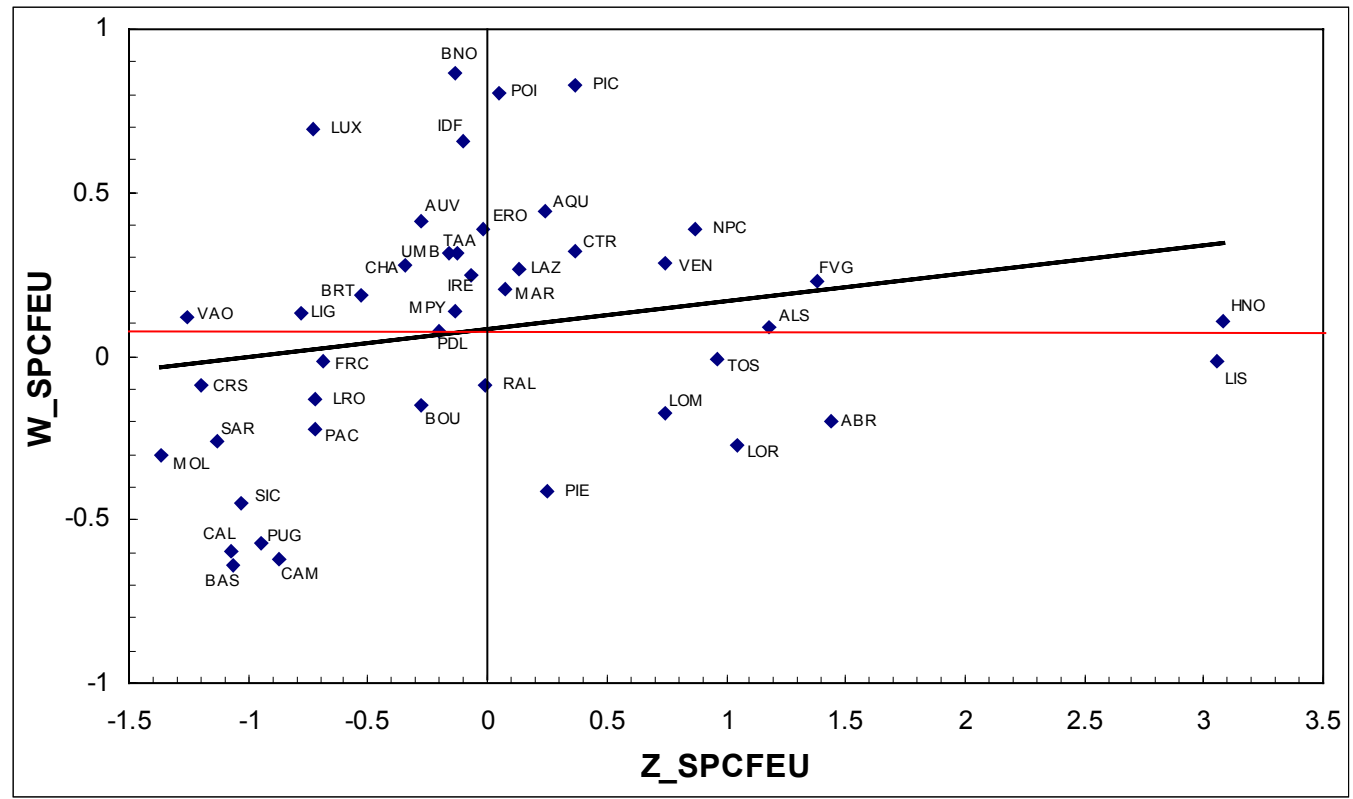

Note: See Graph 1.

Graph B10: Moran Scatterplot: Products of various industries, NUTS 2

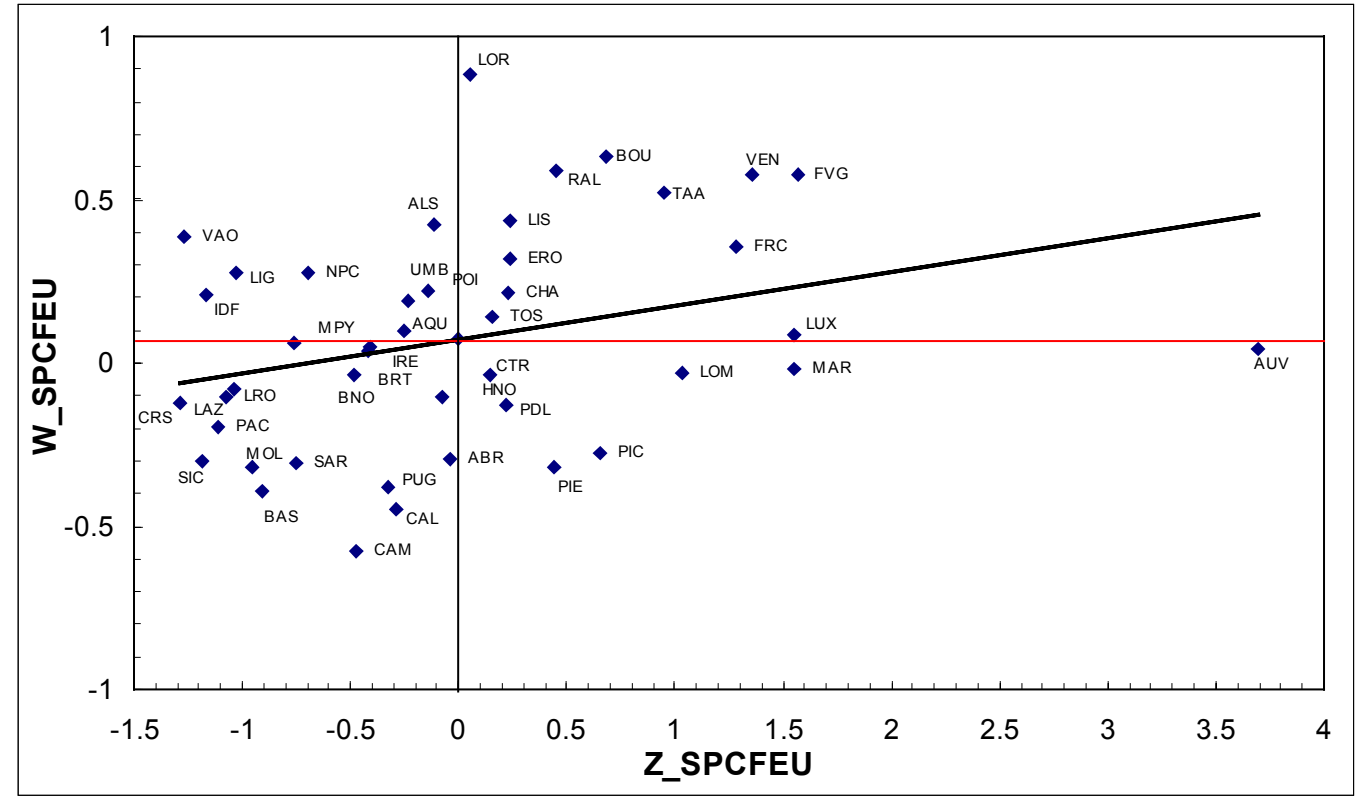

Note: See Graph 1. 
Graph B11: Moran Scatterplot: Building \& construction, NUTS 2

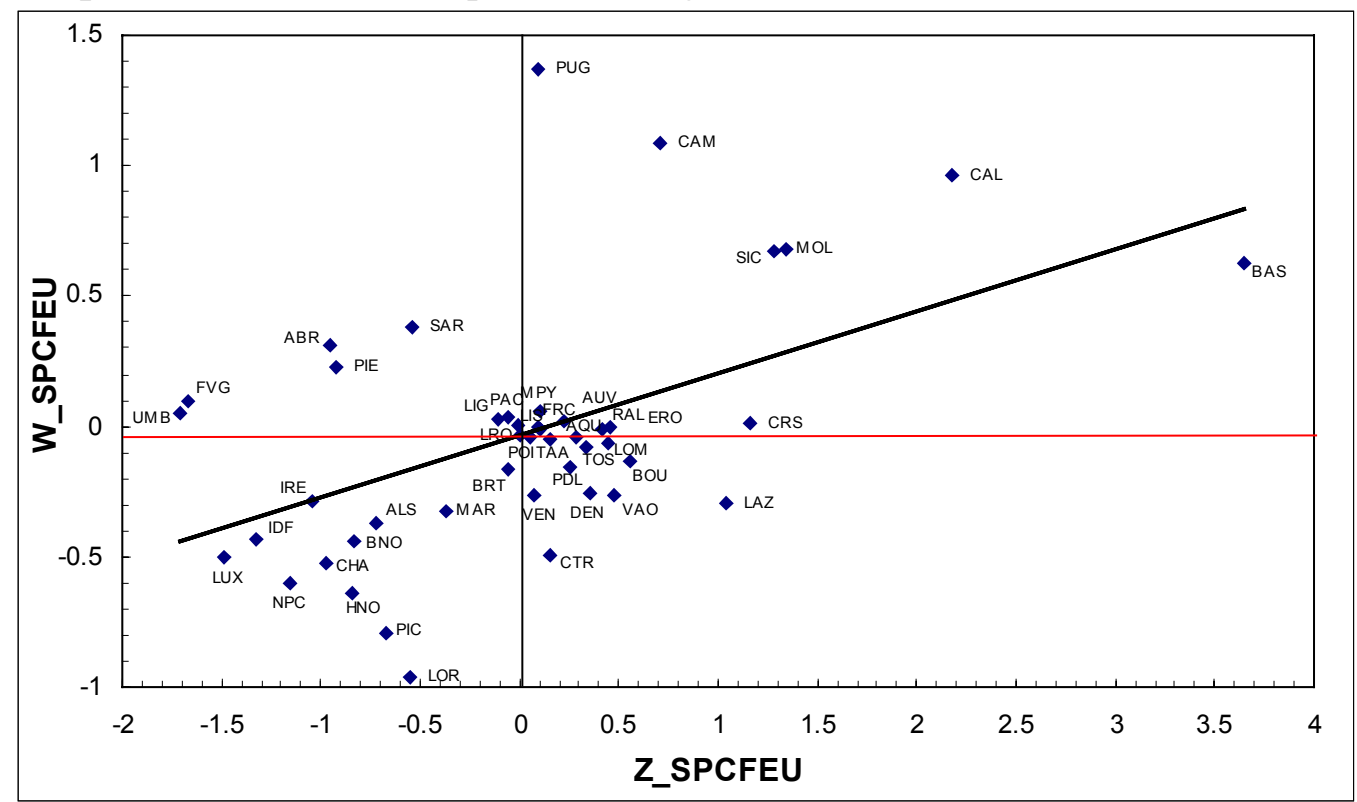

Note: See Graph 1.

Graph B12: Moran Scatterplot: Trade \& lodging services, NUTS 2

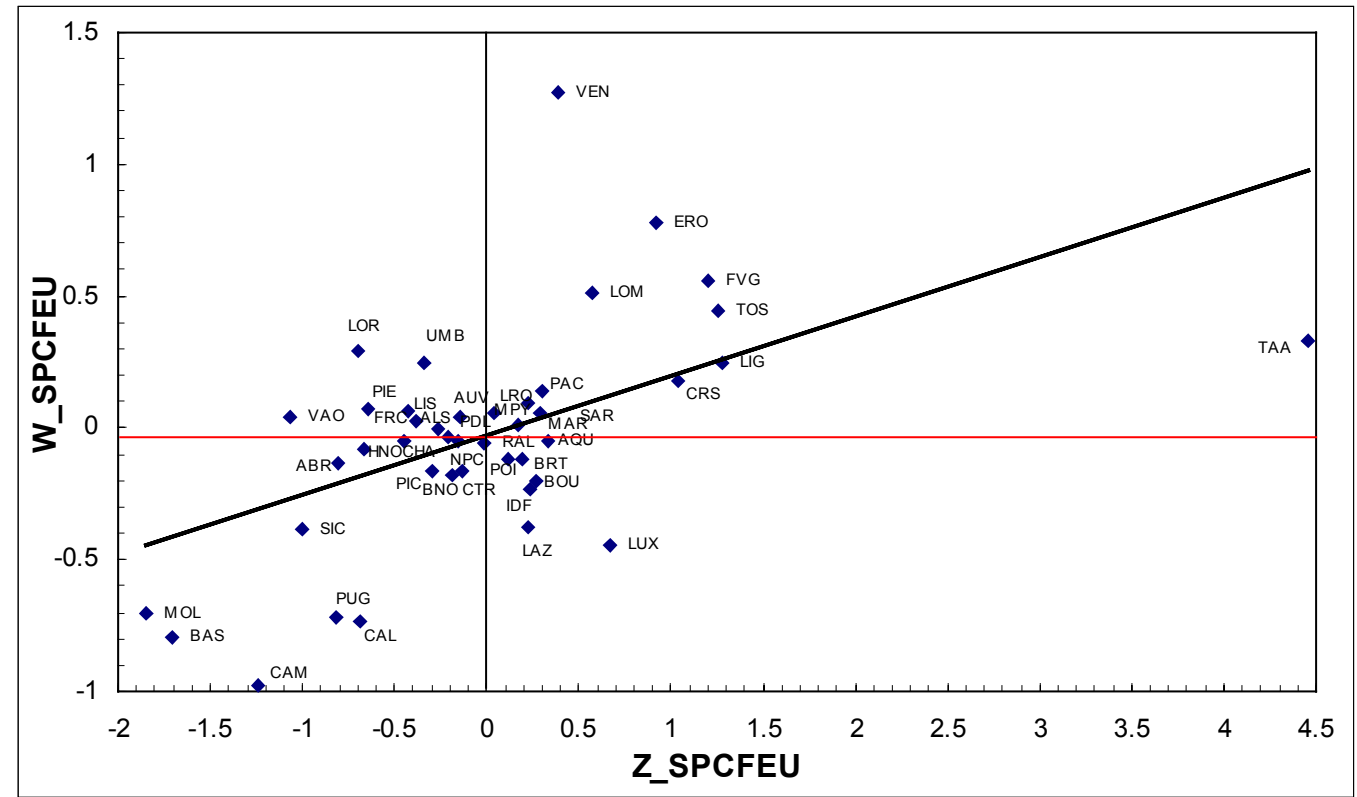

Note: See Graph 1. 
Graph B13: Moran Scatterplot: Services of credit \& insurance institutions, NUTS 2

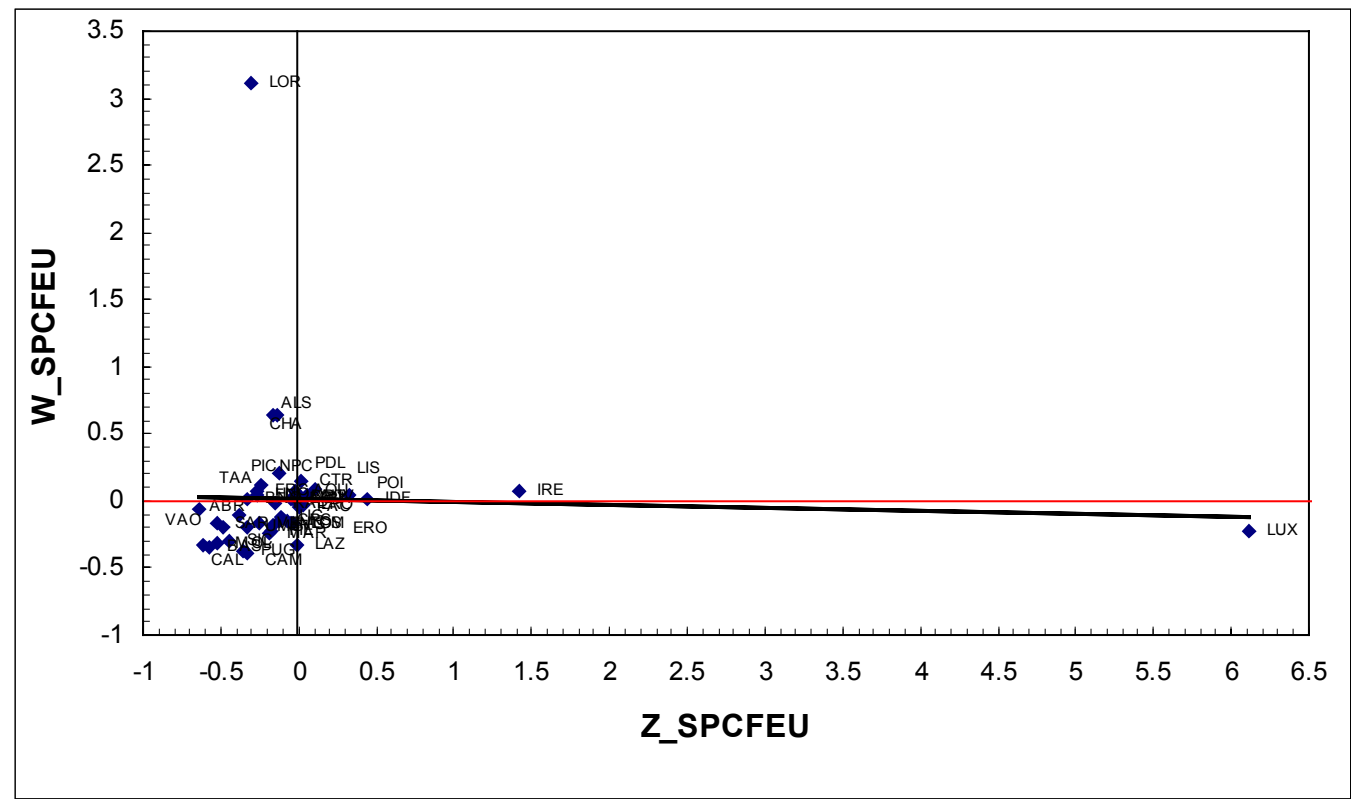

Note: See Graph 1.

Graph B14: Moran Scatterplot: Other market services, NUTS 2

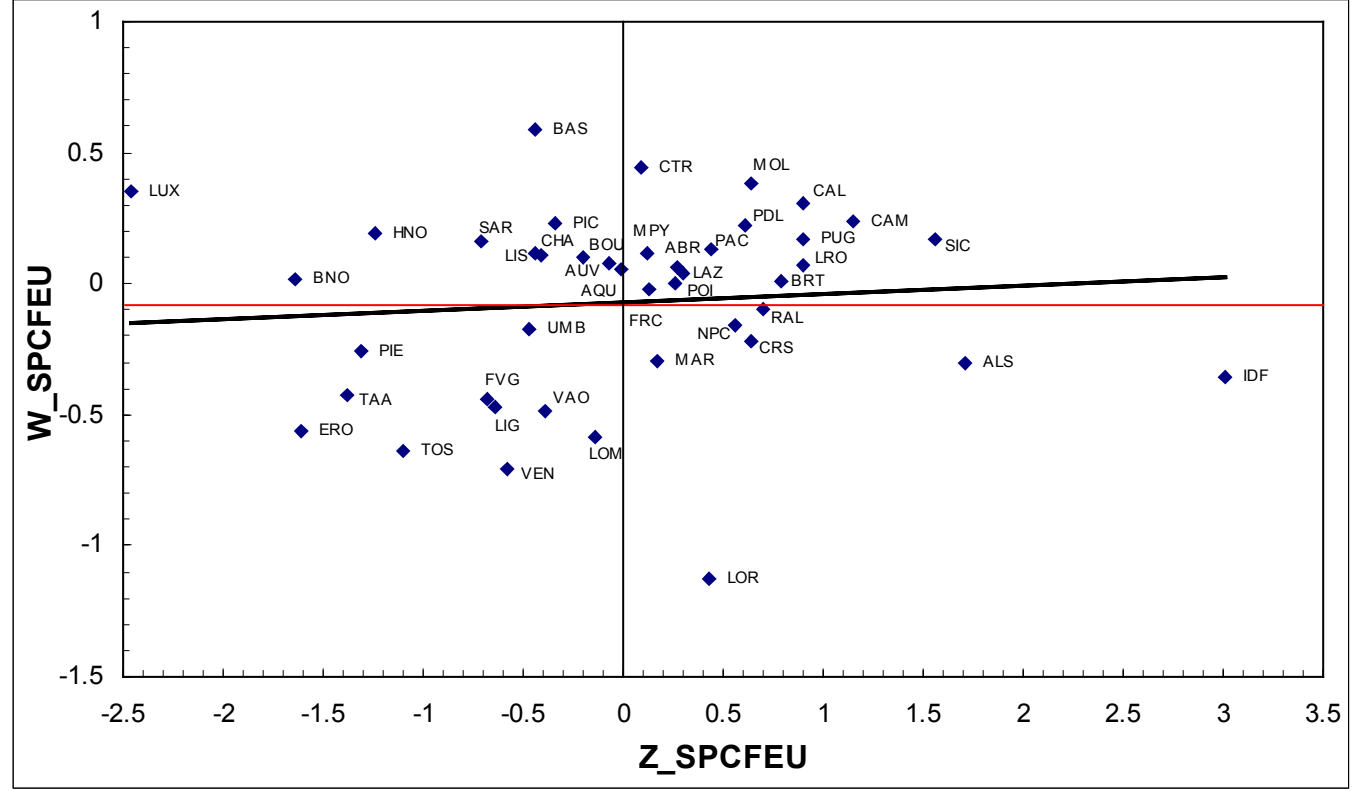

Note: See Graph 1. 
Graph B15: Moran Scatterplot: Non-market services, NUTS 2

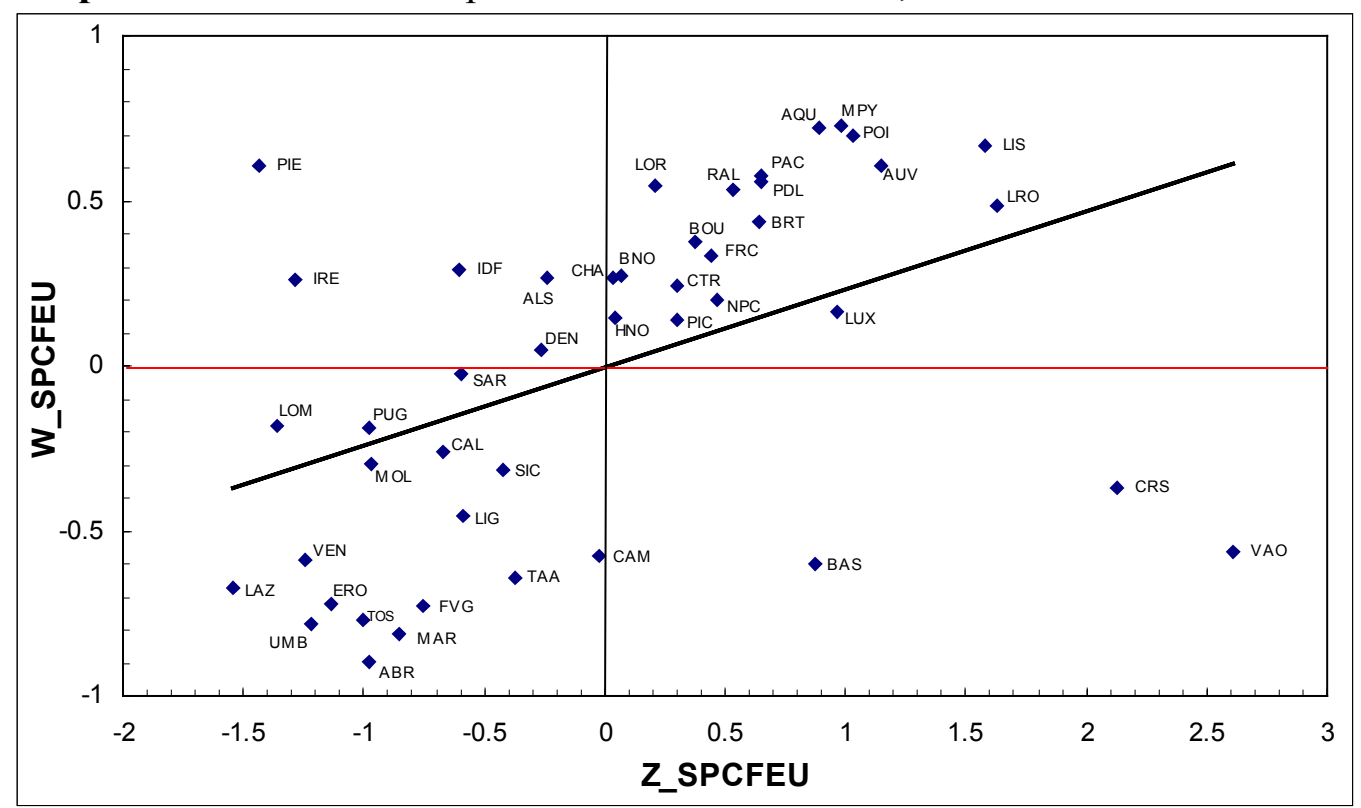

Note: See Graph 1. 


\section{Estimation Results}

Table C1: GLS-Estimates of the Determinants of Sectoral Specialisation, Regional Characteristics

\begin{tabular}{|c|c|c|c|c|c|c|c|c|c|c|c|c|c|c|c|c|c|}
\hline & AGRO & FUEL & META & MINE & CHEM & METP & TREQ & FOOD & TEXT & PAPE & VARI & BUIL & TRLO & \begin{tabular}{|l|} 
TRCO \\
\end{tabular} & \begin{tabular}{|l} 
CRED \\
\end{tabular} & OTHS & NMSE \\
\hline \multirow[t]{2}{*}{ CONSTANT } & 3.6645 & -0.3870 & 3.5323 & 1.9030 & \begin{tabular}{|c|}
0.3975 \\
\end{tabular} & |0.8764 & 0.3562 & 0.8488 & 1.5497 & 1.2906 & $=1.8888$ & 0.7304 & 0.7538 & -0.0152 & $\overline{0.3518}$ & 2.6416 & 0.4809 \\
\hline & 9.19 & -0.94 & 2.78 & 5.41 & 1.83 & 6.76 & 0.60 & 3.93 & 4.62 & 3.94 & 4.90 & 12.20 & 6.49 & -0.06 & 5.94 & 16.89 & 3.45 \\
\hline \multirow[t]{2}{*}{ MAR } & 0.0124 & 0.0014 & 0.0135 & 0.0035 & 0.0045 & .0031 & 0.0039 & 0.0029 & 0.0106 & 0.0011 & .0019 & 0.0009 & 0.0018 & -0.0113 & 0.0009 & -0.0020 & .0008 \\
\hline & 5.15 & 0.58 & 1.81 & 1.71 & 3.53 & 4.00 & 1.13 & 2.26 & 5.38 & 0.56 & 0.85 & 2.57 & -2.71 & -7.24 & -2.49 & -2.14 & -0.89 \\
\hline \multirow[t]{2}{*}{ CENTR } & -0.7152 & 0.6094 & -1.3718 & -0.8509 & -0.5506 & -0.7050 & -0.5671 & -0.8720 & -1.7857 & -0.4652 & -1.2109 & 0.0874 & 0.1351 & 1.6121 & 0.0857 & 0.2696 & 0.1205 \\
\hline & -3.13 & 2.59 & -1.91 & -4.38 & -4.59 & -9.85 & -1.74 & \begin{tabular}{|c|}
-7.32 \\
\end{tabular} & -9.62 & -2.57 & -5.70 & 2.55 & 2.11 & 11.05 & 2.62 & 3.12 & 1.51 \\
\hline \multirow[t]{2}{*}{ UEWP } & 0.0660 & 0.0973 & 0.0116 & -0.0098 & 0.0104 & -0.0346 & 0.0038 & -0.0119 & -0.0151 & -0.0384 & -0.0657 & 0.0097 & 0.0251 & $\mid-0.0258$ & 0.0101 & 0.0202 & .0081 \\
\hline & 6.73 & 9.64 & -0.38 & -1.17 & 2.01 & -11.16 & 0.27 & -2.30 & -1.88 & -4.90 & -7.14 & 6.62 & -9.05 & -4.09 & -7.15 & 5.40 & 2.37 \\
\hline \multirow[t]{2}{*}{ PODEN } & \begin{tabular}{|l|}
-6.8820 \\
\end{tabular} & -1.3280 & -4.3186 & \begin{tabular}{|l}
-1.3549 \\
\end{tabular} & -0.4305 & -0.0103 & 0.9823 & -1.0061 & -0.9594 & 0.0826 & -0.3548 & -0.4181 & 0.5347 & 2.6983 & 0.4755 & 1.3921 & -0.5275 \\
\hline & -9.77 & -1.83 & -1.96 & -2.25 & -1.16 & -0.05 & -0.97 & -2.72 & -1.66 & \begin{tabular}{|c|}
0.15 \\
\end{tabular} & -0.54 & -3.95 & 2.68 & 5.95 & 4.68 & 5.19 & -2.14 \\
\hline \multirow[t]{2}{*}{ AREA } & -0.0213 & 0.0120 & -0.0587 & 0.0003 & -0.0024 & 0.0034 & -0.0153 & -0.0031 & 0.0030 & -0.0024 & 0.0093 & -0.0009 & 0.0054 & 0.0161 & \begin{tabular}{|c|c|}
0.0043 \\
\end{tabular} & 0.0006 & $\mid-0.0078$ \\
\hline & -3.77 & 2.06 & -3.14 & 0.06 & \begin{tabular}{|c|}
-0.81 \\
\end{tabular} & 1.91 & -1.87 & -1.04 & 0.64 & -0.53 & 1.75 & -1.12 & 3.39 & 4.44 & 5.28 & 0.28 & -3.95 \\
\hline \multirow[t]{2}{*}{ DIST } & -1.0713 & 0.1735 & -0.7398 & -0.7202 & -0.3286 & 0.3770 & -0.8404 & -0.8967 & -0.6950 & -0.6214 & -0.6639 & 0.0540 & 0.2104 & 0.4607 & .0163 & 0.2565 & 0.4727 \\
\hline & -6.89 & 1.08 & -1.24 & -5.44 & -3.94 & \begin{tabular}{|c|}
-7.73 \\
\end{tabular} & -3.73 & -11.04 & -5.39 & -5.04 & -4.58 & 2.31 & 4.81 & 4.63 & 0.73 & 4.36 & 8.68 \\
\hline \multirow[t]{2}{*}{ INT } & -0.0141 & 0.0959 & -0.0700 & 0.0029 & 0.0087 & -0.0001 & 0.0814 & 0.0385 & -0.0206 & -0.0054 & 0.0071 & -0.0278 & -0.0113 & 0.1057 & -0.0082 & -0.0983 & 0.0100 \\
\hline & -0.49 & 3.22 & -0.75 & 0.11 & 0.55 & -0.01 & 1.87 & 2.44 & -0.84 & -0.23 & 0.25 & -6.38 & -1.33 & 5.47 & -1.90 & -8.60 & 0.99 \\
\hline \multirow[t]{2}{*}{ DUM_FRA } & $\mid-1.3308$ & 0.7341 & 0.4700 & \begin{tabular}{|l|}
-0.7401 \\
\end{tabular} & -0.0173 & -0.0135 & 0.1876 & 0.2881 & -0.7965 & 0.1771 & -0.1144 & -0.0658 & 0.0490 & \begin{tabular}{|l|}
-0.3410 \\
\end{tabular} & 0.0752 & .1531 & 0.5026 \\
\hline & -15.51 & -8.31 & 1.64 & -10.12 & -0.38 & -0.50 & 1.54 & 6.42 & -11.34 & 2.60 & -1.43 & -5.11 & -2.03 & -6.21 & 6.10 & 4.71 & 16.74 \\
\hline \multirow[t]{2}{*}{ DUM_IRE } & 0.8755 & -2.3674 & 2.9846 & 0.1481 & 0.8922 & \begin{tabular}{l|}
0.7598 \\
\end{tabular} & 0.4253 & 2.0546 & 0.7526 & \begin{tabular}{|l|}
0.6465 \\
\end{tabular} & 0.5525 & -0.2444 & - & \begin{tabular}{|l|}
-1.2490 \\
\end{tabular} & 0.4803 & - & 0.1992 \\
\hline & 2.02 & -5.31 & 1.79 & 0.33 & 3.18 & 4.53 & 0.56 & 7.36 & 1.73 & 1.52 & 1.11 & -3.76 & & -4.13 & 7.08 & & 1.32 \\
\hline \multirow[t]{2}{*}{ DUM_DEN } & $\mid-1.0486$ & $\mid-0.6364$ & -- & -- & - & - & - & - & -- & - & - & -0.0652 & -- & - & -- & -- & 0.4732 \\
\hline & -3.03 & -1.78 & & & & & & & & & & -1.25 & & & & & 3.90 \\
\hline \multirow[t]{2}{*}{ DUM_LUX } & \begin{tabular}{|l|}
-1.1348 \\
\end{tabular} & -0.7172 & 3.3211 & 0.1656 & 0.2371 & 0.2296 & .4839 & 0.2160 & 1.9503 & -0.3970 & 1.6401 & -0.1424 & 0.1114 & 1.6229 & 2.4484 & 0.8406 & .5754 \\
\hline & -3.36 & -2.06 & 2.81 & 0.50 & 1.17 & 1.89 & -0.88 & 1.07 & 6.22 & -1.30 & 4.55 & -2.81 & -1.03 & -6.57 & 44.2 & -5.75 & 4.87 \\
\hline no. of & $\overline{\mid \overline{377}}$ & \begin{tabular}{|c|}
377 \\
\end{tabular} & 353 & 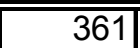 & 360 & $\overline{\overline{361}}$ & 353 & $\overline{\overline{361}}$ & 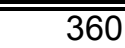 & 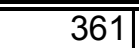 & 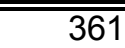 & 377 & 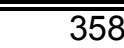 & 363 & 363 & 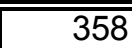 & $\begin{array}{l}377 \\
\end{array}$ \\
\hline rob Chi' & 0.0000 & 0.0000 & 0.0003 & 0.0000 & 0.0000 & 0.0000 & 0.0010 & 0000 & 0.0000 & 0.0000 & 0.0000 & 0.0000 & .0000 & 0.0000 & 0.0000 & 0.0000 & .000 \\
\hline
\end{tabular}


Table C2: Instrumental-Variable Estimates of the Determinants of Sectoral Specialisation, Regional Characteristics

\begin{tabular}{|c|c|c|c|c|c|c|c|c|c|c|c|c|c|c|c|c|c|}
\hline & GRO & FUEL & AETA & MINE & HEM & METP & TREQ & $\overline{\text { FOOD }}$ & TEXT & $\overline{\text { PAPE }}$ & VARI & BUIL & TRLO & TRCO & CRED & OTHS & NMSE \\
\hline \multirow[t]{2}{*}{ CONSTANT } & 3.6739 & $\overline{-0.1711}$ & $\begin{array}{l}3.4874 \\
\end{array}$ & $\overline{1.9587}$ & 0.3971 & $\overline{\overline{0.9532}}$ & 0.6484 & $\overline{\overline{0.9002}}$ & $=1.4278$ & |1.4045 & 2.1656 & 0.6980 & 0.7816 & 0.0431 & 0.3716 & 2.4671 & $\overline{\overline{0.4384}}$ \\
\hline & 8.46 & -0.39 & 2.48 & 5.11 & 1.67 & 6.86 & 0.99 & 3.82 & 4.02 & 3.89 & 5.16 & 11.45 & 6.38 & 0.15 & 5.73 & 15.42 & 2.91 \\
\hline \multirow[t]{2}{*}{ GRP (IV) } & 0.0127 & 0.0022 & 0.0151 & 0.0030 & 0.0050 & 0.0029 & 0.0027 & 0.0034 & 0.0107 & 0.0008 & 0.0013 & 0.0014 & 0.0023 & 0.0111 & 0.0008 & -0.0016 & .0010 \\
\hline & 4.75 & 0.81 & 1.80 & 1.31 & 3.50 & 3.43 & 0.71 & 2.40 & 5.04 & 0.39 & 0.52 & 3.79 & -3.14 & -6.52 & -2.13 & -1.66 & -1.08 \\
\hline \multirow[t]{2}{*}{ CENTR } & $\mid-0.6511$ & 0.5167 & 1.4332 & 0.8326 & -0.5880 & 0.7249 & 0.5460 & -0.8950 & -1.7849 & $\mid-0.4938$ & -1.2266 & 0.0802 & 0.1537 & 1.6616 & 0.0737 & 0.2704 & 0.1318 \\
\hline & -2.65 & 2.06 & -1.84 & -4.00 & -4.53 & -9.61 & -1.55 & -7.00 & -9.23 & -2.52 & -5.38 & 2.33 & 2.31 & 10.79 & 2.10 & 3.11 & 1.55 \\
\hline \multirow[t]{2}{*}{ UEWP (IV) } & 0.0695 & 0.1088 & -0.0072 & -0.0067 & 0.0143 & -0.0362 & -0.0092 & -0.0095 & -0.0088 & $\mid-0.0399$ & -0.0716 & 0.0111 & -0.0265 & -0.0230 & $\mid-0.0087$ & 0.0177 & 0.0083 \\
\hline & 6.10 & 9.36 & -0.20 & -0.69 & 2.36 & -10.27 & -0.55 & -1.60 & -0.97 & -4.35 & -6.73 & 6.95 & -8.52 & -3.20 & -5.30 & 4.35 & 2.11 \\
\hline \multirow[t]{2}{*}{ PODEN } & \begin{tabular}{|l|}
-7.0183 \\
\end{tabular} & .4313 & -4.7721 & -1.1848 & -0.5673 & 0.0246 & 0.7460 & 1.1475 & -0.9967 & 0.1631 & -0.2085 & 0.5717 & 0.6716 & 2.5998 & 0.4710 & 2927 & 0.4648 \\
\hline & -8.93 & -1.78 & -1.92 & -1.77 & -1.36 & 0.10 & -0.66 & -2.78 & -1.60 & 0.26 & -0.28 & -5.19 & 3.13 & 5.24 & 4.15 & 4.62 & -1.70 \\
\hline \multirow[t]{2}{*}{ AREA } & -0.0224 & 0.0115 & -0.0624 & 0.0008 & -0.0041 & 0.0032 & -0.0147 & -0.0044 & 0.0015 & -0.0026 & 0.0097 & -0.0019 & 0.0062 & 0.0167 & \begin{tabular}{l|}
0.0041 \\
\end{tabular} & 0.0002 & -0.0070 \\
\hline & -3.66 & 1.83 & -3.03 & 0.16 & -1.24 & 1.69 & -1.65 & -1.38 & 0.30 & -0.54 & 1.70 & -2.17 & 3.69 & 4.33 & 4.70 & 0.08 & -3.28 \\
\hline \multirow[t]{2}{*}{$\overline{\text { DIST }}$} & 1.0838 & 0.1437 & -0.8158 & -0.6856 & -0.3489 & 0.3812 & 0.8489 & .9049 & .6391 & -0.6369 & -0.6705 & 0.0464 & 0.2325 & 0.4571 & .0166 & .2603 & 0.4743 \\
\hline & -6.61 & 0.86 & -1.28 & -4.94 & -3.95 & -7.57 & -3.55 & -10.61 & -4.86 & -4.87 & -4.41 & 2.02 & 5.24 & 4.45 & 0.71 & 4.49 & 8.34 \\
\hline \multirow[t]{2}{*}{ INT } & -0.0151 & 0.0729 & -0.0626 & -0.0056 & 0.0087 & -0.0039 & 0.0703 & 0.0351 & -0.0163 & -0.0119 & -0.0086 & -0.0248 & -0.0142 & 0.0993 & -0.0105 & -0.0835 & 0.0119 \\
\hline & -0.48 & 2.28 & -0.61 & -0.20 & 0.50 & -0.39 & 1.48 & 2.05 & -0.63 & -0.45 & -0.28 & -5.64 & -1.60 & 4.82 & -2.24 & -7.19 & 1.10 \\
\hline \multirow[t]{2}{*}{ DUM_FRA } & $\mid-1.3266$ & 0.7835 & 0.5049 & -0.7570 & 0.0060 & -0.0195 & 0.1565 & 0.2898 & -0.7702 & 0.1671 & -0.1509 & -0.0545 & 0.0578 & 0.3639 & 0.0717 & 0.1868 & 0.5006 \\
\hline & -14.42 & -8.34 & 1.62 & -9.67 & -0.12 & -0.69 & 1.19 & 6.03 & -10.55 & 2.27 & -1.76 & -4.22 & -2.31 & -6.28 & 5.42 & 5.72 & 15.68 \\
\hline \multirow[t]{2}{*}{ DUM_IRE } & 0.8344 & 2.3878 & 3.1735 & 0.0768 & 0.9697 & 0.7892 & 0.4361 & 2.1101 & 0.8240 & 0.6771 & 0.5389 & -0.2061 & $=$ & -1.3786 & 0.4841 & -- & 0.1515 \\
\hline & 1.82 & -5.10 & 1.79 & 0.16 & 3.27 & 4.57 & 0.54 & 7.21 & 1.86 & 1.51 & 1.03 & -3.21 & & -4.40 & 6.76 & & 0.95 \\
\hline \multirow[t]{2}{*}{ DUM_DEN } & $\mid-1.0998$ & 0.5916 & - & -- & -- & -- & -- & -- & -- & - & - & -0.0661 & -- & -- & -- & -- & .4592 \\
\hline & -3.02 & -1.59 & & & & & & & & & & -1.30 & & & & & 3.64 \\
\hline \multirow[t]{2}{*}{ DUM_LUX } & -1.1839 & -0.5811 & 3.4016 & 0.1542 & 0.2879 & 0.2135 & -0.6776 & .2398 & 2.0208 & $\mid-0.4186$ & 1.5437 & -0.1203 & 0.1422 & 1.6567 & 2.4634 & 0.8086 & .5737 \\
\hline & -3.31 & -1.59 & 2.70 & 0.45 & 1.34 & 1.70 & -1.15 & 1.13 & 6.30 & -1.28 & 4.07 & -2.40 & -1.29 & -6.47 & 42.12 & -5.60 & 4.62 \\
\hline \multirow{2}{*}{\begin{tabular}{|l|} 
no. of obs. \\
Prob F \\
\end{tabular}} & 358 & 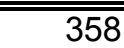 & $\overline{\overline{334}}$ & 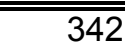 & $\overline{\overline{341}}$ & $\overline{\overline{342}}$ & $\overline{\mid 334}$ & 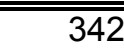 & $\overline{\overline{341}}$ & 342 & 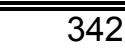 & $\overline{\overline{358}}$ & $\overline{\overline{339}}$ & $\overline{\overline{344}}$ & 344 & $\overline{\overline{339}}$ & 00 \\
\hline & 0000 & 0000 & 0.001 & 0.0000 & 0.0000 & $\overline{0.0000}$ & 0030 & $\overline{0000}$ & 0.0000 & .0000 & 0000 & 0.0000 & 0.0000 & .0000 & 0.0000 & .0000 & .000 \\
\hline
\end{tabular}
Note: Lines below coefficients report the t-values of the IV estimates. The probability of the F-test gives the joint significance of all coefficients. 
Table C3: GLS Estimates of the Determinants of Sectoral Specialisation, Regional Characteristics including RDINT

\begin{tabular}{|c|c|c|c|c|c|c|c|c|c|c|c|c|c|c|c|c|c|}
\hline & $\mathbf{J} \mathbf{l}$ & UEL & ETA & MINE & HEM & METP & TREQ & FOOD & TEXT & PAPE & VARI & BUIL & TRLO & TRCO & CRED & OTHS & JMSE \\
\hline \multirow[t]{2}{*}{ CONSTANT } & 1133 & 0.1035 & 2.4779 & 3.5885 & 0.5799 & 0.9230 & \begin{tabular}{c|}
-0.0689 \\
\end{tabular} & 1.0466 & 1.4919 & 0.7240 & 2.1542 & 0.6701 & $\overline{0.7149}$ & |0.3764 & |0.5655 & 2.1454 & 0.6660 \\
\hline & 6.13 & 0.14 & 1.34 & 5.44 & 1.39 & 4.24 & -0.07 & 2.51 & 2.53 & 1.14 & 3.05 & 7.28 & 3.45 & 0.77 & 5.41 & 9.21 & 2.85 \\
\hline \multirow[t]{2}{*}{ MAR } & .0125 & .0034 & 0.0174 & 0.0030 & 0.0028 & 0.0018 & .0016 & 0.0030 & 0.0111 & -0.0012 & .0005 & 0.0015 & 0.0025 & .0129 & 0.0007 & 0.0001 & 0.0003 \\
\hline & 4.10 & 1.01 & 2.15 & 1.05 & 1.53 & 1.93 & -0.39 & 1.66 & 4.32 & -0.42 & 0.15 & 3.51 & -2.77 & 6.04 & -1.54 & 0.11 & 0.31 \\
\hline \multirow[t]{2}{*}{ CENTR } & 0865 & 4123 & 1.5501 & 0.9904 & 0.5511 & .7260 & 0.8149 & .9342 & 1.8806 & -0.2716 & 1.2023 & .0503 & 0.1842 & .9619 & 0.0026 & .2212 & \\
\hline & -3.77 & 1.31 & -2.04 & -3.66 & -3.22 & -8.14 & -2.14 & -5.47 & -7.78 & -1.05 & -4.16 & 1.27 & 2.17 & 9.77 & -0.06 & 2.32 & 0.98 \\
\hline \multirow[t]{2}{*}{ UEWP } & 0.0367 & 0.1211 & -0.0318 & 0.0082 & 0.0253 & -0.0214 & 0.0024 & -0.0136 & 0.0146 & -0.0399 & -0.0456 & 0.0074 & 0.0271 & \begin{tabular}{|l|}
-0.0224 \\
\end{tabular} & \begin{tabular}{|c|}
-0.0132 \\
\end{tabular} & 0.0215 & -0.0058 \\
\hline & 2.68 & 8.13 & -0.87 & 0.63 & 3.09 & -5.01 & 0.13 & -1.67 & 1.26 & -3.22 & -3.29 & 3.95 & -6.68 & -2.33 & -6.42 & 4.72 & -1.23 \\
\hline \multirow[t]{2}{*}{ PODEN } & 2533 & 9967 & 4.5494 & .6611 & 5617 & 0.2778 & 0.8723 & .0115 & .6714 & 0.3255 & -0.7656 & .4584 & 1.7979 & 3.0794 & 0.5762 & .6855 & 0.4135 \\
\hline & -6.61 & -1.94 & -1.80 & -1.86 & -0.99 & -0.94 & 0.69 & -1.79 & -2.09 & 0.38 & -0.80 & $\begin{array}{l}-3.53 \\
\end{array}$ & 2.85 & 4.64 & 4.07 & 2.17 & -1.26 \\
\hline \multirow[t]{2}{*}{ AREA } & -0.0102 & 0.0059 & -0.0543 & 0.0042 & \begin{tabular}{|c|}
-0.0062 \\
\end{tabular} & 0.0023 & -0.0015 & -0.0039 & 0.0026 & -0.0008 & 0.0065 & -0.0021 & 0.0075 & 0.0217 & $\begin{array}{l}0.0050 \\
\end{array}$ & -0.0047 & -0.0078 \\
\hline & -1.28 & 0.68 & -2.56 & 0.56 & $\mid-1.31$ & 0.94 & -0.14 & -0.82 & 0.38 & -0.12 & 0.81 & -1.88 & 3.16 & 3.88 & 4.23 & -1.76 & -2.80 \\
\hline \multirow[t]{2}{*}{ DIST } & 1.4943 & 0.1317 & 0.6397 & \begin{tabular}{|l|}
-1.1883 \\
\end{tabular} & -0.4030 & -0.5439 & 0.9568 & -0.8748 & \begin{tabular}{|l|}
-0.9861 \\
\end{tabular} & -0.4279 & -0.7923 & 0.0252 & 0.2308 & 0.4144 & $\mid-0.0016$ & 0.2019 & 0.6682 \\
\hline & -6.17 & 0.50 & -1.00 & -5.23 & -2.80 & -7.25 & -2.77 & -6.09 & -4.85 & -1.96 & -3.26 & 0.76 & 3.24 & 2.45 & -0.04 & 2.52 & 7.92 \\
\hline \multirow[t]{2}{*}{ INT } & -0.0265 & 0.0574 & 0.0246 & $\mid-0.1205$ & $\mid-0.0119$ & -0.0086 & 0.0815 & 0.0257 & \begin{tabular}{|l|}
-0.0212 \\
\end{tabular} & 0.0289 & -0.0220 & -0.0203 & -0.0103 & 0.0702 & $\mid-0.0214$ & -0.0534 & 0.0023 \\
\hline & -0.55 & 1.10 & 0.19 & -2.55 & -0.40 & -0.55 & 1.23 & 0.86 & -0.50 & 0.64 & -0.43 & -3.10 & -0.70 & 2.00 & -2.87 & -3.20 & 0.14 \\
\hline \multirow[t]{2}{*}{ RDINT } & 0.0910 & .0032 & 0.1163 & 0.0602 & 0.0858 & 0.0762 & 0.0567 & 0.0137 & 0.0357 & 0.0292 & 0.0985 & -0.0026 & 0.0014 & 0.0019 & \begin{tabular}{|l|}
-0.0138 \\
\end{tabular} & 0.0130 & 0.0722 \\
\hline & -2.41 & 0.08 & -1.16 & 1.69 & 3.80 & 6.48 & 1.12 & -0.61 & 1.12 & 0.85 & 2.58 & -0.50 & 0.12 & 0.07 & -2.44 & 1.03 & -5.49 \\
\hline \multirow[t]{2}{*}{ DUM_FRA } & -1.1326 & -0.8878 & 0.6170 & $\mid-1.2895$ & -0.1884 & -0.2193 & 0.1023 & 0.3861 & \begin{tabular}{|l|}
-1.0134 \\
\end{tabular} & 0.1701 & -0.3029 & -0.0605 & 0.1258 & \begin{tabular}{|l|}
-0.4153 \\
\end{tabular} & \begin{tabular}{|l|}
0.0461 \\
\end{tabular} & 0.1548 & 0.7686 \\
\hline & -7.28 & -5.24 & 1.49 & -8.76 & -2.02 & -4.51 & 0.49 & 4.15 & -7.70 & 1.20 & -1.92 & -2.84 & -2.72 & -3.80 & 1.98 & 2.98 & 14.2 \\
\hline \multirow[t]{2}{*}{ DUM_IRE } & 1.0721 & 2.1278 & -- & -- & -- & -- & -- & -- & -- & -- & -- & -0.1154 & - & \begin{tabular}{|l|}
-1.8847 \\
\end{tabular} & 0.5376 & -- & 0.4023 \\
\hline & 1.92 & -3.50 & & & & & & & & & & -1.51 & & -4.02 & 5.38 & & 2.07 \\
\hline \multirow[t]{2}{*}{ DUM_DEN } & \begin{tabular}{|l|}
-0.8474 \\
\end{tabular} & 0.4824 & -- & -- & - & -- & -- & -- & -- & -- & -- & -0.0592 & - & - & -- & -- & 0.7408 \\
\hline & -1.97 & $\mid-1.03$ & & & & & & & & & & -1.00 & & & & & 4.94 \\
\hline \multirow[t]{2}{*}{ DUM_LUX } & .7105 & .4881 & 3.6216 & 0.0278 & -0.1039 & 0.0917 & .3988 & 0.2164 & 0.8072 & 0.5341 & 0.6796 & -0.0837 & .1007 & 2.2604 & 2.8708 & $\overline{0.7074}$ & 0.7914 \\
\hline & -1.71 & -1.08 & 2.49 & 0.05 & -0.32 & 0.54 & -0.56 & 0.66 & 1.75 & -1.08 & 1.23 & -1.46 & -0.62 & -5.89 & 35.06 & -3.87 & 5.46 \\
\hline 0 & 216 & 216 & 202 & 203 & 203 & 203 & 197 & 203 & 203 & 203 & 203 & 21 & 20 & 205 & 205 & 203 & $\overline{21}$ \\
\hline Prob Chi & 0.0000 & 0.0000 & 0.0101 & 0.0000 & 0.0000 & 0.0000 & 0.0447 & $\overline{0000}$ & 0.0000 & 0.0000 & $\overline{0.0000}$ & 0.0000 & .0000 & 0.0000 & 0.0000 & 0.0000 & $\overline{.0 c}$ \\
\hline
\end{tabular}

Note: Lines below coefficients report the z-values of the GLS estimates. The probability of the Chi ${ }^{2}$-test gives the joint significance of all coefficients. 
Table C4: GLS and IV Estimates of the Determinants of Sectoral Specialisation, including DPROD

\begin{tabular}{|c|c|c|c|c|c|c|c|c|c|c|c|c|c|c|c|c|c|c|}
\hline & FUEL & & MINE & & CHEM & & METP & & TREQ & & FOOD & & TEXT & & PAPE & & BUIL & \\
\hline & GLS & IV & GLS & IV & GLS & IV & GLS & IV & GLS & IV & GLS & IV & GLS & IV & GLS & IV & GLS & IV \\
\hline \multirow[t]{2}{*}{ CONSTANT } & -0.7608 & \begin{tabular}{|c|}
-0.6941 \\
\end{tabular} & 1.4478 & 1.6150 & 0.3171 & 0.2649 & 0.8645 & 0.9544 & -0.0618 & 0.1164 & 0.8483 & 0.8606 & 1.5615 & 1.4407 & 1.3157 & 1.3861 & 0.8240 & 0.7956 \\
\hline & -1.60 & -1.36 & 3.50 & 3.35 & $\overline{1.49}$ & 1.05 & 6.08 & 5.88 & -0.09 & 0.14 & 3.68 & 3.12 & 3.97 & 3.21 & 4.33 & 3.95 & 11.36 & 9.75 \\
\hline \multirow[t]{2}{*}{ MAR } & -0.0028 & -0.0025 & 0.0018 & 0.0009 & 0.0037 & 0.0034 & 0.0040 & 0.0032 & 0.0092 & 0.0082 & 0.0032 & 0.0035 & 0.0132 & 0.0131 & 0.0034 & 0.0029 & 0.0010 & 0.0015 \\
\hline & -0.98 & -0.81 & 0.74 & 0.29 & 2.83 & 2.17 & 4.73 & 3.14 & 2.36 & 1.66 & 2.34 & 2.14 & 5.72 & 4.89 & 1.97 & 1.46 & 2.37 & 3.10 \\
\hline \multirow[t]{2}{*}{ CENTR } & 0.7020 & 0.6580 & -0.9439 & -0.9871 & -0.4561 & -0.4914 & -0.6699 & -0.6810 & -0.4365 & -0.5214 & -0.8084 & -0.8391 & -1.7939 & -1.7957 & -0.6014 & -0.6709 & 0.1034 & 0.0960 \\
\hline & 2.87 & 2.57 & -4.47 & -4.12 & -4.14 & -3.88 & -9.21 & -8.45 & -1.28 & -1.33 & -6.95 & -6.36 & -8.90 & -8.06 & -3.84 & -3.69 & 2.81 & 2.45 \\
\hline \multirow[t]{2}{*}{ UEWP } & 0.0822 & 0.0915 & -0.0083 & -0.0078 & 0.0138 & 0.0190 & -0.0310 & -0.0386 & 0.0515 & 0.0351 & -0.0084 & -0.0045 & -0.0183 & -0.0130 & -0.0149 & -0.0095 & 0.0037 & 0.0035 \\
\hline & 7.52 & 7.37 & -0.86 & -0.66 & 2.87 & 3.13 & -7.27 & -6.46 & 3.10 & 1.46 & -1.64 & -0.70 & -1.89 & -0.88 & -1.81 & -0.81 & 1.69 & 1.04 \\
\hline \multirow[t]{2}{*}{ PODEN } & -1.0314 & \begin{tabular}{|l|}
-0.9767 \\
\end{tabular} & -1.2232 & -1.1116 & -0.2961 & -0.3055 & -0.0512 & 0.2464 & -3.0013 & -2.6540 & -1.0615 & -1.1796 & -1.4035 & -1.5100 & -0.5240 & -0.5156 & -0.4525 & -0.5783 \\
\hline & -1.33 & -1.14 & -1.82 & -1.37 & -0.86 & -0.73 & -0.21 & 0.79 & -2.71 & -1.80 & -2.86 & -2.65 & -2.21 & -2.03 & -1.09 & -0.91 & -3.91 & -4.36 \\
\hline \multirow[t]{2}{*}{ AREA } & 0.0142 & 0.0149 & 0.0074 & 0.0114 & 0.0014 & 0.0011 & 0.0037 & 0.0051 & -0.0259 & -0.0241 & -0.0012 & -0.0014 & 0.0048 & 0.0060 & -0.0047 & -0.0033 & -0.0012 & -0.0029 \\
\hline & 2.03 & 1.90 & 1.21 & 1.52 & 0.42 & 0.28 & 1.75 & 2.02 & -2.61 & -1.90 & -0.37 & -0.35 & 0.83 & 0.85 & -1.08 & -0.63 & -1.19 & -2.43 \\
\hline \multirow[t]{2}{*}{ DIST } & 0.1578 & 0.2562 & -0.9588 & -1.0699 & -0.2631 & \begin{tabular}{|l|}
-0.2858 \\
\end{tabular} & -0.3478 & -0.3506 & -0.5828 & -0.7635 & -0.8654 & -0.9236 & -0.8430 & -0.8573 & -0.6937 & -0.7415 & 0.0598 & 0.0545 \\
\hline & 0.85 & 1.28 & -5.87 & -5.61 & -2.72 & -2.55 & -6.27 & -5.52 & -2.15 & -2.37 & -9.78 & -8.91 & -5.32 & -4.50 & -5.88 & -5.36 & 2.14 & 1.78 \\
\hline \multirow[t]{2}{*}{ INT } & 0.1441 & 0.1268 & 0.0432 & 0.0318 & 0.0055 & 0.0077 & -0.0059 & -0.0097 & 0.0883 & 0.0907 & 0.0314 & 0.0304 & -0.0179 & -0.0120 & -0.0184 & -0.0255 & -0.0300 & -0.0256 \\
\hline & 4.09 & 3.39 & 1.42 & 0.90 & 0.35 & 0.42 & -0.56 & -0.81 & 1.78 & 1.56 & 1.85 & 1.53 & -0.62 & \begin{tabular}{|c|}
-0.37 \\
\end{tabular} & -0.83 & $\begin{array}{l}-1.03 \\
\end{array}$ & -5.71 & -4.53 \\
\hline \multirow[t]{2}{*}{ DPROD } & 0.0110 & 0.0115 & 0.0133 & 0.0139 & 0.0104 & 0.0145 & 0.0018 & \begin{tabular}{|l|}
-0.0042 \\
\end{tabular} & 0.0531 & 0.0375 & 0.0108 & 0.0157 & -0.0104 & -0.0093 & 0.0191 & 0.0265 & -0.0074 & -0.0084 \\
\hline & 5.91 & 5.10 & 1.70 & 1.42 & 3.77 & 3.36 & 0.51 & -0.88 & 5.52 & 2.42 & 3.24 & 2.71 & -1.57 & -0.62 & 4.19 & 3.85 & -4.62 & -3.48 \\
\hline \multirow[t]{2}{*}{ DUM_FRA } & -0.5501 & \begin{tabular}{|l|}
-0.6742 \\
\end{tabular} & -0.6899 & -0.7437 & -0.0669 & \begin{tabular}{|l|}
-0.0511 \\
\end{tabular} & -0.0333 & \begin{tabular}{|l|}
-0.0478 \\
\end{tabular} & 0.3168 & 0.3252 & 0.2526 & 0.2726 & -0.7970 & -0.8067 & 0.1261 & 0.1067 & -0.0525 & -0.0330 \\
\hline & -4.80 & -5.19 & -6.87 & -6.02 & -1.26 & -0.79 & -0.96 & -1.15 & 2.01 & 1.64 & 4.68 & 4.11 & -8.37 & -6.88 & 1.81 & 1.31 & -3.09 & -1.71 \\
\hline \multirow[t]{2}{*}{ DUM_IRE } & -- & -- & -0.1129 & -0.3896 & 0.5355 & 0.6301 & -- & -- & -- & -- & 1.8890 & 1.8203 & 0.5246 & 0.4353 & 0.7949 & 0.7991 & -0.2880 & -0.2264 \\
\hline & & & -0.22 & -0.62 & 2.01 & 1.91 & & & & & 6.72 & 5.21 & 1.08 & 0.74 & 2.19 & 1.84 & -3.49 & -2.44 \\
\hline \multirow[t]{2}{*}{ DUM_DEN } & -0.8637 & \begin{tabular}{|l|}
-0.8163 \\
\end{tabular} & -- & -- & -- & -- & -- & -- & -- & -- & -- & -- & -- & -- & -- & -- & -0.0708 & -0.0665 \\
\hline & -2.05 & -1.80 & & & & & & & & & & & & & & & -1.13 & -0.97 \\
\hline \multirow[t]{2}{*}{ DUM_LUX } & -0.9157 & \begin{tabular}{|c|}
-0.7576 \\
\end{tabular} & 0.0977 & 0.0042 & 0.1709 & 0.1698 & 0.2531 & 0.1953 & 0.3931 & 0.1641 & 0.3151 & 0.3771 & 2.1666 & 2.1256 & -0.0218 & 0.0994 & -0.2953 & -0.2927 \\
\hline & -2.25 & -1.72 & 0.27 & 0.01 & 0.97 & 0.81 & 2.10 & 1.42 & 0.68 & 0.23 & 1.61 & 1.61 & 6.15 & 4.49 & -0.08 & 0.30 & -4.58 & -3.79 \\
\hline no. of obs. & 297 & 253 & 295 & 251 & $\overline{\overline{291}}$ & 248 & 292 & 249 & 284 & 241 & 295 & 251| & 294 & 250 & 289 & 244 & 301 & $\overline{\overline{256}}$ \\
\hline Prob Chi / F & 0.0000 & 0.0000 & 0.0000 & 0.0000 & 0.0000 & 0.0000 & 0.0000 & 0.0000 & 0.0000 & 0.1110 & 0.0000 & 0.0000 & 0.0000 & 0.0000 & 0.0000 & 0.0000 & 0.0000 & 0.0000 \\
\hline
\end{tabular}

Note: Lines below coefficients report the z-(t-)values of the GLS (IV) estimates. The probability of the Chi²/F-test gives the joint significance of all coefficients. 
Table C5: GLS and IV Estimates of the Determinants of Sectoral Specialisation, including DLABCOST

\begin{tabular}{|c|c|c|c|c|c|c|c|c|c|c|c|c|c|c|c|c|c|c|}
\hline & FUEL & & MINE & & CHEM & & METP & & TREQ & & FOOD & & TEXT & & PAPE & & BUIL & \\
\hline & GLS & IV & GLS & IV & GLS & IV & GLS & IV & GLS & IV & GLS & IV & GLS & IV & GLS & $\overline{\text { IV }}$ & GLS & IV \\
\hline \multirow[t]{2}{*}{ CONSTANT } & $\mid .5926$ & \begin{tabular}{|c|}
-4.0129 \\
\end{tabular} & 1.5320 & 2.0262 & "0.4917 & $\mid \overline{\mid c .4337}$ & 0.8843 & 0.5000 & \begin{tabular}{c|}
-0.3690 \\
\end{tabular} & -0.3983 & 0.9922 & 0.9535 & 1.6079 & 1.2914 & \begin{tabular}{|c|}
1.8042 \\
\end{tabular} & 2.0533 & 0.7257 & 0.7030 \\
\hline & -1.18 & -0.67 & 3.65 & 1.76 & 2.23 & 1.49 & 6.23 & 0.76 & -0.52 & -0.44 & 4.25 & 3.13 & 3.99 & 2.24 & 5.50 & 5.38 & 9.89 & 8.05 \\
\hline \multirow[t]{2}{*}{ MAR } & 0.0000 & -0.0112 & 0.0028 & 0.0035 & 0.0052 & 0.0050 & 0.0039 & 0.0021 & 0.0038 & 0.0027 & 0.0041 & 0.0046 & 0.0127 & 0.0133 & 0.0048 & 0.0046 & 0.0011 & 0.0018 \\
\hline & 0.00 & -0.52 & 1.14 & 0.38 & 4.12 & 2.98 & 4.74 & 0.81 & 0.93 & 0.51 & 3.02 & 2.66 & 5.47 & 4.00 & 2.59 & 2.12 & 2.47 & 3.46 \\
\hline \multirow[t]{2}{*}{ CENTR } & 0.6511 & 0.6710 & -0.9640 & 1.1559 & -0.3868 & -0.3892 & -0.6642 & -0.8276 & -0.5268 & -0.4878 & -0.8265 & -0.8594 & -1.7961 & -1.8277 & -0.3964 & -0.4141 & 0.0837 & 0.0742 \\
\hline & 2.51 & 1.01 & -4.51 & -2.61 & -3.44 & -2.81 & -9.13 & -3.40 & $\mid-1.41$ & $\begin{array}{l}-1.04 \\
\end{array}$ & -6.70 & -5.50 & -8.52 & -6.05 & -2.46 & -2.20 & 2.18 & 1.36 \\
\hline \multirow[t]{2}{*}{ UEWP } & 0.0938 & 0.0893 & -0.0136 & -0.0223 & 0.0103 & 0.0142 & -0.0330 & -0.0280 & 0.0040 & -0.0087 & -0.0107 & -0.0061 & -0.0135 & 0.0007 & -0.0328 & -0.0353 & 0.0113 & 0.0111 \\
\hline & 8.22 & 2.17 & -1.44 & -0.81 & 2.10 & 2.15 & -10.31 & -2.35 & 0.25 & -0.41 & -2.03 & -0.87 & -1.49 & 0.05 & -4.35 & $\mid-3.70$ & 6.56 & 2.34 \\
\hline \multirow[t]{2}{*}{ PODEN } & -1.3764 & 3.1175 & $\begin{array}{l}-1.3499 \\
\end{array}$ & \begin{tabular}{|l|}
-1.5177 \\
\end{tabular} & \begin{tabular}{|c|}
-0.5688 \\
\end{tabular} & $\begin{array}{l}-0.4899 \\
\end{array}$ & -0.0198 & 0.7407 & $\begin{array}{l}-0.7234 \\
\end{array}$ & -0.5626 & -1.2293 & -1.3558 & $\begin{array}{l}-1.3795 \\
\end{array}$ & -1.6275 & -0.9729 & $\begin{array}{l}-1.0570 \\
\end{array}$ & -0.4680 & -0.6486 \\
\hline & $\mid-1.67$ & 0.39 & -2.01 & -0.82 & -1.61 & -1.00 & -0.09 & 0.79 & $\mid-0.63$ & -0.37 & -3.27 & -2.83 & -2.14 & -1.74 & -1.84 & $\mid-1.62$ & -3.89 & -4.16 \\
\hline \multirow[t]{2}{*}{ AREA } & 0.0138 & 0.0720 & 0.0066 & 0.0055 & -0.0020 & -0.0006 & 0.0035 & 0.0172 & -0.0107 & -0.0077 & -0.0035 & -0.0018 & 0.0054 & 0.0122 & -0.0131 & -0.0153 & -0.0005 & -0.0033 \\
\hline & 1.82 & 0.71 & 1.07 & 0.17 & -0.58 & -0.13 & 1.66 & 1.13 & -0.96 & -0.52 & $\begin{array}{l}-1.02 \\
\end{array}$ & $\begin{array}{l}-0.36 \\
\end{array}$ & 0.90 & 1.33 & -2.68 & -2.44 & -0.47 & -1.00 \\
\hline \multirow[t]{2}{*}{ DIST } & 0.1943 & 0.4719 & -0.9821 & \begin{tabular}{|l|}
-1.2923 \\
\end{tabular} & $\mid-0.1816$ & -0.1874 & -0.3396 & -0.6357 & -0.6087 & -0.5303 & -0.8529 & -0.9402 & -0.9054 & -1.1835 & -0.5553 & -0.5210 & 0.0414 & 0.0222 \\
\hline & 0.95 & 0.80 & -5.83 & -4.27 & -1.80 & -1.46 & -5.94 & -1.86 & -1.80 & -1.25 & -9.11 & -7.43 & -5.43 & -4.56 & -4.30 & -3.17 & 1.38 & 0.37 \\
\hline \multirow[t]{2}{*}{ INT } & $\begin{array}{l}0.1180 \\
\end{array}$ & 0.2734 & 0.0405 & 0.0209 & -0.0054 & -0.0046 & -0.0062 & 0.0088 & 0.1177 & 0.1236 & 0.0239 & 0.0252 & -0.0222 & -0.0045 & -0.0335 & -0.0458 & -0.0282 & -0.0230 \\
\hline & 3.20 & 0.90 & 1.31 & 0.45 & -0.33 & -0.22 & -0.59 & 0.24 & 2.26 & 1.92 & 1.38 & 1.15 & -0.75 & -0.11 & -1.41 & -1.70 & -5.19 & -3.28 \\
\hline \multirow[t]{2}{*}{ DLABCOST } & -0.0011 & 0.0381 & 0.0005 & -0.0216 & $\mid-0.0001$ & 0.0006 & -0.0004 & 0.0074 & 0.0000 & -0.0003 & -0.0004 & 0.0027 & -0.0005 & 0.0092 & -0.0007 & 0.0001 & 0.0028 & -0.0047 \\
\hline & -0.99 & 0.58 & 0.16 & -0.23 & -1.25 & 0.96 & -1.67 & 0.87 & 0.07 & -0.17 & -0.82 & 1.14 & -0.59 & 1.83 & $\mid-1.88$ & 0.02 & 2.24 & -0.31 \\
\hline \multirow[t]{2}{*}{ DUM_FRA } & -0.6720 & $\begin{array}{l}-0.0978 \\
\end{array}$ & -0.6710 & -0.7741 & $\mid-0.0691$ & -0.0724 & -0.0328 & -0.0376 & 0.2976 & 0.3514 & 0.2424 & 0.2598 & $\begin{array}{l}-0.8348 \\
\end{array}$ & -0.8623 & 0.1272 & 0.1291 & -0.0639 & -0.0367 \\
\hline & -5.49 & -0.08 & $\begin{array}{l}-6.73 \\
\end{array}$ & -5.59 & -1.27 & $\begin{array}{l}-0.99 \\
\end{array}$ & -0.96 & -0.38 & 1.71 & 1.53 & 4.34 & 3.47 & -8.65 & -5.86 & 1.74 & 1.38 & -3.56 & -0.84 \\
\hline \multirow[t]{2}{*}{ DUM_IRE } & -2.2424 & -4.4100 & -0.2876 & -- & 0.9557 & -- & 0.7353 & -- & 0.3429 & -- & 1.9227 & -- & -- & -- & 1.1736 & -- & -0.5751 & -- \\
\hline & -3.50 & -1.13 & -0.31 & & 2.53 & & 2.99 & & 0.24 & & 4.75 & & & & 2.23 & & -3.51 & \\
\hline \multirow[t]{2}{*}{ DUM_DEN } & -- & -- & -- & -- & -- & -- & -- & -- & -- & -- & -- & -- & -- & -- & -- & -- & -0.3237 & -- \\
\hline & & & & & & & & & & & & & & & & & -2.14 & \\
\hline \multirow[t]{2}{*}{ DUM_LUX } & -0.8072 & -0.5131 & 0.2263 & 0.9185 & 0.2267 & -0.3461 & 0.2838 & 0.3920 & -0.2554 & 0.1846 & 0.2614 & 0.1647 & 2.0216 & 0.5354 & -0.4234 & -0.5986 & -0.1511 & -0.0405 \\
\hline & -2.08 & -0.47 & 0.63 & 0.28 & 1.18 & \begin{tabular}{l|l|}
-0.66 \\
\end{tabular} & 2.21 & 0.88 & -0.41 & -0.16 & 1.26 & -0.39 & 5.71 & 0.59 & -1.60 & -1.28 & -2.62 & -0.30 \\
\hline no. of obs. & 296 & 249 & 291 & 245 & 285 & 240 & 291 & 245 & 265 & 210 & 291 & 245 & 286 & 240 & 266 & 212 & 294 & $\overline{246}$ \\
\hline Prob Chi ${ }^{2} / \mathrm{F}$ & 0.0000 & 0.0006 & 0.0000 & 0.0000 & 0.0000 & 0.0002 & 0.0000 & 0.0000 & 0.0964 & 0.2879 & 0.0000 & 0.0000 & 0.0000 & 0.0000 & 0.0000 & 0.0000 & 0.0000 & 0.0000 \\
\hline
\end{tabular}

Note: Lines below coefficients report the $\mathrm{z}$-(t-)values of the GLS (IV) estimates. The probability of the $\mathrm{Chi}^{2} / \mathrm{F}$-test gives the joint significance of all coefficients. 
Table C6: GLS and IV Estimates of the Determinants of Sectoral Specialisation, including ES

\begin{tabular}{|c|c|c|c|c|c|c|c|c|c|c|c|c|c|c|c|c|c|c|}
\hline & UEL & & MINE & & CHEM & & METP & & TREQ & & FOOD & & TEXT & & PAPE & & BUIL & \\
\hline & GLS & IV & GLS & IV & GLS & IV & GLS & IV & GLS & IV & GLS & IV & GLS & IV & GLS & IV & GLS & IV \\
\hline \multirow[t]{2}{*}{ CONSTANT } & 8180 & 2758 & 3444 & 6543 & 1678 & .5443 & $0.8974 \mid$ & .6599 & 6072 & .0852 & 6984 & 1658 & .4898 & .5681 & 1.0207 & 0.6256 & .6405 & $\overline{7.7523}$ \\
\hline & 1.62 & 0.47 & 5.48 & 5.76 & 0.74 & -1.56 & \begin{tabular}{|l|}
6.14 \\
\end{tabular} & 3.13 & -1.00 & -1.30 & 2.56 & 0.40 & 3.56 & 2.40 & 2.53 & 1.14 & 8.25 & 5.98 \\
\hline \multirow[t]{2}{*}{ MAR } & 0015 & 0.0025 & .0040 & .0049 & 0047 & .0066 & 0.0039 & .0064 & .0025 & 0.0035 & .0007 & -0.0013 & .0100 & .0106 & \begin{tabular}{|l|}
-0.0001 \\
\end{tabular} & -0.0009 & .0014 & .0019 \\
\hline & 0.56 & 0.86 & 1.74 & 1.70 & \begin{tabular}{l|l}
3.76 \\
\end{tabular} & 4.09 & 4.92 & 5.70 & 0.76 & 0.86 & \begin{tabular}{l|l}
0.47 \\
\end{tabular} & -0.66 & 4.65 & \begin{tabular}{l|l|}
3.87 \\
\end{tabular} & -0.03 & -0.35 & 3.44 & 4.03 \\
\hline \multirow[t]{2}{*}{ CENTR } & 0.0326 & -0.2963 & -0.9168 & -1.0129 & .8926 & -1.4816 & -0.7064 & -0.8153 & .5508 & -0.5776 & -0.8274 & -0.9160 & 1.9990 & -1.9453 & -0.5334 & -0.5548 & 0.0920 & .0833 \\
\hline & 0.13 & -1.11 & -4.39 & -4.25 & .72 & -8.80 & -9.83 & -9.29 & 1.86 & -1.65 & .34 & -5.68 & -9.37 & -6.40 & -2.74 & -2.47 & 2.52 & 1.93 \\
\hline \multirow[t]{2}{*}{ UEWP } & 0.0645 & 0.0623 & -0.0048 & -0.0069 & .0028 & -0.0068 & -0.0323 & -0.0318 & .0031 & 0.0002 & -0.0115 & -0.0134 & -0.0089 & 0.0045 & -0.0365 & -0.0452 & 0.0092 & .0111 \\
\hline & 5.42 & 4.26 & -0.51 & -0.57 & 0.55 & -0.94 & -10.10 & -7.56 & 0.23 & 0.01 & -2.05 & -1.86 & -1.04 & 0.41 & -4.23 & -4.17 & 5.87 & 5.72 \\
\hline \multirow[t]{2}{*}{ PODEN } & .2902 & -1.1909 & -1.4416 & -1.7174 & .4378 & -0.6988 & 0.4763 & -1.3996 & .5700 & -0.9556 & -0.5061 & 0.0840 & -0.7840 & -1.1886 & 0.3524 & 0.5674 & 0.5754 & -0.7148 \\
\hline & -1.60 & -1.32 & -2.06 & -1.96 & -1.17 & -1.42 & -1.94 & -3.88 & -0.57 & -0.75 & -1.16 & 0.15 & \begin{tabular}{|l|}
-1.19 \\
\end{tabular} & \begin{tabular}{l|}
-1.39 \\
\end{tabular} & 0.54 & 0.72 & -4.87 & -4.98 \\
\hline \multirow[t]{2}{*}{ AREA } & 0.0037 & 0.0014 & -0.0011 & -0.0023 & .0056 & -0.0101 & -0.0005 & -0.0067 & 0.0029 & -0.0054 & 0.0013 & 0.0066 & 0.0070 & 0.0058 & -0.0037 & -0.0028 & -0.0015 & 0.0026 \\
\hline & 0.60 & 0.20 & -0.20 & -0.37 & -1.96 & -2.71 & -0.25 & -2.55 & -0.38 & -0.57 & 0.38 & 1.43 & 1.29 & \begin{tabular}{l|l|}
0.82 \\
\end{tabular} & -0.74 & -0.49 & -1.59 & -2.29 \\
\hline \multirow[t]{2}{*}{ DIST } & .1392 & -0.1714 & -0.7639 & -0.8267 & .3369 & -0.3332 & 0.3743 & -0.3579 & .6295 & -0.7105 & -0.8551 & -0.8749 & -1.0001 & -0.9155 & -0.5288 & -0.4504 & 0.0535 & 0.0479 \\
\hline & -0.83 & -0.96 & -5.29 & -4.59 & -4.32 & -3.37 & -7.67 & -5.90 & -3.09 & -2.91 & -9.69 & -8.23 & -5.83 & -4.13 & -3.93 & -2.83 & 2.13 & 1.61 \\
\hline \multirow[t]{2}{*}{ INT } & .0053 & 0.0346 & 0.0467 & -0.1392 & .0062 & .0333 & .0099 & -0.0126 & .0806 & 0.1308 & .0126 & .0136 & -0.0246 & -0.0275 & \begin{tabular}{l|}
-0.0062 \\
\end{tabular} & 0.0176 & .0203 & .0266 \\
\hline & 0.14 & 0.81 & -1.51 & -3.45 & 0.37 & 1.40 & -0.93 & -0.87 & 1.83 & 2.21 & 0.64 & 0.51 & -0.83 & -0.60 & -0.22 & 0.47 & -3.54 & -3.22 \\
\hline \multirow[t]{2}{*}{ ES } & 0.0119 & 0.0152 & 0.0373 & 0.0477 & .0874 & .1927 & 0.0486 & 0.1557 & 0.0572 & 0.0495 & 0.0752 & .1579 & \begin{tabular}{l|l}
0.0441 \\
\end{tabular} & 0.0018 & 0.0619 & 0.0873 & 0.0013 & 0.0021 \\
\hline & 7.20 & 7.22 & 2.49 & 1.25 & 10.35 & 8.89 & 6.10 & \begin{tabular}{l|l|}
5.70 \\
\end{tabular} & \begin{tabular}{l|l}
10.74 \\
\end{tabular} & 6.58 & \begin{tabular}{l|l}
5.74 \\
\end{tabular} & 5.53 & 2.11 & 0.04 & \begin{tabular}{l|l}
4.00 \\
\end{tabular} & 3.34 & 0.32 & -0.27 \\
\hline \multirow[t]{2}{*}{ DUM_FRA } & -0.4090 & -0.2582 & -0.7184 & -0.8921 & 0.2203 & 0.5750 & 0.0384 & 0.1651 & .1904 & 0.2697 & 0.2409 & 0.2660 & -0.8374 & -0.9224 & 0.2887 & 0.3826 & -0.0401 & -0.0623 \\
\hline & -3.75 & -1.89 & -7.84 & -5.62 & \begin{tabular}{l|l}
4.43 \\
\end{tabular} & 6.44 & 1.28 & 3.41 & 1.65 & 1.82 & 4.51 & 3.78 & -9.01 & \begin{tabular}{l|l|}
-6.91 \\
\end{tabular} & 3.56 & 3.62 & -2.22 & -1.92 \\
\hline & 314 & 262 & 313 & 260 & \begin{tabular}{l|l|}
312 \\
\end{tabular} & 259 & 314 & 262 & 305 & 252 & 291 & 238 & 279 & 202 & 313 & 260 & 287 & 230 \\
\hline Prob Chi / F & 0.0000 & 0.0000 & 0.0000 & 0.0000 & 0.0000 & 0.0000 & 0.0000 & 0.0000 & 0.0000 & 0.0000 & 0.0000 & 0.0000 & 0.0000 & 0.0000 & \begin{tabular}{l|l}
0.0000 \\
\end{tabular} & 0.0000 & 0.0000 & 0.0000 \\
\hline
\end{tabular}

Note: Lines below coefficients report the z-(t-)values of the GLS (IV) estimates. The probability of the Chi²/F-test gives the joint significance of all coefficients. 